Fernando Gomes

\title{
Caracterização funcional da peroxirredoxina mitocondrial (Prx1) na fisiologia redox de Saccharomyces cerevisiae
}

Functional characterization of mitochondrial peroxiredoxin (Prx1) in the redox physiology of Saccharomyces cerevisiae 
Fernando Gomes

\section{Caracterização funcional da peroxirredoxina mitocondrial (Prx1) na fisiologia redox de Saccharomyces cerevisiae}

Functional characterization of mitochondrial
peroxiredoxin (Prx1) in the redox physiology of Saccharomyces cerevisiae

Tese apresentada ao Instituto de Biociências da Universidade de São Paulo, para a obtenção de Título de Doutor em Ciências, na Área de Genética e Biologia Evolutiva.

Orientador (a): Prof. Dr. Luis Eduardo Soares Netto

São Paulo 


\section{FICHA CATALOGRÁFICA}

Gomes, Fernando

Caracterização funcional da peroxirredoxina mitocondrial (Prx1) na fisiologia redox de Saccharomyces cerevisiae

135

Tese (Doutorado) - Instituto de Biociências da Universidade de São Paulo. Departamento de Genética e Biologia Evolutiva.

1. Prx1 2. Mitocôndria 3. Saccharomyces cerevisiae

Universidade de São Paulo. Instituto de Biociências. Departamento de Genética e Biologia Evolutiva.

Comissão Julgadora:

Prof(a). Dr(a).

$\operatorname{Prof}(\mathrm{a}) . \operatorname{Dr}(\mathrm{a})$
Prof(a). Dr(a).

Prof(a). Dr(a).

Prof. Dr. Luis Eduardo Soares Netto

Orientador 
À minha mãe Maria (in memoriam), meu pai Valter, minha irmã Camila e meu irmão Vinícius, que sempre me amaram e me incentivaram em todas as etapas da minha vida.

A minha esposa Helena e ao Enzo, pelo amor e carinho. Amo todos vocês. 
"Talvez não tenha conseguido fazer o melhor, mas lutei para que o melhor fosse feito. Não sou o que deveria ser, mas graças a Deus, não sou o que era antes." 


\section{AGRADECIMENTOS}

Aos meus pais Valter e Maria, que sempre me apoiaram, me ensinaram o valor do trabalho feito com dedicação e, acima de tudo, me amaram incondicionalmente.

A minha esposa Helena Gabriela que esteve do meu lado durante toda essa jornada, me apoiando, e enchendo minha vida com seu valioso carinho e amor.

Aos meus queridos irmãos Camila e Vinicíus, minha principal fonte de inspiração.

Aos meus avós Francisco e Angelina, Aleonilda e Ricardo por terem me amparado quando criança e sempre me apoiado nos meus estudos.

Ao meu enteado Enzo Guilherme que enche minha vida com alegria e divertimento.

A Lúcia Elena, Nestor e Nestor Júnior por todo o apoio e carinho me dado desde que entrei para a família.

Ao meu orientador, professor Dr. Luis Eduardo Soares Netto Netto, por ter me aceitado como aluno de doutorado e depositado em mim a confinça para a realização deste trabalho.

Aos professores Dr. Mário Enrique de Barros e Dra. Marilene Demasi, por terem fornecidos anticorpos indispensáveis para a realização deste trabalho.

Ao meu amigo Flávio Romero Palma por toda a ajuda com os resumos em inglês e seu companherismo indispensável.

Aos amigos de graduação Karen e Bruno, por me incentivarem na realização da pósgraduação. Agradeço também aos amigos da época do mestrado, Cleverson Busso, Erich Tahara, Janaína e Raquel, que me acolheram no início de minha morada em São Paulo.

Aos amigos Eduardo Tassone por ter me ajudado com a construção das proteínas recombinantes e Thiago Alegria pelas inúmeras dicas durante a realização dos experimentos.

Aos amigos do laboratório Renato, Rogério, Amanda, Andressa, Júlia, Eduardo, Verônica, Janaína, Erina, Diogo, Vanessa, César, Simone, Cristina, Angélica, Anita, Renata, Carlos e Valesca.

Aos funcionários do Instituto de Biociências sempre disponíveis na resolução de questões administraivas.

Aos órgãos financiadores deste trabalho, CNPq, CAPES e, principalmente, FAPESP.

A Deus, por todo o seu amor. 


\section{ÍNDICE}

1. INTRODUÇÃO ..................................................................................................... 13

1.1 Mitocôndria: estrutura e função ......................................................................... 13

1.2 Mecanismos de importação das proteínas mitocondriais ................................. 18

1.2.1 O mecanismo de importação pressequencia ..................................................... 18

1.2.2 Processamento final dos precursores contendo pressequencia ...................... 23

1.2.3 O mecanismo de importação acoplado a processo oxidativo ........................... 31

1.3 A produção de espécies reativas de oxigênio na mitocôndria .......................... 34

1.4 Sistemas antioxidantes na mitocôndria de Saccharomyces cerevisiae ........... 36

1.4.1 Superóxidos Dismutases (SODs) ................................................................. 36

1.4.2 $\mathrm{O}$ sistema glutationa mitocondrial ................................................................... 36

1.4.3 Sistema glutarredoxina mitocondrial ....................................................... 38

1.4.4 Sistema tiorredoxina mitocondrial .................................................................. 40

1.4.5 Peroxidases mitocondriais ....................................................................... 41

1.5 Prx1 de Saccharomyces cerevisiae ................................................................... 46

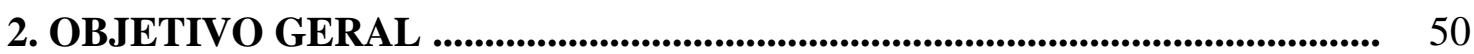

3. MATERIAIS E MÉTODOS .................................................................... 51

3.1 Linhagens de Saccharomyces cerevisiae e Escherichia coli ............................. 51

3.2 Meios de cultura dos microrganismos ................................................................. 52

3.3 Condições de cultivo dos microrganismos .......................................................... 52

3.4 Métodos gerais para manipulação de DNA ....................................................... 53

3.5 Transformação Bacteriana ................................................................................. 54

3.6 Transformação de células de Saccharomyces cerevisiae ................................... 54

3.7 Extração do DNA genômico de S. cerevisiae ...................................................... 55

3.8 Isolamento de mitocôndrias com membrana externa intacta .......................... 56

3.9 Purificação das mitocôndrias em gradiente de densidade de sacarose .......... 57

3.10 Quantificação das proteínas mitocondriais ...................................................... 58

3.11 Subfracionamento mitocondrial ...................................................................... 59

3.12 Solubilidade das proteínas mitocondriais ....................................................... 59

3.13 Análise da estabilidade proteica in organello …………................................... 60

3.14 Extratos proteicos de células de S. cerevisiae ……………….......................... 60

3.15 Eletroforese em gel de poliacrilamida em condição desnaturante (SDS-

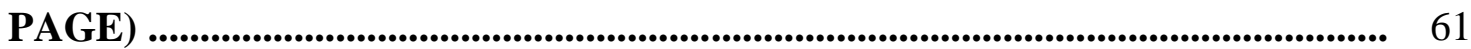

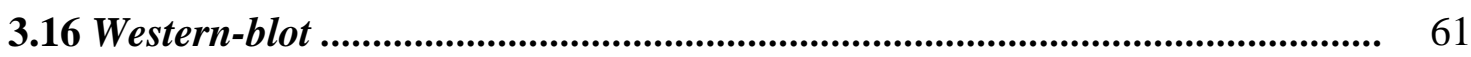

3.17 Isolamento de mitocôndrias para a quantificação da liberação de $\mathrm{H}_{2} \mathrm{O}_{2} \ldots . . .63$

3.18 Quantificação da liberação de $\mathrm{H}_{2} \mathrm{O}_{2}$ mitocondrial ........................................ 64

3.19 Sensibilidade ao estresse oxidativo exógeno .................................................... 65

3.20 Clonagens gênicas ...................................................................................... 65

3.21 Construção de mutantes duplos de $S$. cerevisiae …………………................. 67

3.22 Expressão e purificação das proteínas recombinantes .................................... 68

3.23 Atividade peroxidásica dependente de tiorredoxina _..................................... 69

3.24 Purificação da proteína Prx1 da mitocôndria ………………............................ 70

4. RESULTADOS ............................................................................................ 71 
4.1 Produções de anticorpos e testes de sua especificidade contra as proteínas Prx1, Trr2 e Trx3

4.2 Localização e solubilidade das proteínas Trr2, Trx3 e Prx1 nos subcompartimentos mitocondriais.

4.3 Investigação dos mecanismos de importação mitocondrial das proteínas Trr2, Trx3 e Prx1

80

4.4 Papel funcional da clivagem de Prx1 catalisada pela protease Oct1 ............ 87

4.5 Efeitos da clivagem de Oct1 sobre a atividade peroxidásica de Prx1 ............ 94

4.6 A função de Prx1 na manutenção da atividade mitocondrial ........................ 96

5. DISCUSSÃO ..................................................................................................... 104

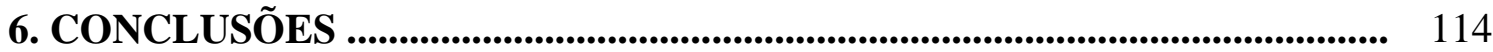

7. REFERÊNCIAS BIBLIOGRÁFICAS ..................................... 116 


\section{LISTA DE FIGURAS}

Figura 1. Representação esquemática da estrutura mitocondrial

Figura 2. Representação esquemática do sistema de fosforilação oxidativa de Saccharomyces cerevisiae 16

Figura 3. Representação esquemática do proteoma de Saccharomyces cerevisiae ...

Figura 4. Visão geral da maquinaria de importação das proteínas mitocondriais em

S. cerevisiae

Figura 5. Representação esquemática do mecanismo de importação das proteínas contendo a pressequencia

Figura 6. Representação esquemática das etapas finas de processamento das proteínas mitocondriais contendo a pressequencia

Figura 7. Motivos de clivagem de proteases da matriz mitocondrial: MPP (A), Icp55 (B) e Oct1 (C)

Figura 8. Representação esquemática da geração de um $N$-degron em Saccharomyces cerevisiae

Figura 9. Representação esquemática do mecanismo de importação acoplado a processo oxidativo

Figura 10. Representação esquemática dos principais sítios geradores do radical ânion superóxido da cadeia respiratória de Saccharomyces cerevisiae

Figura 11. Representação esquemática dos sistemas tiorredoxina e glutarredoxina..

Figura 12. Representação esquemática do ciclo catalítico da peroxirredoxina Tsa1, um representante do grupo das 2-Cys-Prxs

Figura 13. Representação esquemática do ciclo catalítico da peroxirredoxina Prx1, um representante do grupo das 1-Cys-Prxs

Figura 14. Ciclo catalítico de Prx1 deduzido a partir dos dados apresentados no trabalho de Pedrajas et al. (2016)

Figura 15. Purificação das mitocôndrias em gradiente de densidade de sacarose ......

Figura 16. Teste dos anticorpos anti-Prx1p, anti-Trr2p e anti-Trx3p contra as proteínas mitocondriais de $S$. cerevisiae

Figura 17. Purificação da fração mitocondrial enriquecida através de gradiente de densidade de sacarose

Figura 18. Solubilidade mitocondrial das proteínas Trr2, Trx3 e Prx1

Figura 19. Localização das proteínas Trr2, Trx3 e Prx1 nas células crescidas em 
glicerol

Figura 20. Localização submitocondrial das proteínas Trr2, Trx3 e Prx1 nas células crescidas em galactose

Figura 21. Western blot das frações do pellet e do sobrenadante do protocolo de subfracionamento mitocondrial

Figura 22. Importação de Prx1 em linhagens de levedura modificadas geneticamente

Figura 23. Subfracionamento mitocondrial da linhagem $\triangle I M P 2$

Figura 24. Subfracionamento mitocondrial das linhagens WT e $\triangle O C T 1$

Figura 25. Possíveis sítios de clivagem das proteínas Trr2 e Trx3 catalisado pela protease MPP

Figura 26. Purificação da proteína Prx1 da mitocôndria através de cromatografia de afinidade a níquel seguido de análise de espectrometria de massas 86 Figura 27. Ensaio de estabilidade das proteínas in organello

Figura 28. Aminoácidos presentes nos sítios de clivagem das proteases mitocondriais MPP e OCT1

Figura 29. Alinhamento da sequência de aminoácidos presentes na região de endereçamento mitocondrial das peroxirredoxinas 3 de mamíferos

Figura 30. A peroxirredoxina humana Prx3 é clivada pela protease Oct1 de levedura 93

Figura 31. Ensaio de estabilidade de Prx3 in organello 94

Figura 32. Purificação das proteínas recombinantes

Figura 33. Expressão de Prx1 em diferentes fontes de carbono e fases de crescimento

Figura 34. Sensibilidade dos mutantes nulos $\triangle P R X 1, \triangle T R R 2$ e $\triangle T R X 3$ ao estresse oxidativo exógeno causado pelo peróxido de hidrogênio

Figura 35. Confirmação da construção dos duplos mutantes

Figura 36. Sensibilidade dos duplos mutantes ao estresse oxidativo exógeno causado pelo peróxido de hidrogênio

Figura 37. Liberação de $\mathrm{H}_{2} \mathrm{O}_{2}$ em suspensões mitocondriais

Figura 38. Mecanismo proposto de importação mitocondrial da peroxiredoxina Prx1 de $S$. cerevisiae 


\section{RESUMO}

As peroxirredoxinas (Prxs) são peroxidases dependentes de tiol que catalisam a redução de uma ampla variedade de hidroperóxidos. A atividade catalítica das Prxs é suportada por um resíduo de cisteína catalítico altamente conservado, cuja oxidação pelo hidroperóxido gera o ácido sulfênico (Cys-SOH). Prx1 de Saccharomyces cerevsiae é uma enzima mitocondrial que catalisa a redução do $\mathrm{H}_{2} \mathrm{O}_{2}$ gerado no interior da mitocôndria. $\mathrm{O}$ mecanismo de redução do ácido sulfênico de Prx1 é uma questão de debate, com a glutarredoxina 2 (Grx2), tiorredoxina 3 (Trx3), tiorredoxina redutase 2 (Trr2) e ascorbato sendo propostos como possíveis redutores. Para avaliar a importância fisiológica de Prx1 na manutenção da homeostase redox mitocondrial, nós investigamos os mecanismos de importação e processamento mitocondrial de Prx1 assim como os de seus possíveis redutores Trr2 e Trx3. Os ensaios de solubilidade e subfracionamento mitocondrial demonstram que Prx1, Trr2 e Trx3 co-localizam na matriz mitocondrial, associadas fracamente com a membrana mitocondrial interna. Além disso, Prx1 apresenta dupla localização, estando presente também no espaço intermembrana mitocondrial possivelmenete na forma solúvel. O mecanismo de importação de Prx1 para o espaço intermembrana envolve a liberação da proteína precursora no interior da bicamada lipídica da membrana interna em decorrência de uma pequena região hidrofóbica localizada imediatamente após a pressequência. Em seguida, a subunidade Imp2 do complexo proteico IMP catalisa a clivagem da região hidrofóbica liberando Prx1 no espaço intermembrana. Durante a importação de Prx1 para a matriz mitocondrial, a enzima é clivada sequencialmente pelas proteases peptidase de processamento mitocondrial (MPP) e octapeptidil aminopeptidase 1 (Oct1). Oct1 catalisa a remoção de oito resíduos de aminoácidos da região N-terminal de Prx1. Esse processamento aumenta a estabilidade de Prx1 no interior da mitocôndria, mas não interfere na sua atividade peroxidásica in vitro. Apesar das enzimas Trr2 e Trx3 não serem clivadas por Oct1, a ausência de Oct1 causa eleavada instabilidade dessas proteínas. O processamento das Prxs por Oct1 parece ser um processo conservado visto que Oct1 de levedura é capaz de clivar a peroxirredoxina mitocondrial humana Prx3 expressa em $S$. cerevisiae. Estes resultados indicam o envolvimento de Oct1 no processamento das peroxirredoxinas, representando um sistema de controle de qualidade proteico que regula a homeostase das Prxs e, possivelmente, processos redox mitocondriais. 


\begin{abstract}
Peroxiredoxins (Prxs) are thiol-dependent peroxidases that catalyze the reduction of a wide variety of hydroperoxides. The Prxs catalytic activity is provided by the presence of a highly conserved catalytic cysteine residue whose oxidation by hydroperoxide generates sulfenic acid (Cys-SOH). Saccharomyces cerevsiae Prx1 is a mitochondrial enzyme that catalyzes the reduction of the $\mathrm{H}_{2} \mathrm{O}_{2}$ generated endogenously by mitochondria. The mechanism of reduction of Prx harboring Cys-SOH is a matter of debate, with glutaredoxin 2 (GRX2), thioredoxin 3 ( $\operatorname{Tr} x 3)$, thioredoxin reductase 2 ( $\operatorname{Tr} 2)$, and ascorbate being proposed as possible reducers. To assess the functional role of Prx1 in maintaining the mitochondrial redox homeostasis, we investigated its mechanisms of import and processing, as well as those ones involved with its possible reducers, Trr2 and Trx3. Assays of solubility and mitochondrial sub-fractionation show that Prx1, Trr2 and Trx3 co-localize in the mitochondrial matrix compartment, being marginally associated with the inner mitochondrial membrane. In addition, Prx 1 show dual localization, being also present in the mitochondrial intermembrane space, possibly in their soluble form. The import mechanism of Prx 1 to the intermembrane space involves the release of protein's precursor within the lipid bilayer of the inner membrane due to a small, hydrophobic region located downstream the presequence. Imp2 subunit of the IMP protein complex then catalyzes the cleavage of the hydrophobic region of Prx1, releasing it to the mitochondrial intermembrane space. During its import into the matrix, Prx 1 is sequentially cleaved by the mitochondrial processing-peptidase protease (MPP) and by octapeptidil aminopeptidase 1 (Oct1). Oct1 catalyzes the cleavage of eight amino acid residues from the $\mathrm{N}$-terminal region of Prx 1 . This process increases stability of Prx 1 inside the mitochondria, but does not interfere in its peroxidase activity in vitro. Interestingly, absence of Oct1 causes high instability of Trr2 and Trx3, although these proteins are not cleaved by this protease. Remarkably, the processing of Prxs by Oct 1 seems to be a conserved process since yeast Oct 1 is able to cleave the human mitochondrial peroxiredoxin Prx3 expressed in $S$. cerevisiae. Altogether, these results indicate the involvement of Oct1 in the processing of peroxiredoxins, representing a protein quality control system that regulates the homeostasis of Prxs and, possibly, mitochondrial redox processes.
\end{abstract}




\section{INTRODUÇÃO}

\subsection{Mitocôndria: estrutura e função}

A mitocôndria é uma organela essencial da célula eucariótica. Sua função amplamente conhecida é a produção de energia celular na forma de ATP gerada pelo sistema de fosforilação oxidativa (SARASTE, 1999). No entanto, esta organela também participa na regulação de outros importantes processos celulares.

A mitocôndria desempenha uma função central no metabolismo de aminoácidos e lipídeos. Com a exceção da glicólise, todas as vias de oxidação das moléculas de alimento, incluindo o ciclo de Krebs, a $\beta$-oxidação de ácidos graxos e as vias de oxidação de aminoácidos, ocorrem no interior da mitocôndria (de WINDE; GRIVEL, 1993). Atua na biossíntese dos grupos heme e ferro-enxofre, sendo esta última a função essencial da mitocôndria para a célula eucariótica (HAMZA; DAILEY, 2012; KARNKOWSKA et al., 2016; LILL et al., 2012; ZHANG; HACH, 1999). Em adição a sua função central em diversas vias bioquímicas, a mitocôndria atua na regulação da via intrínseca da morte celular por apoptose (TAIT; GREENN, 2010) e tem sido associada na patologia de numerosas doenças, incluindo desordens neurodegenerativas (ITOH et al., 2013; LARSSON, 2010; MISHRA; CHAN, 2014).

Estruturalmente, a mitocôndria é composta por duas membranas, a membrana externa e interna. Estas delimitam dois compartimentos distintos. O espaço delimitado pela membrana interna é denominado matriz mitocondrial e a região existente entre as duas membranas é conhecido como espaço intermembrana (Figura 1). Matriz e espaço intermembrana diferem fortemente com relação à composição de íons e moléculas, principalmente em decorrência da permeabilidade seletiva da membrana interna (HERRMANN; RIEMER, 2010b). Enquanto que a membrana externa permite a livre difusão de moléculas de $\sim 5 \mathrm{KDa}$ entre o citoplasma e o espaço intermembrana, a membrana interna é altamente seletiva, sendo o transporte através de si fortemente controlado por translocadores substrato-específicos (RIEMER et al., 2015). Através da utilização de proteínas fluorescentes sensíveis às modificações redox foi demonstrado que o espaço intermembrana é significativamente mais oxidativo do que o citoplasma e a matriz mitocondrial (HERRMANN; RIEMER, 2010b).

Estudos pioneiros de microscopia eletrônica realizados na década de 50 (PALADE, 1952; SJOSTRAND, 1953) demonstraram que a membrana interna apresenta inúmeras dobras, ou invaginações, comumente denominadas de cristas mitocondriais. Por muito tempo, as cristas mitocondriais foram consideradas apenas prolongamentos da membrana interna, 
possibilitando um grande aumento da área de superfície, o que facilitaria a alocação de inúmeras unidades do sistema de fosforilação oxidativa. Nesse modelo, toda a região do espaço intermembrana constituiria um compartimento único e homogêneo.

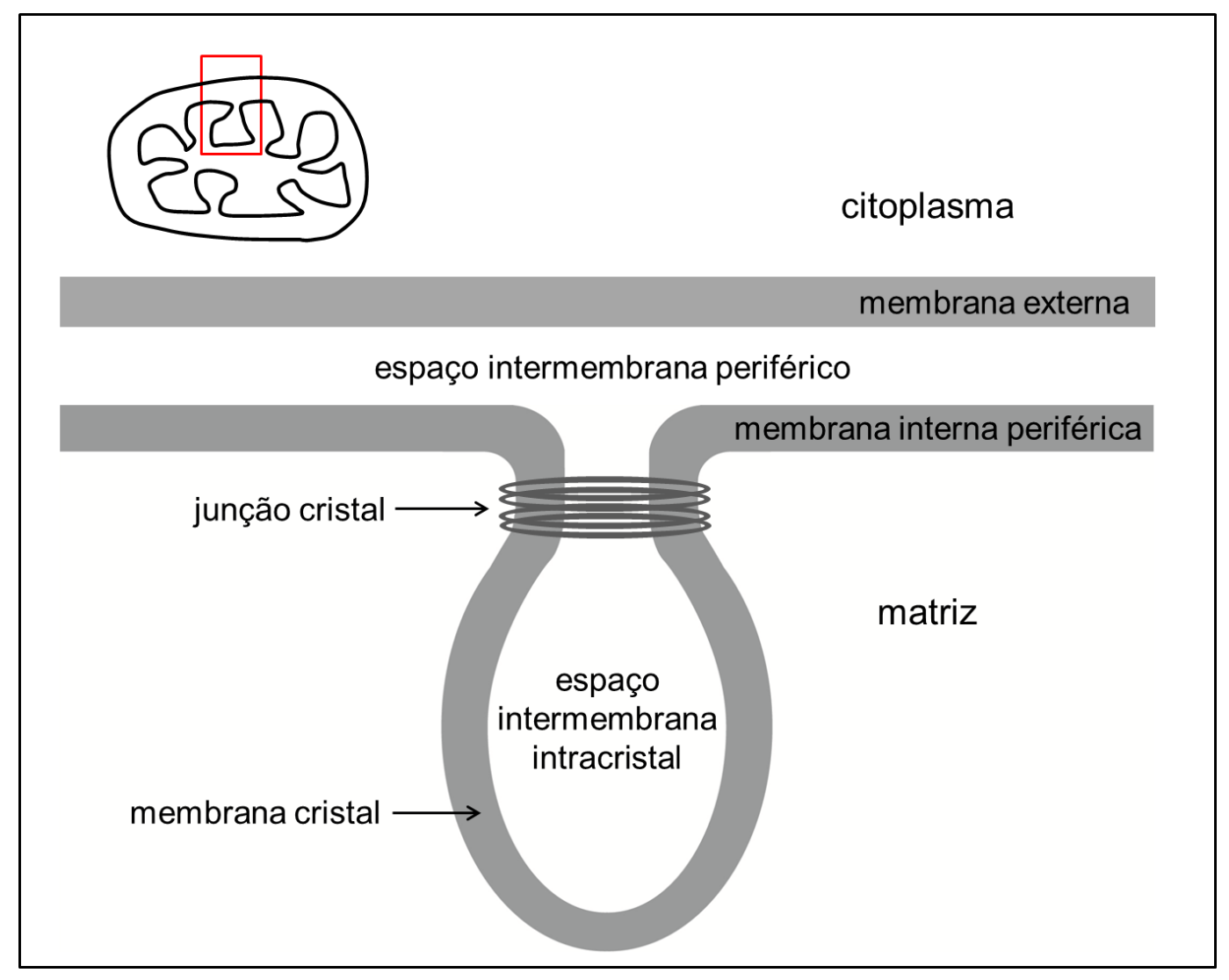

Figura 1. Representação esquemática da estrutura mitocondrial. O espaço intermembrana é estruturalmente subdividido em dois compartimentos: o espaço intermembrana periférico é definido como a região situada entre a membrana externa e a membrana interna periférica. Já o espaço intracristal compreende a região delimitada pela membrana cristal. A junção cristal é uma estrutura tubular que delimita esses dois compartimentos. FONTE: Adaptado de: Herrmann e Riemer (2010b).

O conceito de um espaço intermembrana único e contínuo foi questionado após a descoberta de pequenas estruturas tubulares formadas pela membrana interna, conhecidas como junções cristais (FREY; MANNELLA, 2000; MANNELLA et al., 1994, 1997; PERKINS et al., 1997) (Figura 1). As junções cristais delimitam duas regiões distintas da membrana interna: a membrana cristal, que compõe a crista mitocondrial, e a membrana periférica que representa a porção da membrana interna localizada próxima à membrana externa. Além disso, a junção cristal também delimita duas regiões distintas do espaço intermembrana: o espaço intermembrana periférico e o espaço intracristal (HERRMANN; RIEMER, 2010b; van der LAAN, 2012; van der LAAN, 2016). Apesar das junções cristais delimitarem regiões distintas da membrana interna, contendo diferentes composições 
proteicas, existe uma constante troca de proteínas entre as mesmas dependendo das necessidades celulares (STOLDT et al., 2012; van der LAAN, 2016).

Na membrana cristal existe uma grande concentração dos componentes do sistema de fosforilação oxidativa, responsável pela síntese de ATP. Esse sistema é composto pela cadeia transportadora de elétrons e pelo complexo da ATP sintase.

A cadeia transportadora de elétrons, ou simplesmente cadeia respiratória, é composta por uma série de carregadores que catalisam a transferência sequencial de elétrons oriundos das oxidações das moléculas de alimentos para o oxigênio molecular. A maioria desses carregadores encontram-se agrupados em quatro complexos multiproteicos embebidos na membrana interna, conhecidos como complexos respiratórios I (NADH:ubiquinonaoxidorredutase), II (succinato-ubiquinona-oxidorredutase), III (ubiquinona:citocromo $c$ oxidorredutase) e IV (citocromo $c$-oxidase). Em adição aos complexos I, II, III e IV outras duas moléculas completam a cadeia respiratória: uma quinona hidrofóbica conhecida como ubiquinona, ou simplesmente conzima Q, e o citocromo $c$ (HATEFI, 1985; LENAZ; GENOVA, 2010; SCHAFFER; SULEIMAN, 2007; TZAGOLOFF, 1982).

A fosforilação oxidativa inicia-se com a entrada de elétrons na cadeia respiratória, a partir das coenzimas reduzidas NADH e FADH2, geradas a partir das oxidações das moléculas de alimento. NADH e FADH2 são oxidadas pelos complexos I e II, respectivamente. Os elétrons são então transferidos sequencialmente para a ubiquinona, o complexo III, o citocromo $c$, o complexo IV e, finalmente, para o oxigênio molecular (SARASTE, 1999).

A energia liberada durante a passagem dos elétrons, através da cadeia respiratória, impulsiona o bombeamento de prótons da matriz mitocondrial para o espaço intermembrana. Dessa forma é gerado um armazenamento temporário de energia potencial eletroquímica, decorrente da diferença de concentração de prótons, e da separação de cargas através da membrana mitocondrial interna. A energia potencial eletroquímica, conhecida como força próton-motriz, impulsiona a síntese de ATP, à medida que os prótons fluem de volta à matriz mitocondrial de acordo com o gradiente eletroquímico, através de um poro associado com o complexo da ATP-sintase (SCHULTZ; CHAN, 2001).

A cadeia respiratória da levedura Saccharomyces cerevisiae possui certa particularidade em virtude desse organismo não possuir o complexo respiratório I funcional (Figura 2). Ao invés dele, a levedura possui três NADH desidrogenases localizadas na membrana mitocondrial interna, que catalisam a oxidação do NADH e concomitante redução da ubiquinona (BAKKER et al., 2001). As enzimas Nde1 e Nde2 catalisam a oxidação do 
NADH proveniente do citoplasma (LUTTIK et al., 1998), enquanto Ndi1, o NADH da matriz mitocondrial (MARRES et al., 1991). Ao contrário do complexo respiratório I, essas enzimas são incapazes de bombear prótons para o espaço intermembrana durante o processo de transferência de elétrons.

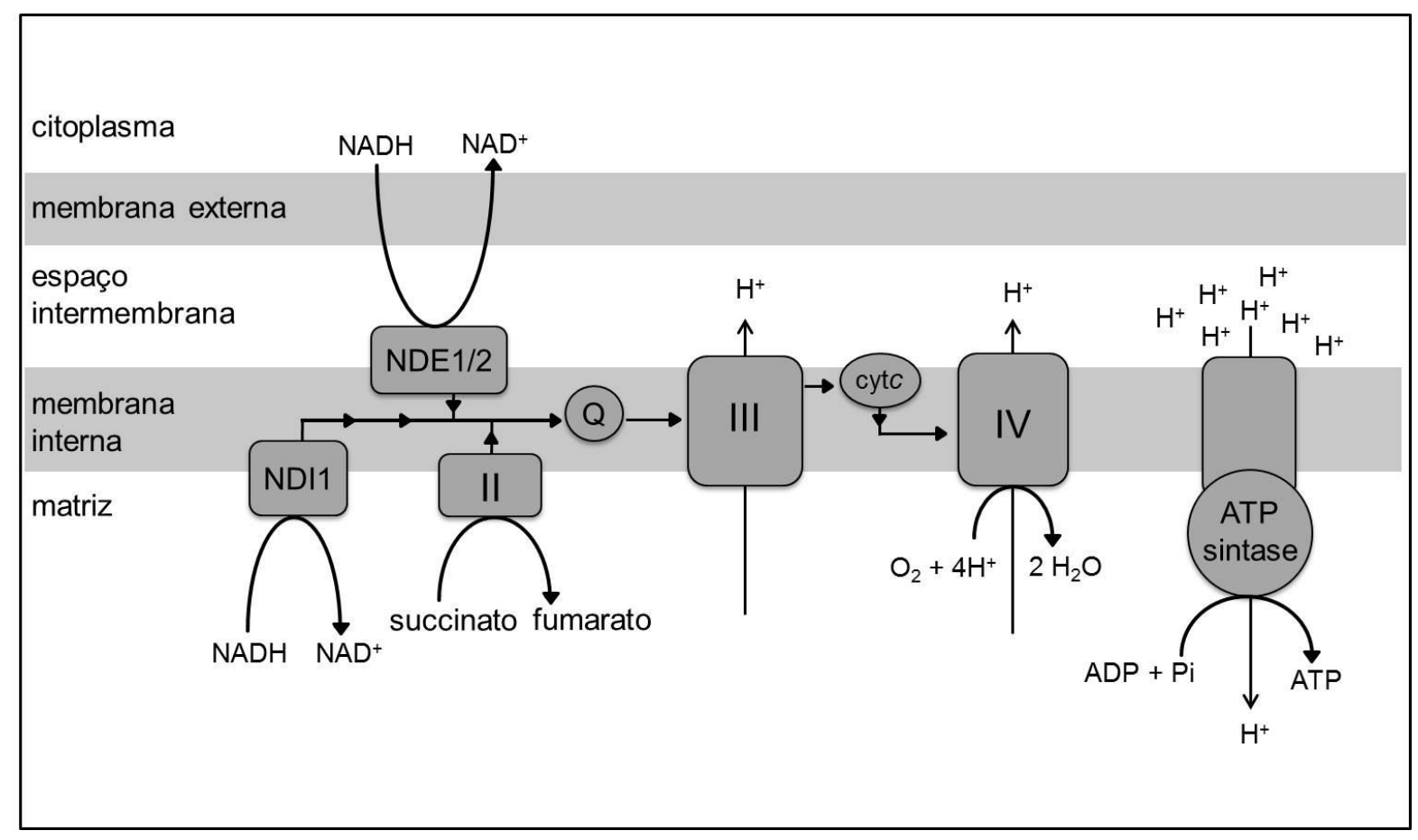

Figura 2. Representação esquemática do sistema de fosforilação oxidativa de Saccharomyces cerevisiae. As setas indicam o fluxo de elétrons através dos componentes da cadeia respiratória mitocondrial. Os elétrons derivados do NADH e succinato são transferidos para o oxigênio molecular por meio de uma série de carreadores presentes na membrana mitocondrial interna. O gradiente eletroquímico gerado pela transferência de elétrons impulsiona a síntese de ATP por meio do complexo da ATP-sintase. Para fins de simplificação não estão sendo demonstradas as junções cristais. NDE1/2 - NADH desidrogenase externa 1/2, NDI1 - NADH desidrogenase interna 1, II - complexo respiratório II, III - complexo respiratório III, IV - complexo respiratório IV, Q coenzima Q, cytc - citocromo $c$. FONTE: Adaptado de Herrero et al. (2008).

Existem inúmeras evidências que suportam a teoria endossimbionte para o surgimento das mitocôndrias. De acordo com essa teoria as mitocôndrias são derivadas de uma $\alpha$ proteobactéria ancestral, que foi engolfada por uma célula eucariótica primordial há aproximadamente 1,5-2 bilhões de anos (GRAY et al., 1999). No decorrer da evolução, o genoma mitocondrial sofreu uma extensiva redução devido a inúmeras perdas ou transferências de genes para o DNA nuclear (ANDERSSON; KURLAND, 1998). No entanto, na célula eucariótica atual existe um pequeno número de proteínas e RNAs funcionais codificados pelo DNA mitocondrial (mtDNA). Em S. cerevisiae, por exemplo, o genoma mitocondrial contém os genes codificantes para três subunidades do complexo respiratório 
IV: $C O X 1, C O X 2$ e $C O X 3$, três subunidades da ATP-sintase: ATP6, ATP8 e ATP9, uma subunidade do complexo III: COB1, uma proteína ribossomal: VAR1, para os RNAr 15S e 21S e finalmente para os 24 tRNA que perfazem todos os códons (FOURY et al.,1998).

Um estudo proteômico identificou 851 proteínas que fazem parte de um conjunto de aproximadamente 1000 proteínas preditas fazerem parte da composição da mitocôndria de $S$. cerevisiae (REINDERS et al., 2006) (Figura 3). Como mencionado anteriormente, apenas um pequeno número delas $(\sim 1 \%)$ são codificados pelo mtDNA, sendo a grande maioria ( 99\%) codificadas por genes nucleares, traduzidas no citoplasma e posteriormente importadas para o interior da mitocôndria (MEISINGER et al., 2009). Dessa forma, há necessidade de um complexo mecanismo de importação que as receba, processe e as distribua pelos diferentes compartimentos mitocondriais (BECKER et al., 2012; BOLENDER et al., 2008; CHACINSKA et al., 2009; DUDEK et al., 2013; HARBAUER et al., 2014; NEUPERT; HERRMANN, 2007; SCHMIDT et al., 2010; STOJANOVSKI et al., 2012).

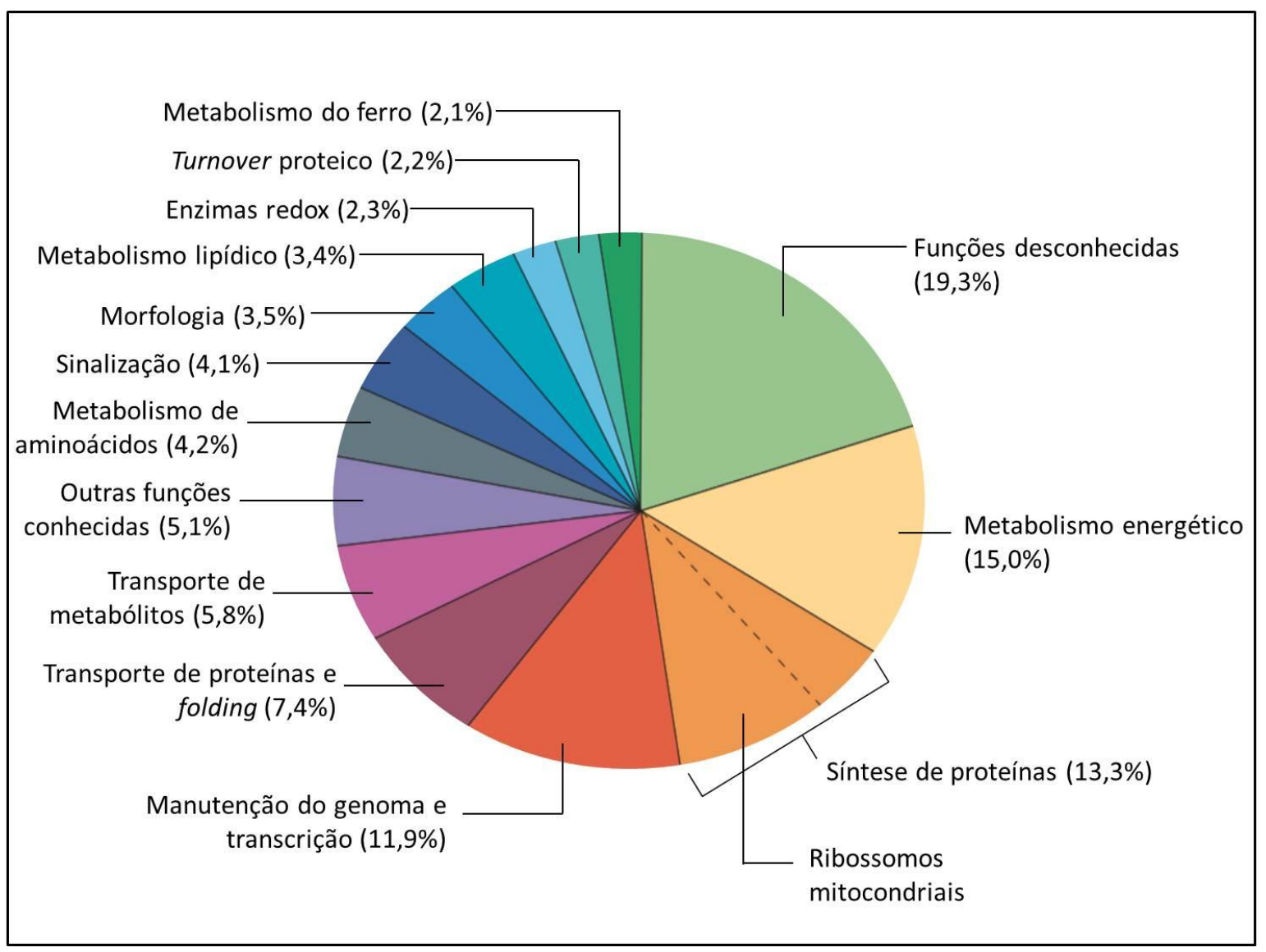

Figura 3. Representação esquemática do proteoma de Saccharomyces cerevisiae. As porcentagens de proteínas envolvidas nos diferentes processos mitocondriais foram definidas de acordo com o trabalho de Reinders et al. (2006). FONTE: Adaptado de Schmidt et al. (2010). 


\subsection{Mecanismos de importação das proteínas mitocondriais}

Grande parte do conhecimento da maquinaria de importação das proteínas mitocondriais foi obtida através de estudos utilizando a levedura $S$. cerevisiae como modelo (Figura 4). Com exceção das proteínas codificadas pelo mtDNA e proteínas $\alpha$-hélices da membrana externa, o restante dos precursores proteicos mitocondriais são translocados para o interior da organela através do complexo proteico TOM (translocase of the outer membrane) localizado na membrana externa. Dessa forma, TOM pode ser visto como o portão de entrada para a importação da grande maioria das proteínas mitocondriais (CHACINSKA et al., 2009; DOLEZAL et al., 2006; HERRMANN et al., 2012; SCHMIDT et al., 2010; STOJANOVSKI et al., 2012). A partir do complexo TOM, os precursores podem seguir diferentes rotas de importação. A via de importação a ser seguida irá depender de sinais específicos presentes na sequência de aminoácidos da proteína precursora. Quatro principais vias de importação (A, B, $\mathrm{C}$ e D da figura 4) que direcionam as proteínas para os diferentes sub-compartimentos da mitocôndria tem sido amplamente caracterizadas (BOHNERT et a., 2015; HARBAUER et al., 2014; SCHMIDT et al., 2010).

A seguir, segue-se uma descrição das vias de importação dos precursores contendo pressequência (rota de importação A da figura 4) e dos precursores ricos em resíduos de cisteínas (rota de importação B da figura 4) das proteínas mitocondriais de S. cerevisiae.

\subsubsection{O mecanismo de importação pressequencia}

Grande parte das proteínas mitocondriais é traduzida a partir do RNAm com uma extensão $\mathrm{N}$-terminal conhecida como pressequencia. A pressequencia direciona a importação da maioria das proteínas para a matriz mitocondrial e de uma fração considerável para a membrana interna (MOSSMANN et al., 2012; SCHMIDT et al., 2010). Proteínas contendo a pressequencia são inicialmente translocadas através do complexo TOM seguido do complexo

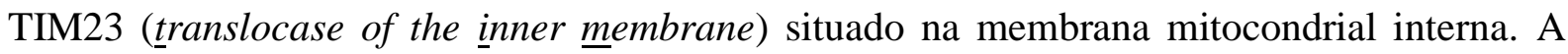
partir de TIM23 elas podem ser liberadas lateralmente para a membrana interna ou então serem completamente importadas para a matriz com auxílio do complexo PAM (pressequence translocase-associated motor) (CHACINSKA et al., 2009; DOLEZAL et al., 2006; NEUPERT; HERRMANN, 2007; SCHMIDT et al., 2010) (Figura 5). 


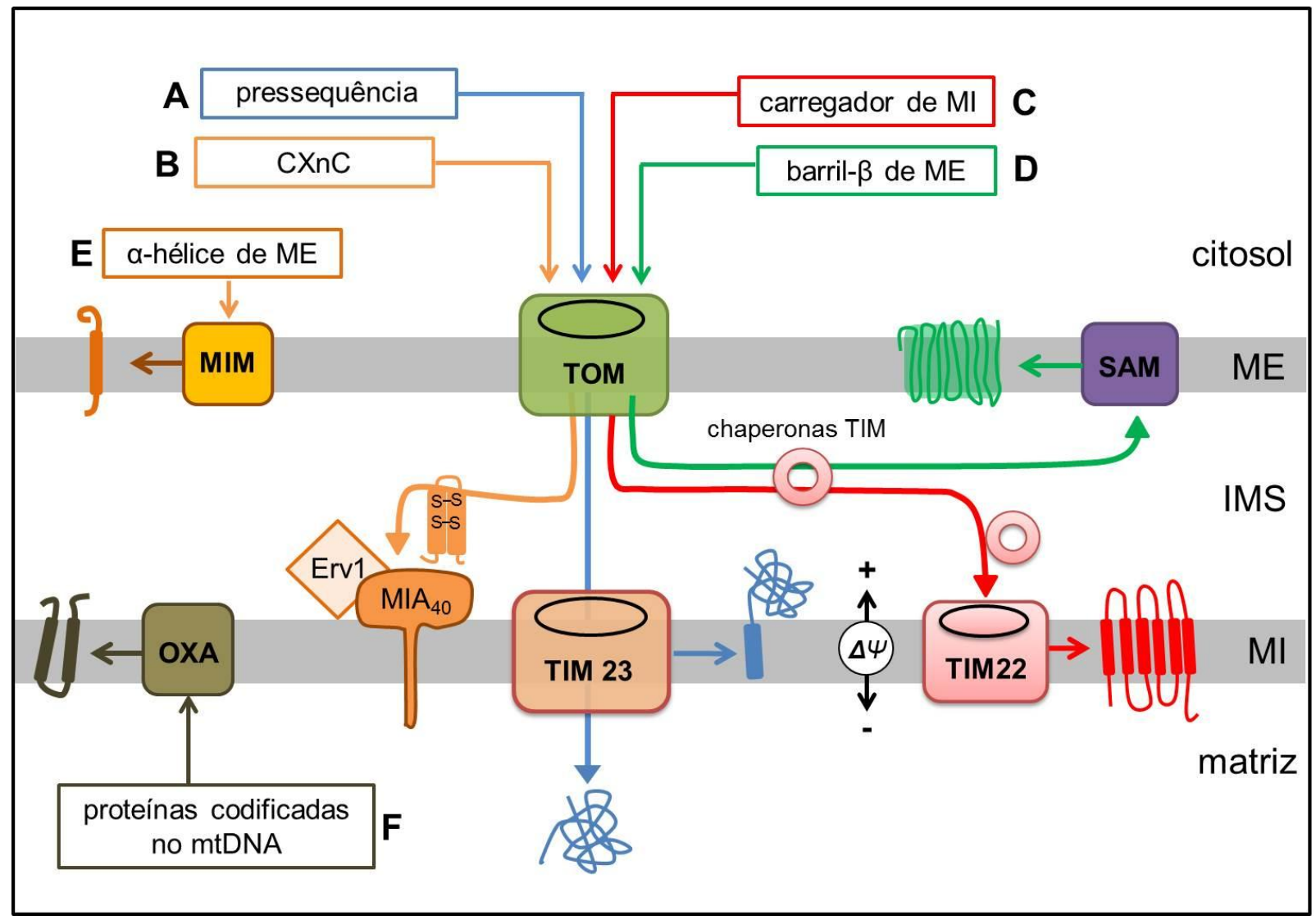

Figura 4. Visão geral da maquinaria de importação das proteínas mitocondriais em $S$. cerevisiae. Com a exceção das proteínas codificadas no mtDNA e as proteínas $\alpha$-hélices da membrana externa o restante dos precursores proteicos mitocondriais são translocados para o interior da organela através do complexo proteico TOM localizado na membrana externa. A - Os precursores contendo pressequência cliváveis são translocados para a matriz mitocondrial através do complexo TIM23 localizado na membrana interna. Esse processo requer a energia do gradiente eletroquímico de prótons. B - Os precursores ricos em resíduos de cisteínas destinados ao espaço intermembrana são importados através da maquinaria MIA. MIA ${ }_{40}$ funciona como um receptor e uma oxido-redutase para os precursores, catalizando a inserção de ligações dissulfetos nas proteínas precursoras. Erv1 reoxida $\mathrm{MIA}_{40}$ para que ela possa realizar um novo evento de importação. $\mathbf{C}$ - Os precursores dos carregadores metabólicos hidrofóbicos da membrana interna são ligados pelas proteínas TIM no espaço intermembrana e posteriormente inseridos na membrana interna através do complexo TIM22 em um processo dependente da energia do gradiente eletroquímico de prótons. D - Os precurosres das proteínas barril- $\beta$ da membrana externa são transferidos para a maquinaria SAM com auxílio das chaperonas TIM. A maquinaria SAM insere esses precursores na membrana externa. E - As proteínas de membrana exerna com segmentos $\alpha$-hélice transmembrana são inseridas na membrana através de mecanismos pouco caracterizados. No exemplo demonstrado, a importação desses precursores requer a participação da maquinaria MIM. F - As proteínas codificadas no mtDNA são inseridas na membrana interna com auxílio da maquinaria OXA. Adaptado de Bohnert et al. (2015).

A composição da pressequencia é rica em aminoácidos carregados positivamente e em aminoácidos hidrofóbicos os quais formam uma $\alpha$-hélice anfipática. Os aminoácidos positivos são dominantes em um dos lados da hélice enquanto no outro lado estão presentes resíduos hidrofóbicos (ABE et al., 2000; CHACINSKA et al., 2009; DOLEZAL et al., 2006; ENDO et al., 2011; HABIB et al., 2007; MOSSMANN et al., 2012; NEUPERT; HERRMANN, 2007). 
As pressequencias possuem um tamanho médio de 15-50 resíduos e são reconhecidas sequencialmente pelos complexos TOM e TIM23 durante a etapa de translocação (CHACINSKA et al., 2009). Aproximadamente $60 \%$ ou mais de todas as proteínas mitocondriais são sintetizadas com pressequencias (VÖGTLE et al., 2009).

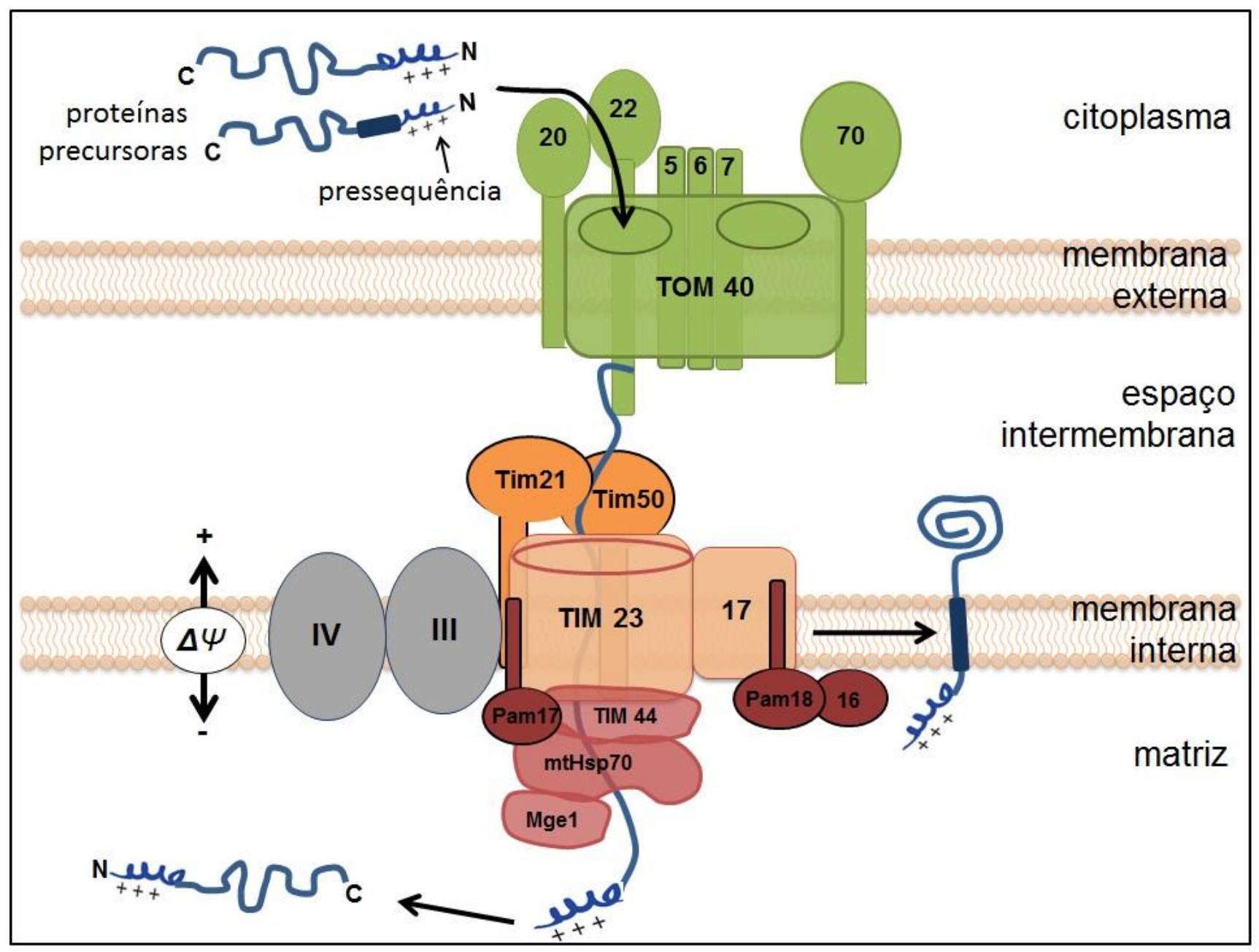

Figura 5. Representação esquemática do mecanismo de importação das proteínas contendo a pressequencia. Os componentes do complexo TOM (translocase of the outer membrane) estão coloridos em verde, os do complexo TIM23 (translocase of the inner membrane) estão destacados em tons de vermelho e laranja. As proteínas precursoras são inicialmente translocadas através do complexo de membrana externa TOM. Nessa etapa, os receptores Tom20 e Tom 22 interagem com a pressequencia e direcionam os precursores para o poro formado por Tom 40 . Após emergirem no espaço intermembrana, os precursores são transferidos para o complexo TIM23 com auxílio dos domínios receptores de Tim50 e Tim21 que se projetam para o espaço intermembrana. Impulsionados pelo potencial de membrana $(\Delta \Psi)$, os precursores são translocados através do poro formado por Tim23. A etapa final de importe para a matriz é impulsionado pelo complexo PAM, no qual a chaperona mtHsp70 puxa os polipeptídeos para o interior da matriz utilizando a energia da hidrólise do ATP. Proteínas contendo uma pequena região hidrofóbica após a pressequencia são lateralmente liberadas na bicamada lipídica da membrana interna. Detalhes de cada um dos componentes estão descritos no texto. IV e III - complexos respiratórios IV e III, respectivamente. FONTE: Adaptado de Becker et al. (2012). 
Nas etapas iniciais da translocação através do complexo TOM a região hidrofóbica da pressequencia interage com o domínio receptor de Tom20, enquanto que a região carregada positivamente é reconhecida por Tom22 (SAITOH et al., 2007; SHIOTA et al., 2011; YAMANO et al., 2008b). Após a etapa de reconhecimento, os precursores são translocados através de um canal formado pela proteína barril- $\beta$ Tom40. Durante esse processo, os precursores adquirem a forma de cadeias polipeptídicas lineares, podendo adquirir uma conformação estendida ou de $\alpha$-hélice (SCHMIDT et al., 2010).

Após emergirem do complexo TOM, os precursores são reconhecidos pelo complexo TIM23 localizado na membrana mitocondrial interna (Figura 5). Durante a translocação por TIM23 as proteínas podem seguir através de duas possíveis rotas de importação: ser liberadas lateralmente para a membrana interna ou então direcionadas para a matriz mitocondrial (CHACINSKA et al., 2009; NEUPERT; HERRMANN, 2007; SCHMIDT et al., 2010). Proteínas destinadas à matriz são hidrofílicas e a pressequencia geralmente contem a informação necessária para a sua importação. Por outro lado, um pequeno número de precursores contem um segmento hidrofóbico adicional localizado imediatamente após a pressequencia. Esta porção hidrofóbica bloqueia a translocação através de Tim23, induzindo a liberação das proteínas para o interior da fase lipídica da membrana interna (GLICK et al., 1992).

O mecanismo de translocação por meio do complexo TIM23 é considerado o processo mais complexo dentre a maquinaria geral de importação (CHACINSKA et al., 2009). A translocação por este complexo envolve a cooperação com o complexo TOM, a cadeia respiratória, o complexo PAM e duas diferentes fontes de energia: o gradiente eletroquímico (potencial de membrana) e o ATP (BECKER et al., 2012; CHACINSKA et al., 2009; SCHMIDT et al., 2010).

O complexo TIM23 pode ser subdivido em dois componentes: um embebido na membrana interna, formando um poro; e outro na matriz, atuando como um motor impulsionando a translocação (HERRMANN et al., 2012). As subunidades Tim50, Tim23 e Tim21 da porção embebida na membrana possuem domínios que se projetam para o interior do espaço intermembrana que interagem com o complexo TOM. Isto permite a eficiente translocação dos precursores que emergem do complexo TOM para o interior do complexo TIM23 (CHACINSKA et al., 2005; GEISSLER et al., 2002; MOKRANJAC et al., 2009; TAMURA et al., 2009; YAMAMOTO et al., 2002).

Inicialmente, os precursores que emergiram do complexo TOM são reconhecidos pelo domínio receptor da subunidade Tim50 do complexo TIM23 (SCHULZ et al., 2011). Tim50 
se associa fortemente com o domínio de Tim23 exposto para o espaço intermembrana. Dessa forma, a informação sobre o surgimento de uma proteína a partir do complexo TOM é diretamente transferida para o poro formado pela subunidade TIM23 (MOKRANJAC et al., 2009; TAMURA et al., 2009). Ocorre então a translocação através desse poro sendo ele grande o suficiente para permitir a passagem de uma cadeia polipeptídica em uma conformação de $\alpha$-hélice (TRUSCOTT et al., 2001). A subunidade Tim17 é estruturalmente similar a Tim23 e, apesar de sua função não estar completamente elucidada, ela parece desempenhar uma função regulatória na abertura do poro formado por Tim23 (MARTINEZCABALLERO et al., 2007; MEIER et al., 2005).

A proteína Tim21 possui uma função dupla: interage tanto com o complexo TOM, quanto com componentes da cadeia respiratória mitocondrial (van der LAAN et al., 2006). Tem sido postulado que a interação de Tim21 com componentes da cadeia respiratória assegura um eficiente uso do gradiente eletroquímico durante o processo de translocação através de Tim23 (DIENHART 2008; van der LAAN et al., 2006; WIEDEMANN et al., 2007). O gradiente eletroquímico gerado através da membrana interna é crucial para a translocação dos precursores através de TIM23. Basicamente ele exerce duas funções: a ativação de TIM23 e a criação de um efeito eletroforético que impulsiona a importação dos precursores contendo a pressequencia, já que o gradiente eletroquímico é negativo no interior da matriz, enquanto as pressequencias são carregadas positivamente (CHACINSKA et al., 2009; MEINECKE et al., 2006; TRUSCOTT et al., 2001).

A etapa final de translocação das proteínas para a matriz mitocondrial requer a ação do complexo PAM que atua como um motor impulsionador do importe. A subunidade central do complexo PAM é formada pela chaperona mtHsp70 (proteína do choque térmico da matriz de 70KDa). Esta se liga nas cadeias polipeptídicas desenoveladas dos precursores, impulsionando sua translocação para o interior da matriz de maneira dependente da hidrólise de ATP (CHACINSKA et al., 2009; NEUPERT; HERRMANN, 2007; SCHMIDT et al., 2010).

Durante sua ação, mtHsp70 coopera com algumas co-chaperonas, dentre elas Mge1, Tim44, Pam16, Pam17 e Pam18. Mge1, também conhecida como GrpE, é um fator de troca de nucleotídeo que estimula a liberação do ADP de mtHsp70. Tim44 atua como um sitio de ancoragem para mtHsp70 no complexo TIM23. As co-chaperonas Pam16, Pam17 e Pam18 são necessárias para coordenar a função de mtHsp70 com o complexo TIM23 (SCHMIDT et al., 2010). 
Nos últimos anos, surgiram dois modelos que tentam explicar o mecanismo pelo qual mtHsp70 impulsiona a translocação de proteínas para o interior da matriz. O primeiro deles, conhecido como aprisionamento passivo (passive trapping), prediz que as moléculas de mtHsp70 se ligam nos precursores polipeptídicos desenovelados a medida que eles emergem de TIM23. Isto impede que os mesmos retornem (back-sliding) para o espaço intermembrana. À medida que novos segmentos do polipeptídio alcançam a matriz por difusão novas moléculas de mtHsp70 se ligam nos mesmos, favorecendo um movimento direcional do precursor para o interior da matriz (LIU et al., 2003; OKAMOTO et al., 2002; YAMANO et al., 2008a). O segundo modelo, conhecido como puxamento ativo (active pulling), prediz que as moléculas de mtHsp70 ligadas a membrana através de Tim44 alteram sua conformação impulsionando ativamente o precursor para o interior da matriz (CHAUWIN et al., 1998). Estudos funcionais utilizando mutantes de mtHsp70 indicam que ambos os modelos operam durante a importação dos precursores para o interior da matriz (KRAYL et al, 2007).

\subsubsection{Processamento final dos precursores contendo pressequencia}

Após os precursores alcançarem a matriz mitocondrial, a maioria das pressequencias são proteoliticamente removidas através da ação de uma enzima denominada peptidase de processamento mitocondrial (MPP) (GAKH et al., 2002; KALOUSEK et al., 1993; MOSSMANN et al., 2012; TAYLOR et al., 2001) (Figura 6). MPP é um heterodímero solúvel constituído por duas proteínas homólogas Mas1 ( $\beta$-MPP) e Mas2 ( $\alpha$-MPP). Ambas subunidades de MPP são essenciais para a viabilidade celular, indicando o papel central da remoção da pressequencia na maturação das proteínas mitocondrias (SCHMIDT et al., 2010).

MPP também é capaz de reconhecer e clivar pressequencias de proteínas que foram lateralmente liberadas na bicamada lipídica da membrana interna durante a translocação através de Tim23 (MOSSMANN et al., 2012). Conforme anteriormente citado, proteínas que utilizam esta rota de importação possuem uma pequena região hidrofóbica localizada logo após a pressequência. Este segmento hidrofóbico causa um bloqueio da translocação através do complexo TIM23, induzindo a liberação lateral das proteínas para o interior da bicamada lipídica da membrana interna (GLICK et al., 1992). A pressequencia que inicialmente foi lançada para o interior da matriz é clivada pela protease MPP.

No caso de proteínas da membrana interna, o sinal hidrofóbico tipicamente permanece como parte da proteína madura e ancora a proteína na bicamada lipídica. Para proteínas solúveis do espaço intermembrana, o sinal hidrofóbico é clivado pelo complexo IMP (inner 
membrane peptidase), liberando a proteína madura nesse compartimento (CHACINSKA et al., 2009; SCHMIDT et al., 2010; MOSSMANN et al., 2012) (Figura 6).

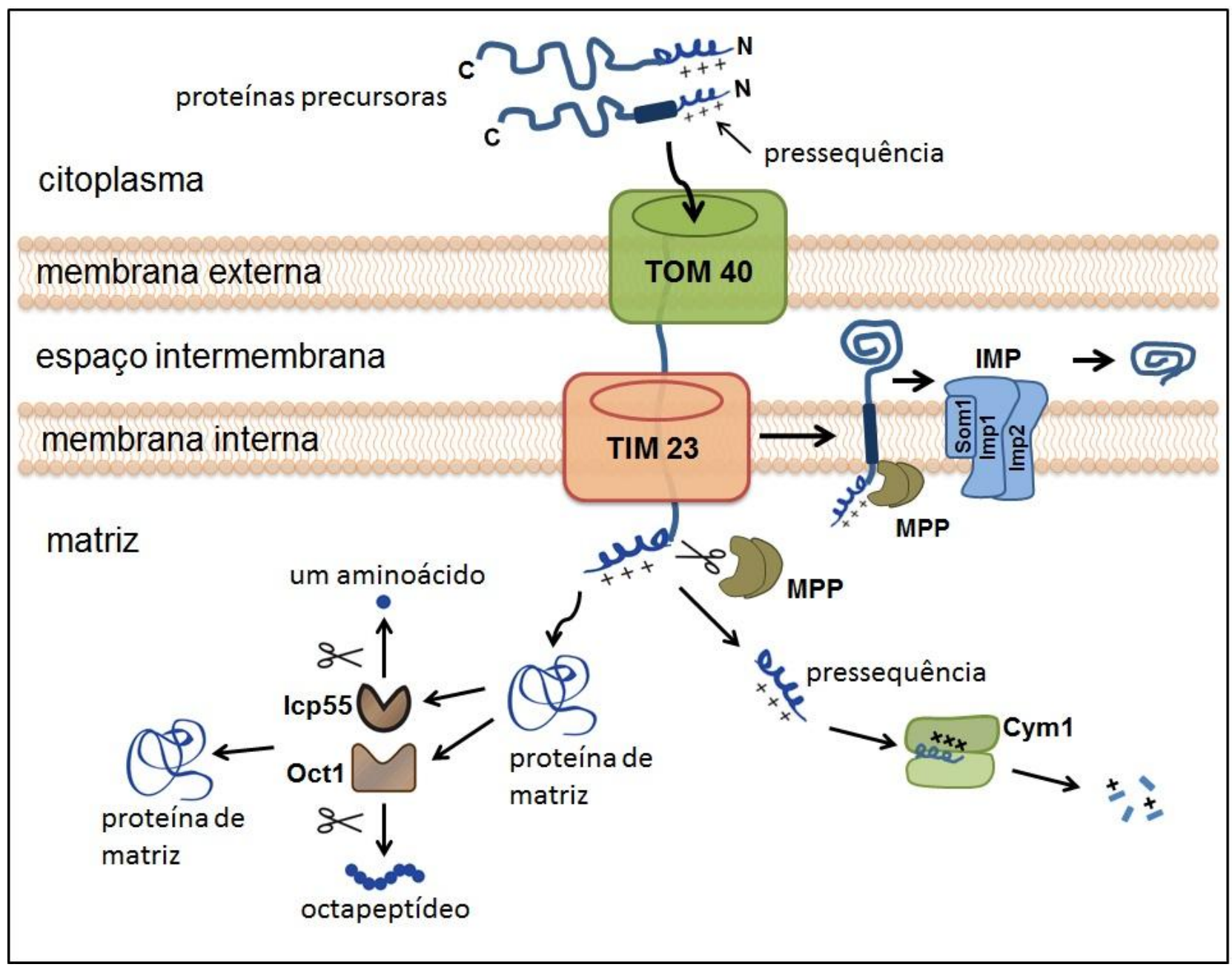

Figura 6. Representação esquemática das etapas finas de processamento das proteínas mitocondriais contendo a pressequencia. Após alcançarem a matriz mitocondrial as pressequencias são removidas pela peptidase MPP. MPP também atua na clivagem de proteínas que foram lateralmente liberadas na bicamada lipídica. As pressequencias clivadas por MPP são posteriormente degradadas pela ação da oligopeptidase Cym1. Para um grupo bem menor de proteínas, proteases adicionais catalisam posteriores eventos de clivagem. Icp55 e Oct1 catalisam respectivamente a clivagem de um e oito resíduos de aminoácidos da região $\mathrm{N}$-terminal gerada por MPP. Detalhes de cada um dos componentes estão descritos no texto. FONTE: Adaptado de Becker et al. (2012).

O complexo IMP consiste de um hetero-oligomero composto por duas subunidades catalíticas (Imp1 e Imp2) e uma subunidade regulatória (Som1) (JAN et al., 2000; NUNNARI et al., 1993; SCHNEIDER et al., 1994). As subunidades catalíticas Imp1 e Imp2 possuem os sítios catalíticos expostos para o espaço intermembrana e atuam na clivagem da região hidrofóbica das proteínas precursoras cujas formas maduras residem no espaço intermembrana (BAUER et al., 1994; JAN et al., 2000; NUNNARI et al., 1993; SCHMIDT et 
al., 2010; SCHNEIDER et al., 1994). Atualmente existem apenas seis substratos conhecidos do complexo IMP: as proteínas Cox2, Mcr1, Gut2, Cyb2 e Ptc5 são clivadas por Imp1 enquanto Cyc1 é clivada por Imp2 (GASSER et al., 1982; HARTL et al., 1987; NUNNARI et al., 1993; ESSER et al., 2004). Curiosamente, não há um consenso entre os sítios de clivagem de ambas as proteases. Imp1 parece requerer um aminoácido acídico (D ou E) na posição -1 em relação ao sítio de clivagem e um aminoácido hidrofóbico não aromático na posição -3. Imp2 requer um resíduo de alanina nas posições -1 e -3 (LUO et al., 2006; NUNNARI et al., 1993; POVEDA-HUERTES et al., 2016; TEIXEIRA e GLASER, 2013).

As pressequencias clivadas por MPP são rapidamente degradadas evitando que as mesmas interfiram com o potencial de membrana mitocondrial em decorrência de suas cargas positivas (MOSSMANN et al., 2012). A degradação das pressequencias é catalisada pela oligopeptidase Cym1 localizada na matriz mitocondrial (ALIKHANI et al., 2011) (Figura 6).

A atividade catalítica de MPP reside na subunidade Mas1, ao qual pertence ao grupo das metaloproteases, possuindo um motivo de ligação ao zinco (GAKH et al., 2002). A análise da estrutura cristalina de MPP em complexo com peptídeos sintéticos revelou que a clivagem ocorre com as pressequencias em uma conformação estendida, em contraste a conformação de $\alpha$-hélice adotada durante a translocação pelos complexos TOM e TIM23 (TAYLOR et al., 2001).

Durante muitos anos o sítio exato de clivagem de MPP foi determinado apenas para um pequeno conjunto de proteínas, tradicionalmente através do sequenciamento de Edman, utilizando proteínas purificadas das mitocôndrias. Com bases nessas informações, programas de predição de sítios de clivagens foram criados (EMANUELSSON et al., 2007), porém suas predições muitas vezes eram incorretas devido ao limitado número de informações (VÖGTLE et al., 2009). A situação mudou significativamente com um trabalho proteômico global realizado por Vögtle et al. (2009). Neste trabalho, os autores determinaram sistematicamente a região N-terminal de 615 diferentes proteínas dentre as 851 proteínas descritas na mais completa análise proteômica da mitocôndria de levedura (REINDERS et al., 2006).

O estudo de Vögtle et al. (2009) possibilitou realizar o alinhamento da região Nterminal da maioria das proteínas mitocondriais que possuem pressequencia. Isto permitiu identificar todos os sítios de clivagem de MPP, fornecendo informações valiosas para a criação de um consenso de clivagem para esta peptidase (VÖGTLE et al., 2009). O motivo de clivagem de MPP possui uma arginina altamente conservada na posição -2 em relação ao Nterminal maduro das proteínas (MOSSMANN et al., 2012; VÖGTLE et al., 2009; VÖGTLE et al., 2011) (Figura 7A). 

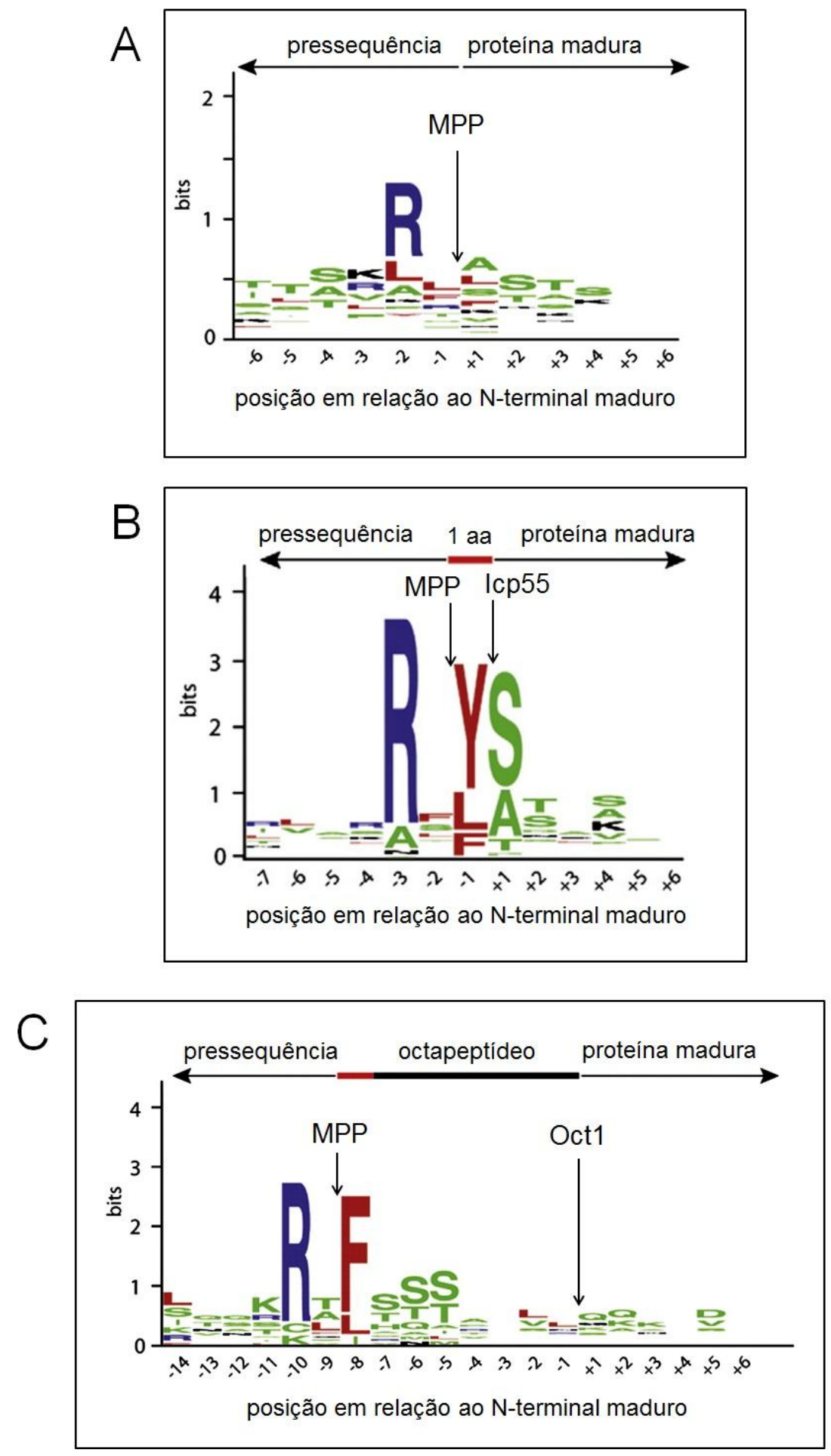

Figura 7. Motivos de clivagem de proteases da matriz mitocondrial: MPP (A), Icp55 (B) e Oct1 (C). O alinhamento dos sítios de clivagem dos substratos das proteases permitiu gerar os motivos de clivagem consenso das mesmas. No total, foram utilizadas as sequências de 38 proteínas substratos de Icp55 (B) e 12 de Oct1 (C). FONTE: Adaptado de Mossmann et al. (2012).

A clivagem da pressequencia feita por MPP libera a proteína madura ao qual adquire seu enovelamento final. No entanto, para algumas proteínas, etapas de clivagem adicionais 
são necessárias para a maturação final. As enzimas Oct1 (octapeptidyl aminopeptidase 1) e Icp55 (intermediate cleaving peptidase 55) catalisam clivagens adicionais na região Nterminal de algumas proteínas clivadas por MPP (Figura 6) (MOSSMANN et al., 2012; NAAMATI et al., 2009; VÖGTLE et al. 2009; VÖGTLE et al. 2011).

Icp55 é uma aminopeptidase que cliva um único aminoácido (fenilalanina, tirosina ou leucina) da região N-terminal de um conjunto de proteínas clivadas por MPP (Figura 6) (NAAMATI et al., 2009; VÖGTLE et al., 2009). Esta enzima é uma metaloprotease altamente conservada, localizada na matriz mitocondrial e associada perifericamente à membrana interna (VÖGTLE et al., 2009). A deleção do gene ICP55 não causa nenhum defeito de crescimento em meio fermentativo ou respiratório (VÖGTLE et al., 2009).

A clivagem feita por Icp55 é estritamente dependente do processamento inicial de MPP (MOSSMANN et al., 2012). A descoberta de Icp55 confirma o motivo altamente conservado de MPP, no qual uma arginina está presente na posição -2 em relação ao local da sua clivagem. Antes da descrição de Icp55, um número considerável de proteínas substratos de MPP apresentava um resíduo de arginina na posição -3. Isto levou a hipótese de que MPP também poderia atuar no motivo contendo a arginina na posição -3. No entanto, com a descoberta de Icp55 ficou evidente que o sítio de clivagem de MPP é de fato uma arginina na posição -2, pois em seguida, Icp55 remove mais um aminoácido (MOSSMANN et al., 2012; VÖGTLE et al., 2009) (Figura 7B).

Atualmente 39 proteínas foram descritas como substratos de Icp55 (MOSSMANN et al., 2012; SCHMIDT et al., 2010). Essas proteínas atuam em diferentes processos mitocondriais e a função da clivagem catalisada por Icp55 permanece pouco entendida (veja a seguir uma discussão conjunta do papel das clivagens de Icp55 e Oct1 na estabilização proteica).

Assim como Icp55, Oct1 é uma metaloprotease localizada na matriz mitocondrial, mas que catalisa a clivagem de oito resíduos de aminoácidos (octapeptídeo) da região $\mathrm{N}$-terminal de algumas proteínas clivadas por MPP (Figura 6) (BRANDA; ISAYA 1995; GAKH et al., 2002; GAVEL; von HEIJNE, 1990; ISAYA et al., 1994; KOPPEN; LANGER, 2007; MARCONDES et al., 2010; VÖGTLE et al., 2011). A enzima possui um motivo de ligação ao zinco e dois resíduos de cisteínas altamente conservados importantes para a estabilidade da enzima (CHEW et al., 1996; GAKH et al., 2002). Semelhante a Icp55, a clivagem feita por Oct1 é estritamente dependente do primeiro evento de clivagem catalisado por MPP (MOSSMANN et al., 2012). 
A deleção do gene $O C T 1$ não é letal para as células de levedura, porém causa a perda completa do DNA mitocondrial (mtDNA) (ISAYA et al., 1994), indicando o importante papel de Oct1 na maturação das proteínas mitocondriais.

O alinhamento dos sítios de clivagem dos substratos de Oct1 caracterizados até o momento permitiu gerar um motivo de clivagem consenso dessa peptidase (MOSSMANN et al., 2012; VÖGTLE et al., 2011). O sítio de clivagem de Oct1 possui um resíduo de arginina altamente conservado na posição -10 em relação ao N-terminal maduro das proteínas (Figura 7C). De fato, conforme anteriormente citado, um resíduo de arginina é encontrada na posição -2 do sítio de clivagem de MPP (considerando-se apenas o primeiro evento de clivagem, a arginina encontra-se na posição -2 em relação ao sítio de clivagem de MPP e -10 em relação ao sítio de clivagem por Oct1). A posição -8 é também altamente conservada, podendo ser encontrado resíduos hidrofóbicos como fenilalanina, leucina e isoleucina. Finalmente, observa-se uma prevalência de resíduos de serina e treonina distribuídos nas posições $-5,-6$ e -7 (MOSSMANN et al., 2012; VÖGTLE et al., 2011).

Até o momento, foram descritas 18 proteínas como substratos da peptidase Oct1 na levedura Saccharomyces cerevisiae. Dentre elas, algumas foram extensivamente caracterizadas e confirmadas como verdadeiros substratos de Oct1 através de estudos in vitro e in vivo. Esse é o caso das proteínas Rip1, CoxIV e Mdh1 (BRANDA; ISAYA 1995; GRAHAM et al., 1993; HURT et al., 1985; ISAYA et al., 1994; NETT et al., 1997; NETT; TRUMPOWER, 1999; VÖGTLE et al., 2011). Outras foram apenas parcialmente caracterizadas por meio de estudos in vitro: Sdh1, Mrps28, Lpd1, Rim1, Tuf1, Imo32 (BRANDA; ISAYA 1995; VÖGTLE et al., 2011). Finalmente, as proteínas Crp3, Mrp21, Rsm24, Prx1, Ysa1, Hem15, Idp1, Pet122 e Mrpl20, foram apenas preditas como possíveis substratos de Oct1, não havendo dados experimentais (BRANDA; ISAYA 1995; MOSSMANN et al., 2012; VÖGTLE et al., 2009; VÖGTLE et al., 2011).

As proteínas substratos de Oct1 possuem funções diversas, atuando na cadeia respiratória, ciclo de Krebs, manutenção do mtDNA, tradução mitocondrial, ciclo da ureia, enovelamento proteico e resposta a estresse (VÖGTLE et al., 2011). O papel funcional da clivagem catalisada por Oct1 não está completamente entendido. Um estudo inicial sobre as proteínas Rip1 e CoxIV (as proteínas Rip1 e CoxIV fazem parte dos complexos respiratórios III e IV, respectivamente) demonstrou que a forma intermediária de CoxIV se acumula na matriz mitocondrial, enquanto o intermediário de Rip1 é corretamente inserido na membrana mitocondrial interna (ISAYA et al., 1994) (BECKMANN et al., 1989; DOWHAN et al., 1985). Posteriormente, Nett e Trumpower (1999) demonstraram que ambas as formas 
intermediária e processada de Rip1 são funcionais sendo corretamente incorporadas no complexo respiratório III.

Evidências indicam que as clivagens catalisadas por Icp55 e Oct1 possuem um importante papel na estabilidade das proteínas-alvo na matriz mitocondrial (Vögtle et al. 2009; 2011). Os intermediários gerados pela clivagem de MPP são instáveis e a posterior remoção de aminoácidos catalisada pelas enzimas Icp55 e Oct1 convertem os polipeptídeos em produtos proteicos mais estáveis (HARBAUER et al., 2014; MOSSMANN et al., 2012; VÖGTLE et al., 2009; VÖGTLE et al., 2011).

A hipótese do aumento da estabilidade proteica parece ter relação com a regra $\mathrm{N}$ terminal ( $N$-end rule) da proteólise de proteínas citosólicas (VARSHAVSKY, 2008). A regra $\mathrm{N}$-terminal foi inicialmente descrita para proteínas da levedura Saccharomyces cerevisiae através de estudos demonstrando que a estabilidade de proteínas geradas artificialmente era diretamente relacionada com a natureza do aminoácido N-terminal (BACHMAIR et al., 1986; BACHMAIR; VARSHAVSKY, 1989). Estudos posteriores revelaram que o sistema proteolítico ubiquitina-proteassomo é o responsável pelo reconhecimento e degradação dessas proteínas citosólicas (DOUGAN et al., 2012; TASAKI et al., 2012) (Figura 8). Embora no sistema citosólico as proteínas responsáveis pela regra N-terminal tenham sido identificadas, no sistema mitocondrial os componentes responsáveis pelas modificações pós-traducionais dos aminoácidos e degradação das proteínas alvos ainda são pouco caracterizados (VÖGTLE et al., 2011). De qualquer forma, a composição de aminoácidos na região N-terminal parece afetar a estabilidade das proteínas-alvo no citosol e na mitocôndria de forma similar (VÖGTLE et al., 2009; 2011).

O aminoácido N-terminal responsável por uma elevada taxa de degradação proteica é denominado aminoácido desestabilizante. Aminoácidos desestabilizantes presentes na região $\mathrm{N}$-terminal são conhecidos como marcas de degradação ou simplesmente $N$-degrons. Além do aminoácido desestabilizante os $N$-degrons são constituídos por um resíduo de lisina presente na região interna da proteína e outro resíduo de lisina na região $\mathrm{N}$-terminal desestruturada (BACHMAIR; VARSHAVSKY, 1989; PRAKASH et al., 2004; SUZUKI; VARSHAVSKY, 1999; VARSHAVSKY, 1996).

Durante a síntese das proteínas, os $N$-degrons não estão presentes, surgindo no decorrer da vida da proteína, como parte de um processo regulado de degradação. Os mecanismos moleculares pelo qual os $N$-degrons são gerados permanecem pouco entendidos. Durante a criação de um $N$-degron, os aminoácidos N-terminais são convertidos 
sequencialmente em desestabilizadores terciários, secundários e primários (SRIRAM; KWON, 2010; SRIRAM et al., 2011) (Figura 8 ).

Em Saccharomyces cerevisiae, a geração de um $N$-degron em proteínas citosólicas inicia-se com a desaminação dos aminoácidos desestabilizadores terciários asparagina e glutamina, catalisada pela enzima Nta1 ( $N$-terminal amidase) (BAKER; VARSHAVSKY, 1995). Os aminoácidos gerados, aspartato e gluatamato, são considerados desestabilizadores secundários. Estes por sua vez, são convertidos em desestabilizadores primários através de uma reação de arginilação catalisada pela enzima Ate1 (arginyl-tRNA-protein transferase 1) (BALZI et al., 1990). O resíduo de arginina é um aminoácido desestabilizador primário e caracteriza o término da geração do $\mathrm{N}$-degron.

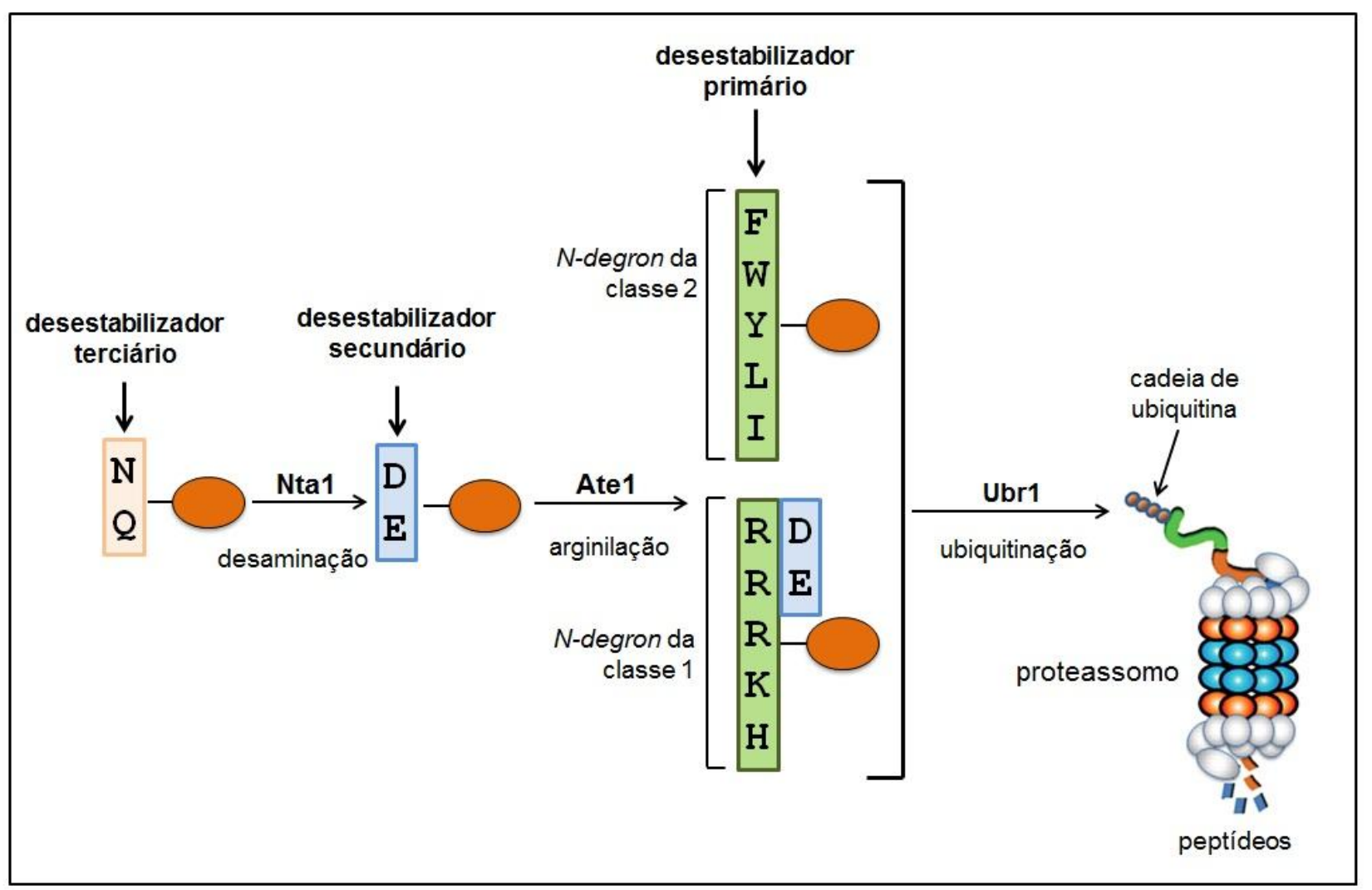

Figura 8. Representação esquemática da geração de um $\mathbf{N}$-degron em Saccharomyces cerevisiae. A proteína direcionada a degradação está representada por uma esfera laranja. A geração do $\mathrm{N}$-degron inicia com a desaminação dos aminoácidos desestabilizadores terciários glutamina e asparagina catalisada pela enzima Nta1. A desaminação gera os aminoácidos desestabilizadores secundários aspartato e glutamato, aos quais são posteriormente convertidos no desestabilizador primário arginina, através de uma reação de arginilação catalisada pela enzima Ate1. A etapa de degradação inicia-se com a ubiquitinação do $\mathrm{N}$-degron catalisada por uma enzima E3 ligase conhecida como N-recognina Ubr1. A ubiquitinação encaminha o polipeptídeo para a degradação através do sistema proteolítico proteassmo. Além da arginina, outros aminoácidos são desestabilizadores primários. Eles podem ser agrupados em duas classes: $N$-degrons da classe 1 - engloba aminoácidos carregados positivamente, $\mathrm{H}, \mathrm{L}$ e R; $\mathrm{N}$-degrons da classe 2 - engloba aminoácidos hidrofóbicos volumosos, F, L, W, I e Y. FONTE: Adaptado de Sriram et al. (2011). 
O processo de degradação de proteínas citosólicas envolve o reconhecimento do $\mathrm{N}$ degron através de uma enzima denominada N-recognina Ubr1(ubiquitin ligase $N$-recognin 1 ). Esta é uma enzima E3 ligase que catalisa a ligação de uma cadeia de ubiquitina no resíduo de lisina presente no interior da proteína alvo (BACHMAIR et al., 1986; BARTEL et al., 1990; VARSHAVSKY, 1996). Uma vez formada, a cadeia de ubiquitina será reconhecida pelo sistema proteolítico proteassomo, ao qual irá degradar o polipeptídeo alvo (DOHMEN et al., 1991). Além da arginina e da lisina ubiquitinada, Ubr1 é capaz de reconhecer outros

aminoácidos desestabilizadores primários que constituem os $N$-degrons da classe 1 e 2 (BYRD et al., 1998; DU et al., 2002).

A regra $\mathrm{N}$-terminal para estabilidade de proteínas citosólicas está presente em todos os organismos examinados, incluindo a levedura, mamíferos, plantas e bactérias. No entanto, cada organismo possui um conjunto de aminoácidos desestabilizadores característicos (SRIRAM et al., 2011; TASAKI et al., 2012).

Baseado na hipótese da regra N-terminal, Vögtle et al. $(2009,2011)$ propuseram que a clivagem de proteínas da matriz mitocondrial por MPP cria regiões $\mathrm{N}$-terminais contendo aminoácidos desestabilizadores. Por outro lado, as clivagens catalisadas pelas enzimas Icp55 e Oct1 geram proteínas com aminoácidos estabilizadores na região $\mathrm{N}$-terminal. Dessa forma, embora a regra do N-terminal apresente semelhanças para proteínas citosólicas e mitocondriais, os mecanismos subjacentes parecem ser bastante distintos.

No entanto, para um total de 39 proteínas substratos de Icp55 e 18 de Oct1, apenas 6 proteínas foram experimentalmente analisadas (3 proteínas substratos de Icp55 - Aco1, Atp3 e Tim21 e 3 de Oct1 - CoxIV, Rip1 e Mdh1). Além disso, o significado fisiológico das clivagens de Icp55 e Oct1, bem como os mecanismos envolvidos no ganho de estabilidade gerado pela ação dessas proteases, não estão claros.

\subsubsection{O mecanismo de importação acoplado a processo oxidativo}

O mecanismo de importação acoplado a processo oxidativo é responsável pela importação de grande parte das proteínas solúveis para o espaço intermembrana (Figura 9). Ao contrário das proteínas de matriz, que possuem a pressequencia, o sinal de importação dessas proteínas é composto por resíduos de cisteínas altamente conservados presentes no interior das sequências proteicas (FISCHER; RIEMER, 2013; HERRMAN; RIEMER, 2010a; HERRMANN; RIEMER, 2012; HERRMANN; RIEMER, 2014; RIEMER et al., 2009; 
RIEMER et al., 2011). Durante o processo de importação esses resíduos são oxidados, originando a formação de ligações dissulfetos.

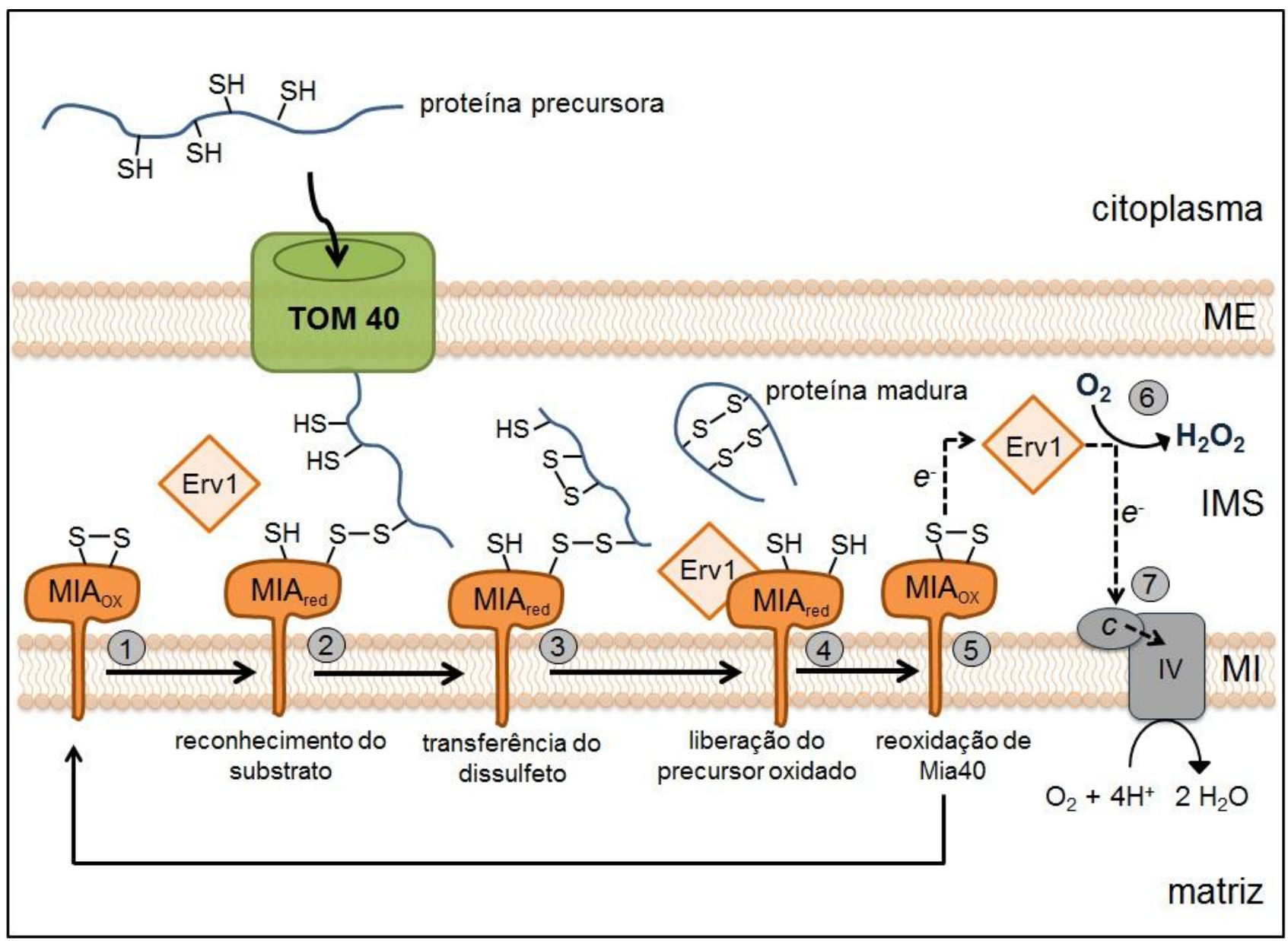

Figura 9. Representação esquemática do mecanismo de importação acoplado a processo oxidativo. A grande maioria das proteínas solúveis do espaço intermembrana possuem resíduos de cisteínas altamente conservados presentes no interior das suas sequências. As proteínas precursoras são sintetizadas no citosol e seus resíduos de cisteínas devem ser mantidos na forma reduzida (Cys$\mathrm{SH})$. Após serem translocadas através do complexo TOM, os precursores são reconhecidos pela oxidoredutase Mia40 que se encontra na forma oxidada (1). Um dos resíduos de cisteínas do precursor faz um ataque nucleofílico na ligação dissulfeto de Mia40, originando um intermediário misto Mia40precursor (2). O intermediário misto é resolvido pelo ataque de outra cisteína da proteína-alvo ao dissulfeto misto, originando dissulfeto intramolecular no precursor (3), liberando Mia40 na sua forma reduzida e o substrato oxidado na sua forma madura (4). Mia40 é reoxidada através da ação da flavoenzima Erv1 (5). Os elétrons de Mia40 são inicialmente transferidos para o motivo CxxC altamente conservado de Erv1. Em seguida, o cofator FAD presente na molécula de Erv1 reoxida o motivo CxxC. Os elétrons do cofator FAD podem seguir dois possíveis caminhos: eles podem ser transferidos diretamente para o oxigênio molecular originando peróxido de hidrogênio $\left(\mathrm{H}_{2} \mathrm{O}_{2}\right)$ (6) ou serem lançados na cadeia respiratória através da proteína citocromo $c$ (7). IV - complexo respiratório IV, ME - membrana externa, MI - membrana interna. FONTE: Adaptado de Schmidt et al. (2010).

Os precursores proteicos são inicialmente translocados através do complexo TOM presente na membrana externa. Durante a translocação os precursores são mantidos em uma conformação desenovelada com os resíduos de cisteínas na forma reduzida (tiól - Cys-SH). 
Após emergirem no espaço intermembrana, os precursores são reconhecidos pela oxido-

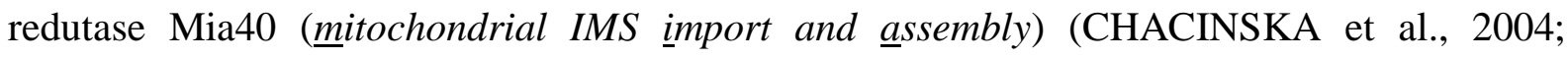
FISCHER; RIEMER 2013; SCHMIDT et al., 2010). Nesta etapa, o ânion tiolato (Cys-S) de um dos resíduos de cisteína da proteína precursora faz um ataque nucleofílico na ligação dissulfeto de Mia40, originando uma ligação dissulfeto intermolecular mista entre a proteína precursora e Mia40 (BIEN et al., 2010; MESECKE et al., 2005). A formação dessa ligação dissulfeto garante o aprisionamento das proteínas no espaço intermembrana, evitando assim o retorno (backslidin) para o citoplasma (BANCI et al., 2010; BRAGOSZEWSKI et al., 2015; FISCHER; RIEMER, 2013).

A interação entre Mia40 e a proteína precursora é desfeita através da formação de ligações dissulfetos intramoleculares na molécula precursora. Desta forma, Mia40 é liberada na sua forma reduzida enquanto o precursor é oxidado para sua forma oxidada e totalmente processada (BIEN et al., 2010; CHACINSKA et al., 2004; FISCHER; RIEMER, 2013; GRUMBT et al., 2007; MESECKE et al., 2008; MILENKOVIC et al., 2007; SIDERIS; TOKATLIDIS, 2007; TERZIYSKA et al., 2009).

Para que o mecanismo de importação continue em funcionamento as moléculas reduzidas de Mia40 precisam ser recicladas para sua forma oxidada. A oxidação de Mia40 é catalisada por uma segunda proteína denominada Erv1 (essential for respiration and viability 1) (BIEN et al., 2010). Erv1 pertence ao grupo das flavoproteínas e, portanto, possui um domínio de ligação a FAD (flavina adenina dinucleotídeo) e um motivo CxxC altamente conservado. O motivo CxxC encontra-se próximo ao FAD o que permite a transferência de elétrons do motivo CxxC reduzido para o cofator FAD (COPPOCK; THORPE, 2005; FASS, 2008).

A oxidação de Mia40 ocorre através da transferência de seus elétrons para o motivo CxxC de Erv1 oxidado (BIEN et al., 2010). O motivo CxxC de Erv1 é então re-oxidado pelo cofator FAD. A partir de FAD os elétrons que foram incialmente removidos das proteínas substratos possuem dois possíveis destinos: eles podem ser transferidos diretamente para o oxigênio molecular produzindo peróxido de hidrogênio $\left(\mathrm{H}_{2} \mathrm{O}_{2}\right)$ ou serem lançados na cadeia respiratória através da molécula de citocromo c (BIEN et al., 2010; BIHLMAIER et al., 2007; KOEHLER; TIENSON, 2009).

Tem sido postulado que a transferência de elétrons de Erv1 diretamente para o oxigênio molecular pode gerar quantidades significativas de $\mathrm{H}_{2} \mathrm{O}_{2}$ no espaço intermembrana mitocondrial (KOEHLER; TIENSON, 2009). 


\subsection{A produção de espécies reativas de oxigênio na mitocôndria}

O termo "espécies reativas de oxigênio" (EROs) é utilizado na descrição de um coletivo de espécies químicas (com propriedades distintas) formadas pela redução incompleta do oxigênio molecular (D’AUTRÉAUX; TOLEDANO, 2007). Portanto, sempre que possível é melhor a descrição individual de cada EROs em um dado sistema enzimático ou celular (WINTERBOURN, 2008; FORMAN et al., 2015).

A redução mono-eletrônica do $\mathrm{O}_{2}$ produz o radical ânion superóxido $\left(\mathrm{O}_{2}{ }^{-}\right)$, uma molécula com um tempo de meia-vida curto, que pode ser rapidamente convertido em $\mathrm{H}_{2} \mathrm{O}_{2}$ por uma reação de dismutação entre duas moléculas de $\mathrm{O}_{2}{ }^{--}$, gerando uma molécula de $\mathrm{H}_{2} \mathrm{O}_{2} \mathrm{e}$ outra de oxigênio molecular. A reação de dismutação pode ocorrer espontaneamente ou ser catalisada enzimaticamente pela enzima superóxido dismutase (SOD). $\mathrm{O} \mathrm{H}_{2} \mathrm{O}_{2}$ é relativamente estável com um tempo de meia-vida de aproximadamente $1 \mathrm{~ms}$ em sistemas celulares. Entretanto, na presença de metais de transição reduzidos tais como $\mathrm{Fe}^{2+}$ e $\mathrm{Cu}^{+}, \mathrm{o}_{2} \mathrm{O}_{2}$ é parcialmente reduzido, originando o radical hidroxil $(\mathrm{OH})$. Este é considerado um dos mais potentes oxidantes, reagindo indiscriminadamente com diversas moléculas biológicas, incluindo proteínas, lipídeos e DNA (D’AUTRÉAUX; TOLEDANO, 2007).

Em condições fisiológicas, as EROs são produzidas em uma ampla variedade de processos biológicos, sendo a mitocôndria considerada a principal geradora dessas espécies e o $\mathrm{O}_{2}{ }^{--}$o precursor da maioria das EROs (ADAM-VISI; CHINOPOULOS, 2006; BALABAN et al., 2005; BRAND, 2010; FIGUEIRA et al., 2013; HOLMSTRÖM; FINKEL, 2014; KOWALTOWSKI et al., 2009; MURPHY, 2009) (Figura 10).

Dentro da cadeia respiratória, os principais centros geradores de $\mathrm{O}_{2}{ }^{--}$são os sítios de ligação da ubiquinona dos complexos respiratórios I e III e os grupos prostéticos flavina do complexo I (BLEIER et al., 2015; BRAND, 2010; DRÖSE et al., 2014; KOOPMAN et al., 2010; KOWALTOWSKI et al., 2009; SUN; TRUMPOWER, 2003; TURRENS, 2003). Saccharomyces cerevisiae não possui o complexo respiratório I. No entanto, suas NADH desidrogenases externas (Nde1 e Nde2) e interna (Ndi1) também estão envolvidas na geração de $\mathrm{O}_{2}{ }^{--}$(FANG; BEATTIE, 2003; GOMES, et al., 2012).

A geração do $\mathrm{O}_{2}{ }^{-}$no interior da mitocôndria parece ser um processo regulado, e as EROs mitocondriais (mtEROs) podem desempenhar funções benéficas e maléficas (FIGUEIRA et al., 2013). Assim, o $\mathrm{H}_{2} \mathrm{O}_{2}$ pode atuar como uma molécula sinalizadora, modulando direta ou indiretamente a atividade de proteínas através da oxidação de resíduos de cisteínas específicos (D’AUTRÉAUX; TOLEDANO, 2007; HAMANAKA; CHANDEL, 
2010; HOLMSTRÖM; FINKEL, 2014; MURPHY et al., 2011; MURPHY, 2012; NETTO;

ANTUNES, 2016; RHEE et al., 2005; RIEMER et al., 2015; VEAL., et al., 2007).

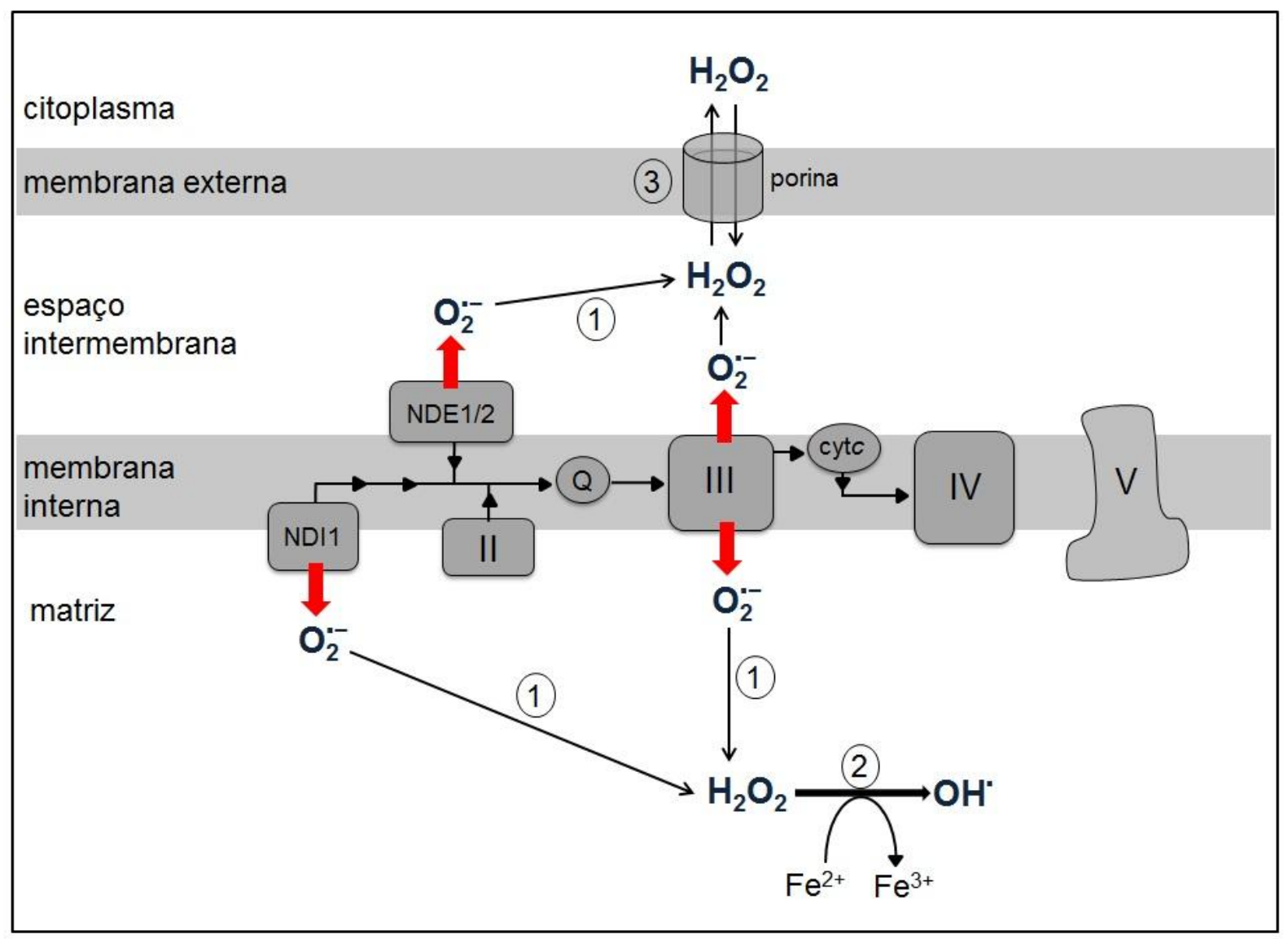

Figura 10. Representação esquemática dos principais sítios geradores do radical ânion superóxido da cadeia respiratória de Saccharomyces cerevisiae. As pontas das setas pretas indicam o fluxo de elétrons através dos componentes da cadeia respiratória mitocondrial. As setas vermelhas indicam a geração do $\mathrm{O}_{2}{ }^{-}$. Os principais sítios de geração do $\mathrm{O}_{2}{ }^{-}$são o sítio de ligação da ubiquinona do complexo III e as enzimas contendo flávina NADH desidrogenases Nde1/2 e Ndil. O $\mathrm{O}_{2}{ }^{-}$é rapidamente dismutado (reação 1) a $\mathrm{H}_{2} \mathrm{O}_{2}$ e oxigênio molecular. $\mathrm{Na}$ presença de metais de transição reduzidos, tais como o $\mathrm{Fe}^{2+}, \mathrm{o}_{2} \mathrm{O}_{2}$ é parcialmente reduzido (reação 2 - também conhecida como reação de Fenton) originando o $\mathrm{OH}: \mathrm{O} \mathrm{H}_{2} \mathrm{O}_{2}$ tem a propriedade de se difundir através das membranas mitocondriais (não demonstrado) devido à ausência de cargas. Além disso, ele pode facilmente se difundir através dos canais de porina presentes na membrana mitocondrial externa (reação 3). NDE1/2 - NADH desidrogenase externa 1/2, NDI1 - NADH desidrogenase interna 1, II complexo respiratório II, III - complexo respiratório III, IV - complexo respiratório IV, Q - coenzima Q, cytc - citocromo $c$. FONTE: Adaptado de Herrero et al. (2008).

Por outro lado, a produção excessiva de mtEROs gera danos em biomoléculas e isto tem sido relacionado com o desenvolvimento e progressão de uma série de doenças, incluindo o câncer, diabetes, doenças inflamatórias e doenças neuro-degenerativas (HAMANAKA; CHANDEL, 2010; ITOH et al., 2013; KOWALTOWSKI et al., 2009; LARSSON, 2010; MARTIN, 2010; MISHRA; CHAN, 2014). Dessa forma, os níveis de EROs mitocondriais 
precisam ser estritamente controlados de forma a garantir o funcionamento adequado da mitocôndria (MARÍ et al., 2013).

\subsection{Sistemas antioxidantes na mitocôndria de Saccharomyces cerevisiae}

Para controlar os níveis de EROs e manter a funcionalidade adequada, a mitocôndria contem uma série de sistemas enzimáticos que atuam diretamente na eliminação dessas espécies.

\subsubsection{Superóxidos Dismutases (SODs)}

As enzimas superóxido dismutases (SODs) convertem o $\mathrm{O}_{2}{ }^{--}$em oxigênio molecular e $\mathrm{H}_{2} \mathrm{O}_{2}$, o qual pode posteriormente ser reduzido a água pela ação das catalases e peroxidases (discutido posteriormente). A atividade catalítica das SODs requer a participação de um metal (FRIDOVICH, 1995). As células de Saccharomyces cerevisiae expressam duas SODs: uma citosólica dependente de cobre e zinco, conhecida como Sod1, e uma mitocondrial dependente de manganês, denominada Sod2 (CULOTTA et al., 2006).

A enzima Sod2 localizada na matriz mitocondrial, desempenha um papel central na detoxificação do $\mathrm{O}_{2}{ }^{--}$gerado pela cadeia respiratória mitocondrial. De fato, o mutante nulo $\triangle S O D 2$ apresenta um severo defeito de crescimento sob condições respiratórias (GUIDOT et al., 1993; van LOON et al., 1986). Apesar de Sod1 ter sido classicamente descrita como uma enzima citosólica, Sturtz et al. (2001) demonstraram que uma pequena fração da enzima também se localiza no espaço intermembrana mitocondrial, desempenhando um importante papel na proteção contra os danos oxidativos nesse compartimento.

\subsubsection{O sistema glutationa mitocondrial}

A glutationa (GSH) é um tripeptídeo contendo tiol e que está presente em elevadas concentrações na maioria dos organismos (MEISTER; ANDERSON, 1983). Muitas funções têm sido propostas para a GSH em uma variedade de processos celulares incluindo transporte de aminoácidos, síntese de ácidos nucléicos e proteínas, síntese de grupos ferro-enxofre e detoxificação de agentes xenobióticos e carcinogênicos (JAMIESON et al., 1998; MORANO et al., 2012; PENNINCKX et al., 1993; TOLEDANO et al., 2013). Cabe destacar o envolvimento de GSH no metabolismo das EROs, desempenhando uma importante função na manutenção do estado de oxido-redução dos grupos sulfidrilas (-SH) proteicos (CARMEL- 
HAREL; STORZ, 2000; DEPONTE, 2013; GRANT et al., 1996) que está diretamente relacionado a este trabalho.

Em Saccharomyces cerevisiae e na maioria dos eucariontes, GSH é sintetizada unicamente no citoplasma através da ação sequencial das enzimas Gsh1 ( $Y$-glutamylcysteine synthetase) e Gsh2 (glutathione synthase) (GRANT et al., 1997; OHTAKE; YABUCHI, 1991). Após sua síntese, GSH é distribuída para vários compartimentos celulares, incluindo núcleo, retículo endoplasmático e mitocôndria (TOLEDANO et al., 2013).

GSH é um componente essencial para a levedura. Células que não possuem GSH (obtidas através da deleção do gene GSH1) são inviáveis, porém são capazes de crescer devido à adição exógena de GSH ao meio de cultivo (GRANT et al., 1996; STEPHEN; JAMIESON, 1996). A natureza essencial de GSH parece estar relacionada com a sua função na maturação dos grupos ferro-enxofre que são sintetizados na matriz mitocondrial e atuam como co-fatores de enzimas essenciais da célula de levedura (KUMAR et al., 2011; SIPOS et al., 2002; TOLEDANO et al., 2013).

O papel de GSH no metabolismo das EROs está centrado no grupo sulfidrila (-SH) do seu resíduo de cisteína que, por exemplo, fornece elétrons para a redução de ligações dissulfeto de proteínas antioxidantes, como as enzimas glutationa peroxidases e glutarredoxinas (discutidas posteriormente) (CARMEL-HAREL; STORZ, 2000; FRIDOVICH, 1989). Ao realizar essas funções, a GSH se oxida em GSSG. A redução de GSSG é catalisada por uma flavo-enzima denominada glutationa redutase (Glr1) que recebe seus elétrons do NADPH (DEPONTE, 2013; OUTTEN; CULOTTA, 2004). GSH também reduz dissulfetos e ácidos sulfenicos (entre outras formas) que foram gerados em decorrência da ação das EROs. A reação de GSH com um dissulfeto protéico gera um dissulfeto misto entre uma molécula de GSH e a proteína, o que poderia proteger o grupo tiól protéico de posteriores oxidações (SHELTON et al., 2005).

Apenas GSH é transportada para o interior da mitocôndria, sendo GSSG incapaz de sair desse compartimento (GRIFFITH; MEISTER, 1985; OLAFSDOTTIR; REED, 1998). Outten e Culotta (2004) demonstraram que a enzima glutationa redutase Glr1, além de estar no citoplasma, também se localiza na matriz mitocondrial e atua na redução da GSSG desse compartimento. A geração da isoforma mitocondrial a partir do único gene GLRl é feita através da utilização de um sítio de início de tradução alternativo, gerando assim uma sequência de endereçamento mitocondrial (OUTTEN; CULOTTA, 2004).

Atualmente, há controvérsias com relação às metodologias empregadas no cálculo dos valores dos potencias de oxido-redução do par redox GSH/GSSG presente nos diferentes 
compartimentos celulares. No entanto, há um consenso de que a maior parte do pool de glutationa do citoplasma encontra-se no estado reduzido. Valores de potencial de óxidoredução do estado estacionário $(\mathrm{E})$ que variam de $\mathrm{E}_{\mathrm{GSH}}=-286 \mathrm{mV}$ a $\mathrm{E}_{\mathrm{GSH}}=-320 \mathrm{mV}$ foram reportados através do emprego de sondas redox, construídas a partir da fusão de proteínas do metabolismo redox com GFP (BRAUN et al., 2010; HU et al., 2008; KOJER et al., 2012; MORGAN et al., 2011; OSTERGAARD et al., 2004).

Kojer et al. (2012) demonstraram que o pool de glutationa do citoplasma e espaço intermembrana estão cineticamente conectados, apresentando valores de potencial de óxidoredução de $\mathrm{E}_{\mathrm{GSH}}=-306 \mathrm{mV}$ e $\mathrm{E}_{\mathrm{GSH}}=-301 \mathrm{mV}$, respectivamente. Segundo os autores, canais de porinas presentes na membrana mitocondrial externa asseguram o rápido equilíbrio do pool de glutationa entre os dois compartimentos.

A maioria da glutationa presente na matriz mitocondrial também se encontra na forma reduzida. No entanto, o pool de glutationa da matriz é regulado de maneira totalmente independente do citoplasma e espaço intermembrana (KOJER et al., 2012; KOJER; RIEMER, 2014; RIEMER et al., 2015). Kojer et al. (2012) reportaram um valor de potencial de óxidoredução de $\mathrm{E}_{\mathrm{GSH}}=-301 \mathrm{mV}$ para o pool da matriz mitocondrial.

\subsubsection{Sistema glutarredoxina mitocondrial}

As glutarredoxinas (GRXs) são proteínas que atuam na redução de dissulfetos proteicos ou dissulfetos mistos formados entre glutationa e proteína. A reação é dependente de resíduos de cisteínas altamente conservados presentes no interior do sítio ativo das GRXs (FERNANDES; HOLMGREN, 2004; HERRERO et al., 2008; HOLMGREN, 1989; TOLEDANO et al., 2007). A atividade oxido-redutase das GRXs é suportada pelo sistema glutationa (discutido acima).

Durante o ciclo catalítico, as GRXs reduzem as ligações dissulfetos utilizando elétrons de seus resíduos de cisteínas. A GRX oxidada é então reduzida pela GSH que por sua vez foi reduzida pelo NADPH em uma reação catalisada pela glutationa redutase Glr1 (DISCOLA et al., 2009; HERRERO et al., 2008; HOLMGREN, 1989) (Figura 11).

GRXs podem catalisar reações através de dois mecanismos. No mecanismo monotiólico, apenas um resíduo de cisteína no sítio ativo participa da catalise. Já no mecanismo ditiólico, dois resíduos de cisteínas do sítio ativo de Grx são necessários. Reações de redução de dissulfetos mistos entre glutationa e proteínas se processam pelo mecanismo 
monotiólico de Grxs, enquanto reações de redução de ligações dissulfeto em proteínas se processam pelo mecanismo ditiólico (FERNANDES; HOLMGREN, 2004).

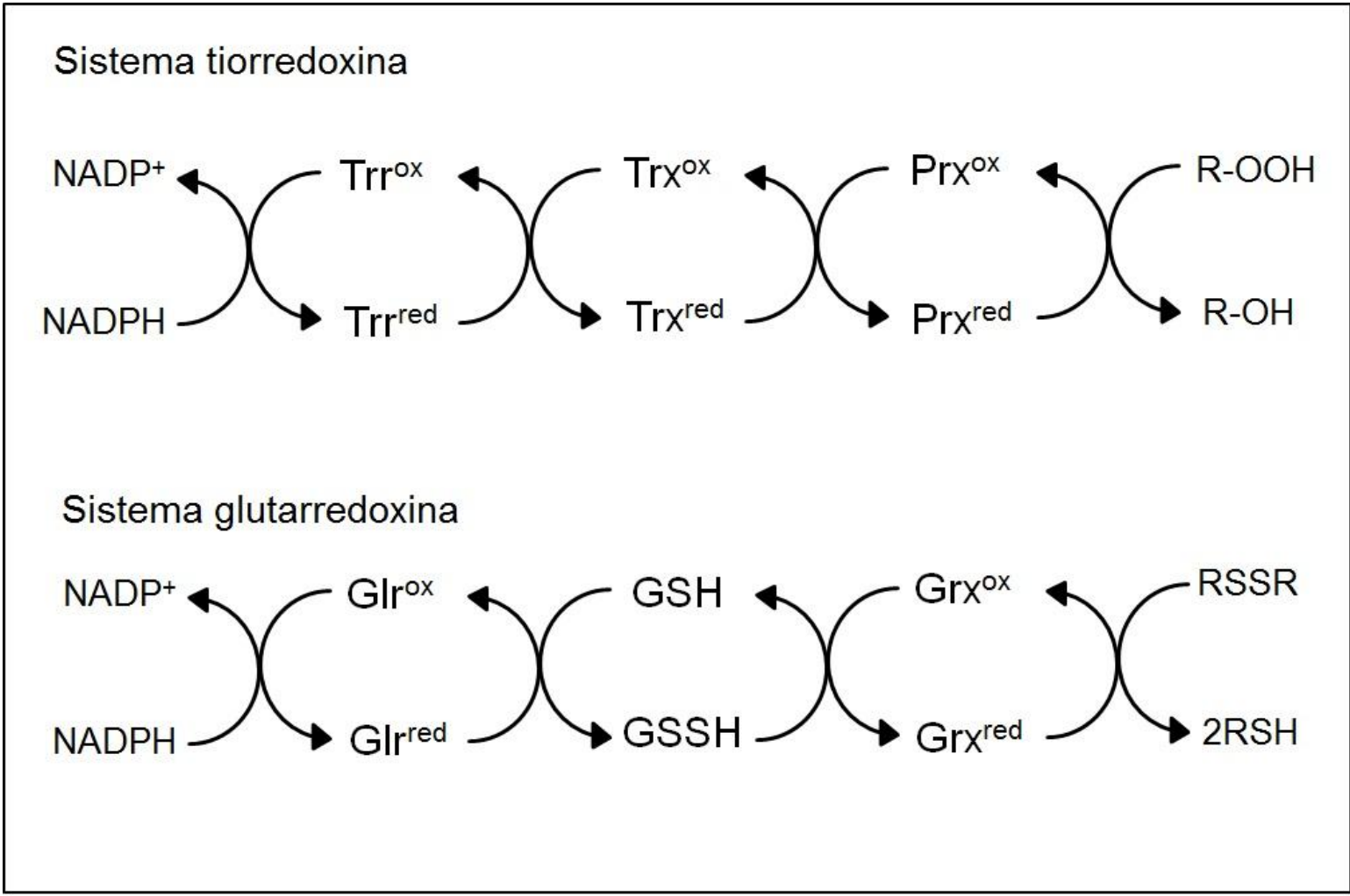

Figura 11. Representação esquemática dos sistemas tiorredoxina e glutarredoxina. Em ambos os sistemas, a fonte inicial do poder redutor é fornecido pela molécula de nicotinamida adenina dinucleotídeo fosfato (NADPH). As flavo-enzimas tiorredoxina redutase (Trr) e glutationa redutase (Glr) inicialmente reduzidas pelo NADPH catalisam a redução de tiorredoxina (Trx) e glutationa (GSH), respectivamente. Um dos principais substratos da tiorredoxina são as peroxirredoxinas. As Prxs reduzem uma ampla variedade de peróxidos incluindo o $\mathrm{H}_{2} \mathrm{O}_{2}$. Por outro lado, as glutarredoxinas são reduzidas pela glutationa, pois possuem sítios de ligação para esta molécula. As Grxs são capazes de reduzir ligações dissulfetos em proteínas RSSR e também dissulfetos mistos formados entre glutationa e proteínas. FONTE: Adaptado de Herrero et al. (2008).

Saccharomyces cerevisae possui cinco GRXs amplamente caracterizadas. As Grx1 e Grx2 atuam pelo mecanismo ditiólico e estão localizadas no citoplasma (FERNANDES; HOLMGREN, 2004). Apesar de Grx1 e Grx2 compartilharem 64\% de identidade na sequencia de aminoácidos, a atividade específica de Grx2 é 15 vezes maior do que a de Grx1 (DISCOLA et al., 2009). Semelhante ao que ocorre com Glr1, Grx2 apresenta dupla localização entre o citoplasma e a mitocôndria (PORRAS et al., 2006). Ambas as isoformas são produzidas a partir do único gene $G R X 2$. A isoforma mitocondrial é gerada através de um códon de tradução alternativo que permite a síntese de uma sequencia de endereçamento 
mitocondrial (PORRAS et al., 2006; PORRAS et al., 2010). Na mitocôndria, Grx2 possui dupla localização. Uma parte é encontrada na matriz mitocondrial de forma solúvel e a outra na porção externa da membrana mitocondrial externa (PORRAS et al., 2006).

Recentemente, Kojer et al. (2015) demonstraram que a isoforma citosólica de Grx2 desprovida da sequência de endereçamento mitocondrial também está presente em pequenas quantidades no espaço intermembrana. Os autores demonstraram que Grx2 desempenha um importante papel na formação das ligações dissulfeto das proteínas substratos da via de importação acoplada a processo oxidativo (discutido no item 1.2.3).

Grx3 e Grx4 são enzimas monotiólicas localizadas no núcleo (MOLINA et al., 2004). Ambas atuam na regulação da localização nuclear do fator de transcrição Aft1, responsável pela ativação de genes envolvidos no metabolismo do ferro (OJEDA et al., 2006; PUJOLCARRIÓN et al., 2006).

Grx5 é uma enzima monotiólica localizada na matriz mitocondrial que possui um papel central nos estágios finais da biogênese dos grupos ferro-enxofre (MÜHLENHOFF et al., 2003; RODRÍGUEZ-MANZANEQUE, et al., 2002). A ausência desta enzima desencadeia um acumulo de ferro na mitocôndria e uma diminuição nas atividades de enzimas que contém grupamentos ferro-enxofre (RODRÍGUEZ-MANZANEQUE et al., 2002).

\subsubsection{Sistema tiorredoxina mitocondrial}

As tiorredoxinas (Trxs) são tiól-dissulfeto oxido-redutases de baixo peso molecular $(12-13 \mathrm{kDa})$ que reduzem ligações dissulfetos em proteínas como enzimas e fatores de transcrição. De forma semelhante às GRXs, a atividade oxido-redutase das TRXs é baseada em resíduos de cisteínas altamente conservados presentes no sítio ativo das enzimas (HERRERO et al., 2008; HOLMGREN, 1989; RIETSCH; BECKWITH, 1998; TOLEDANO et al., 2007). Diferentemente das Grx, as Trxs não apresentam sítios de ligação a GSH (NETTO et al., 2016).

Algumas enzimas foram descritas como substratos das TRXs, incluindo a ribonucleotídeo redutase (RNR) (necessária para a síntese de dNTP, componentes do DNA), a 3'-fosfoadenosina 5'fosfosulfato redutase (PAPS, necessária para a assimilação de enxofre), as tiorredoxinas peroxidases ou peroxirredoxinas (discutidas posteriormente) e fatores de transcrição como NF-kB (CAMIER et al., 2007; KOC et al., 2006; MULLER, 1991; QIN te al., 1995). 
Durante o ciclo catalítico, as Trxs reduzem ligações dissulfeto de proteínas alvo, utilizando elétrons de seus resíduos de cisteínas. A Trx oxidada é então reduzida por uma flavo-enzima conhecida como tiorredoxina redutase (Trr). Esta possui uma função semelhante à glutationa redutase, no qual sua atividade é suportada por elétrons fornecidos pelo NADPH. Porém, ao contrário de Glr que reduz a glutationa, Trr catalisa a redução de Trx (Figura 11).

Saccharomyces cerevisiae possui duas Trxs (Trx1 e Trx2) e uma Trr (Trr1) citosólicas (GAN, 1991). Nosso grupo estudou o sistema tiorredoxina citosólico e mostrou que Trr1 é muito especifica para a redução de Trxs de levedura em relação à Trxs humanas e bacterianas (Oliveira et al., 2010). Em adição, a levedura S. cerevisiae possui um sistema tiorredoxina mitocondrial completo, composto pela tiorredoxina Trx3 e pela tiorredoxina redutase Trr2 (PEDRAJAS et al., 1999). O sistema Trx mitocondrial parece atuar preferencialmente na proteção contra o estresse oxidativo gerado em decorrência da produção de EROs mitocondriais já que, até o momento, o único alvo identificado é a Prx1, uma Prx mitocondrial que é alvo do presente estudo. No entanto, Trr2 parece apresentar uma função antioxidante independente de Trx3, uma vez que o mutante nulo $\triangle T T R 2$ é extremamente sensível ao estresse oxidativo quando comparado com o mutante $\triangle T R X 3$ que não apresenta nenhuma sensibilidade (PEDRAJAS et al., 2000; TROTTER; GRANT, 2005).

Um estudo do proteoma do espaço intermembrana da mitocôndria de levedura demonstrou que as enzimas Trr1 e Trx1 também se localizam nesse compartimento, além de estarem presentes no citosol. No entanto, não foi demonstrado o mecanismo molecular de importação nem o papel que essas proteínas desempenham no equilíbrio redox da mitocôndria (VÖGTLE et al., 2012).

\subsubsection{Peroxidases mitocondriais}

As peroxidases compreendem um diverso grupo de enzimas capazes de reduzir peróxidos orgânicos e inorgânicos utilizando-se de resíduos de cisteína reativos ("Cys-based peroxidases") ou grupos heme ("heme-based peroxidases").

No espaço intermembrana da mitocôndria da levedura existe uma peroxidase com atividade baseada em grupo heme que catalisa a redução do $\mathrm{H}_{2} \mathrm{O}_{2}$, conhecida como citocromo $c$ peroxidase (Ccp1). Ccp1 é reduzida por elétrons derivados do ferro presente na molécula de citocromo $c$, um dos componentes da cadeia respiratória mitocondrial. Recentemente, Ccp1 foi demonstrada ser um componente essencial para o crescimento de uma linhagem que não possui 8 peroxidases ( 48 strain - deleção das 5 peroxiredoxinas e 3 gluationa peroxidases, 
descritas posteriormente) (KAYA et al., 2015). Linhagens $\Delta 8$ apresentaram aneuploidia do cromossomo XI e a consequente superexpressão do gene $C C P 1$, presente neste cromossomo, parece ser um fator compensatório importante. A superexpressão de Ccp1 aliviou o estresse oxidativo causado pela deficiência das 8 peroxidases, suportando o crescimento da linhagem 48. Esses resultados também sugerem um papel central da mitocôndria na manutenção da homeostase redox celular.

No caso das peroxidases com atividade baseada em resíduos de cisteína, o substrato redutor é em geral um tiól como GSH ou Trx. Com base no substrato redutor, essas peroxidases são divididas em duas famílias: glutationa peroxidases, que utilizam principalmente a glutationa, e tiorredoxina peroxidases (também conhecidas como peroxirredoxinas) que utilizam principalmente Trx como redutores (FLOHÉ et al., 2011; HERRERO et al., 2008).

As enzimas glutationa peroxidases (GPXs) reduzem o $\mathrm{H}_{2} \mathrm{O}_{2}$ e outros hidroperóxidos orgânicos, tais como hidroperóxidos de ácidos graxos, utilizando o poder redutor fornecido pela molécula de glutationa (HERBETTE et al., 2007; MARGIS et al., 2008; MORANO et al., 2012). Existem duas principais classes de enzimas GPX: GPX clássicas e fosfolipídeo hidroperóxido GPX (PHGPX - phospholipid hydroperoxide GPXs).

As GPX clássicas são tetraméricas, solúveis e atuam na redução de hidroperóxidos orgânicos e inorgânicos. Por outro lado, as PHGPXs são geralmente monoméricas e encontram-se aderidas às membranas celulares. Além de hidroperóxidos solúveis, elas reduzem hidroperóxidos de lipídeos derivados da peroxidação lipídica (HERRERO et al., 2008; ROVERI et al., 1994).

As GPXs foram classicamente descritas em humanos, no qual o seu mecanismo catalítico envolve ciclos de oxidação-redução do grupo tiol presente no sítio ativo (FLOHÉ et al., 1973). No entanto, para a maioria das GPXs humanas (Gpx1, Gpx2, Gpx3 e Gpx4) o grupo tiol é substituído por um aminoácido incomum, a selenocisteína. Após a redução do hidroperóxido, a selenocisteína oxidada é reduzida pela molécula de GSH (HERBETTE et al., 2007; VEAL et al., 2007).

Estudos iniciais indicaram que a levedura expressa três GPXs, denominadas Gpx1, Gpx2 e Gpx3 (INOUE et al., 1999). Posteriormente, foi demonstrado que as três enzimas são da classe PHGPXs, apresentando atividades contra hidroperóxidos solúveis e lipídicos (AVERY; AVERY, 2001). Nenhuma das três PHGPXs tem selenocisteína e a atividade peroxidásica está baseada em resíduos de Cys. Curiosamente, ao contrário das GPXs humanas que são reduzidas por glutationa, as enzimas de levedura são preferencialmente reduzidas por 
tiorredoxina (DELAUNAY et al., 2002; MORANO et al., 2012; OHDATE et al., 2010; TANAKA et al., 2005).

Com relação à localização sub-celular, as três enzimas GPXs estão presentes no citoplasma aparentemente atuando na proteção contra a peroxidação lipídica e resistência contra metais pesados (AVERY; AVERY, 2001; AVERY et al., 2004; BASU et al., 2004; INOUE et al., 1999). Gpx3 também possui um importante papel atuando como um sensor e transdutor da resposta ao estresse oxidativo mediada pelo fator de transcrição Yap1 (D’AUTRÉAUX; TOLEDANO, 2007; DELAUNAY et al., 2002).

Ukai et al. (2011) demonstraram que Gpx2 apresenta dupla localização, sendo encontrada no citoplasma e na mitocôndria. Na mitocôndria a enzima encontra-se associada com a membrana externa (com face voltada para o citoplasma) e interna (com face voltada para a matriz).

De maneira semelhante, Vögtle et al. (2012) demonstraram através de um estudo proteômico que Gpx3 também se localiza no espaço intermembrana. No entanto, o papel dessa peroxidase nesse compartimento ainda não foi avaliado.

Outro grupo de peroxidases com atividade baseada em cisteína, as peroxirredoxinas (Prxs), catalisam a redução de diversas moléculas de peróxido, incluindo $\mathrm{H}_{2} \mathrm{O}_{2}$, peroxinitrito $\left(\mathrm{OONO}^{-}\right)$e hidroperóxidos orgânicos (ROOH) (NELSON et al., 2011). As Prxs são enzimas muito abundantes e possuem elevada eficiência catalítica apresentando constantes de velocidade de segunda ordem que variam entre $10^{6}$ a $10^{8} \mathrm{M}^{-1} \mathrm{~s}^{-1}$ (OGUSUCU et al., 2007; PARSONAGE et al., 2005; PESKIN et al., 2007; TOLEDO et al., 2011; TRUJILLO et al., 2007). Além da abrangência de substratos, as Prxs estão presentes em diversos compartimentos celulares como mitocôndria, núcleo, retículo endoplasmático e citosol (PARK et al., 2000; RHEE et al., 2012). Tais propriedades indicam que as Prxs desempenham um importante papel na proteção das células contra os danos oxidativos gerados pelas EROs (SENA; CHANDEL, 2012).

Todas as peroxirredoxinas conhecidas possuem um resíduo de cisteína altamente conservado presente no sítio ativo da enzima. Este resíduo, denominado cisteína peroxidásica $\left(\mathrm{C}_{\mathrm{P}}\right)$, reage diretamente com o substrato peróxido durante a catálise enzimática (CHAE et al., 1994a; CHOI et al., 1998; FLOHÉ et al., 2011; HALL et al., 2011; KIM et al., 1988; NELSON et al., 2011; RHEE; WOO, 2011).

No início do ciclo catalítico o resíduo de cisteína peroxidásica $\left(\mathrm{C}_{\mathrm{P}}\right)$ encontra-se na forma desprotonada $\left(\mathrm{RS}^{-}\right)$, denominado tiolato. A catálise inicia-se com o ataque nucleofílico do tiolato da $\mathrm{C}_{\mathrm{P}}$ à molécula de peróxido liberando o álcool correspondente (água no caso do 
$\left.\mathrm{H}_{2} \mathrm{O}_{2}\right)$, enquanto que a $\mathrm{C}_{\mathrm{P}}$ torna-se oxidada para a forma de ácido sulfênico $\left(\mathrm{C}_{\mathrm{P}}-\mathrm{SOH}\right)$ (FLOHÉ et al., 2011; HALL et al., 2011) (Figura 12).

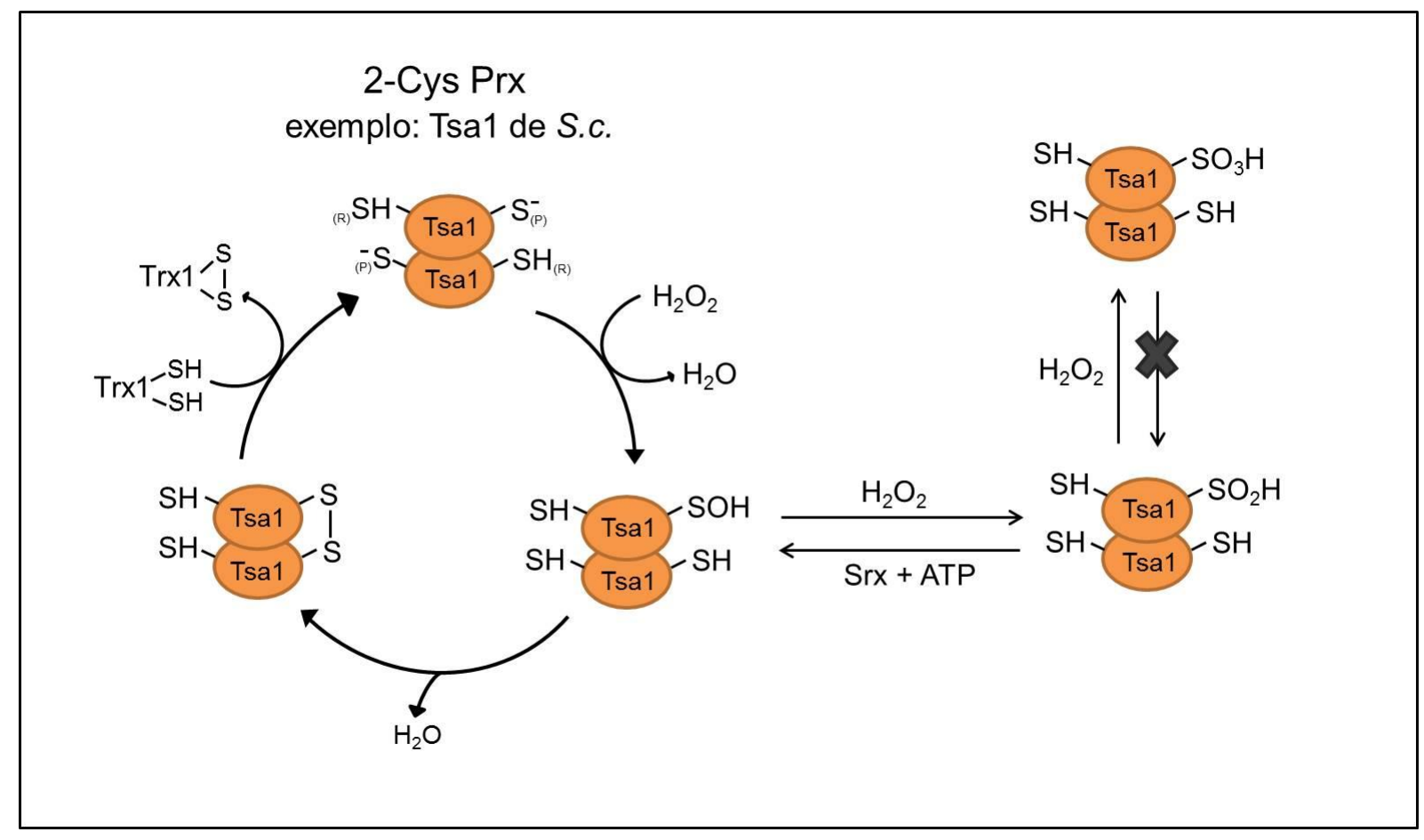

Figura 12. Representação esquemática do ciclo catalítico da peroxirredoxina Tsa1, um representante do grupo das 2-Cys-Prxs. A unidade catalítica da enzima é um homodímero organizado de forma anti-paralela. Cada monômero possui dois resíduos de cisteínas altamente conservados, denominados cisteína peroxidásica $S_{(\mathrm{P})}$ e cisteína de resolução $S_{(\mathrm{R})}$. No início do ciclo catalítico, a forma desprotonada do resíduo de cisteína peroxidásica $\mathrm{S}_{(\mathrm{P})}^{-}$de um dos monômeros reduz o $\mathrm{H}_{2} \mathrm{O}_{2}$ liberando uma molécula de água. Durante a reação, $\mathrm{S}^{-}$é oxidada para forma de ácido sulfênico (Cys-SOH). $\mathrm{O}$ resíduo de cisteína de resolução $\mathrm{S}_{(\mathrm{R})}$ do segundo monômero reage com o ácido sulfênico gerando uma ligação dissulfeto inter molecular entre os dois resíduos de cisteínas. A ligação dissulfeto é posteriormente reduzida pela proteína tiorredoxina 1 (Trx1). O ácido sulfênico também pode reagir com uma segunda molécula de peróxido originando o ácido sulfínico $\left(\mathrm{SO}_{2} \mathrm{H}\right)$. Esta representa a forma superoxidada da enzima. O ácido sulfínico pode ser reduzido pela proteína sulferredoxina (Srx) em uma reação dependente de ATP ou ainda reagir com outra molécula de peróxido originando o acido sulfônico e assim, inativando completamente a enzima. FONTE: Adaptado de D'Autréaux e Toledano (2007).

O ácido sulfênico gerado é posteriormente reduzido e o mecanismo pelo qual isso ocorre diferencia as Prxs em dois grupos (NETTO et al., 2007; WOOD et al., 2003a, WOOD et al., 2003b). No grupo das 2-Cys-Prxs um segundo resíduo de cisteína presente na própria molécula de Prx, denominado cisteína de resolução $\left(C_{R}\right)$, reage com o ácido sulfênico da $C_{P}$ liberando uma molécula de água e originando uma ligação dissulfeto entre os dois resíduos de cisteínas (CHAE et al., 1994a; CHAE et al., 1994b; HALL et al., 2011; NETTO et al., 2007) (Figura 12). Já no grupo das 1-Cys-Prx uma segunda proteína ou até mesmo uma molécula de 
baixo peso molecular é quem reage com o ácido sulfênico da $\mathrm{C}_{\mathrm{P}}$. Isto é decorrente do fato das 1-Cys-Prx não possuírem a cisteína de resolução (NETTO et al., 2007) (Figura 13).

Para o grupo das 2-Cys-Prxs, o dissulfeto formado entre os resíduos de $C_{P}$ e $C_{R}$ é posteriormente reduzido na maior parte dos casos por Trx. Fazendo isto, a Trx torna-se oxidada enquanto a Prx é reciclada para sua forma reduzida, podendo assim iniciar um novo ciclo catalítico (CHAE et al., 1994a) (Figura 12). O mecanismo de redução das 2-Cys-Prxs catalisado pela proteína Trx tem sido amplamente caracterizado (HALL et al., 2011; NETTO et al., 2007). Por outro lado, há grande discussão em relação ao mecanismo de redução das 1 Cys-Prx. A análise da literatura revela uma ampla variedade de mecanismos (ver texto a seguir para o caso de Prx1 de levedura).

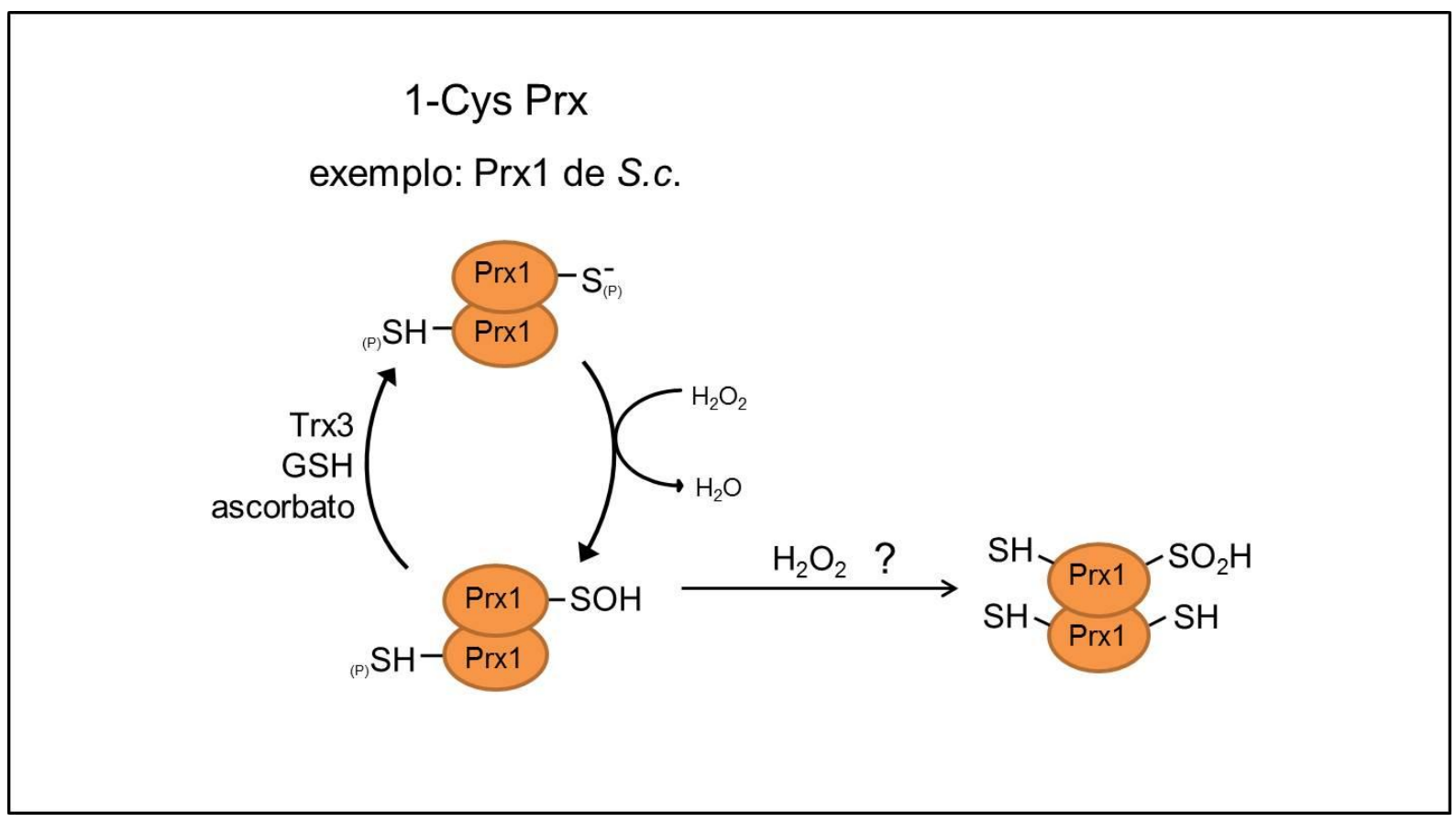

Figura 13. Representação esquemática do ciclo catalítico da peroxirredoxina Prx1, um representante do grupo das 1-Cys-Prxs. Assim como Tsa1, a unidade catalítica básica da enzima é um homodímero organizado de forma anti-paralela. As enzimas do grupo 1-Cys-Prxs não possuem o resíduo de cisteína de resolução. Desta forma, o ácido sulfênico gerado após a reação da $\mathrm{S}^{-}$ (P) com o peróxido precisa ser diretamente reduzido através de um composto contendo um grupo tiol. Há grande discussão na literatura com relação à natureza do composto que reduz Prx1 de levedura (ver texto). Além de Trx3 e GSH que são compostos tiólicos, o ascorbato que não apresenta um grupo tiol têm sido apontados como possíveis redutores de Prx1. Em principio, Prx1 também poderia sofrer reação de superoxidação, porém os mecanismos moleculares envolvidos nesse processo permanecem desconhecidos. FONTE: Adaptado de Wood et al. (2003b). 


\subsection{Prx1 de Saccharomyces cerevisiae}

A levedura Saccharomyces cerevisiae possui cinco peroxirredoxinas (Tsa1, Tsa2, Dot5, Ahp1 e Prx1) localizadas em diferentes compartimentos celulares (HERRERO et al., 2008; PARK et al., 2000; TOLEDANO et al., 2013). As enzimas Tsa1, Tsa2 e Ahp1 são citoplasmáticas e Dot5 é nuclear.

Prx1, alvo de estudo do presente trabalho, se localiza na mitocôndria e parece desempenhar importante papel na redução do $\mathrm{H}_{2} \mathrm{O}_{2}$ gerado no interior dessa organela (PEDRAJAS et al., 2000). Dentre as cinco Prxs de levedura ela é a única do grupo das 1-CysPrxs e, conforme salientado acima, o mecanismo envolvido na redução do ácido sulfênico, e consequente regeneração da enzima, permanece pouco entendido.

Segue-se a descrição dos mecanismos que atuam na redução de Prx1, propostos no decorrer dos anos, apresentando contradições entre si. Inicialmente, foi demonstrado que o sistema Trx mitocondrial pode reduzir Prx1 (PEDRAJAS et al., 2000). Neste caso, o ácido sulfênico de Prx1 é reduzido diretamente pela proteína Trx3. Trx3 por sua vez é reduzida pela Trr2 ao qual foi inicialmente reduzida pelo NADPH (Figura 11).

Posteriormente, Greetham e Grant (2009) demonstraram que o ácido sulfênico de Prx1 pode também reagir com a glutationa (glutationilação), originando um dissulfeto misto Prx1 GSH. Após a etapa de gluationilação, o dissulfeto misto seria reduzido pela enzima Trr2 formando um intermediário misto Prx1-Trr2. O intermediário seria posteriormente reduzido por uma segunda molécula de glutationa, levando a regeneração da enzima. Portanto, nesse modelo, Trx3 não desempenha nenhum papel no mecanismo de redução de Prx1.

O modelo apresentado acima foi contestado por Pedrajas et al. (2010) que salientaram que Trr2 não possui um motivo de ligação a glutationa. Neste segundo trabalho, os autores confirmaram que o ácido sulfenico de Prx1 inicialmente reage com a gluationa. No entanto, posteriormente, o dissulfeto misto de Prx1-GSH seria reduzido pela isoforma mitocondrial de Grx2 e não por Trr2. Nesse novo modelo, Grx2 suportaria a atividade catalítica de Prx1 em um sistema contendo NADPH, GSH e Glr1 (PEDRAJAS et al., 2010).

O modelo de Pedrajas et al. (2010) não exclui a possibilidade de que o sistema Trr2 e Tx3 também atue na redução de Prx1. Os autores demonstraram que as proteínas Trr2 e Trx3 funcionam melhor em pH próximo de 7. Por outro lado, o sistema GSH e Grx2 possui uma maior atividade em $\mathrm{pH}$ próximo de 8. Nesse contexto, o sistema GSH e Grx2 poderia operar em condições respiratórias (no qual o pH da matriz mitocondrial estaria mais alcalino em 
decorrência da geração do potencial de membrana) enquanto o sistema Trx3 e Trr2 atuaria e condições fermentativas (PEDRAJAS et al., 2010).

Recentemente, Pedrajas et al. (2016) apresentaram novos mecanismos envolvidos na redução de Prx1, sem contextualizar com o modelo proposto anteriormente pelos próprios autores (PREDAJAS et al., 2010). Após Prx1 catalisar a redução do peróxido, o ácido sulfênico formado poderia ser reduzido de duas maneiras (Figura 14). Em uma delas, ele reagiria com a glutationa formando um dissulfeto misto Prx1-GSH, conforme anteriormente reportado (GREETHAM; GRANT, 2009; PEDRAJAS et al., 2010). A deglutationilação de Prx1 poderia ser então catalisada por Grx2 (PEDRAJAS et al., 2010) ou por Trx3 (PEDRAJAS et al., 2016). Os autores propõem que a etapa de deglutationilação de Prx1, catalisada por Trx3, ocorre através de um mecanismo ditiólico, com o envolvimento dos dois resíduos de cisteínas de Trx3.

O ácido sulfênico formado também poderia reagir com outra cisteína de Prx1 (Cys-91 catalítica), originando uma ligação dissulfeto intermolecular. Os autores propõem que a cisteína catalítica de um dos monômeros de um dímero de Prx1 forme uma ligação dissulfeto com outra cisteína catalítica de um monômero de um segundo dímero. As ligações dissulfetos poderiam ser formadas entre três dímeros de Prx1, originando uma estrutura hexamérica. Para os autores, as ligações dissulfetos seriam mais facilmente reduzidas por Trx3, do que o ácido sulfênico formado após a reação com o peróxido. Isto explicaria a atividade peroxidásica de Prx1 suportada pelo sistema Trr2 e Trx3 (PEDRAJAS et al., 2000), visto que o substrato preferível de Trx são ligações dissulfetos formadas nas Prxs. A formação das ligações dissulfetos poderia proteger a enzima de sofrer inativação através da superoxidação do ácido sulfênico para ácidos sulfínico e sulfônico (PEDRAJAS et al., 2016). Mais estudos são necessários para elucidar a catálise por Prx1 já que a Cp de 1-Cys Prx está bastante enterrada na cadeia polipeptídica (CHOI et al., 1998) e nunca foi reportada uma ligação dissulfeto desse tipo para essa classe de Prxs.

No decorrer dos trabalhos citados acima, Monteiro et al. (2007) propuseram que o composto não tiólico ascorbato (vitamina C) também é capaz de suportar a atividade peroxidásica de Prx1 in vitro. Este trabalho representou uma mudança de paradigma, demonstrando pela primeira vez a redução de uma peroxirredoxina através de um redutor não tiólico. Saccharomyces cerevisiae sintetiza um composto semelhante ao ascorbato denominado eritroascorbato. A hipótese de que esse composto atua na redução de Prx1 in vivo ainda não foi avaliada (MONTEIRO et al., 2007). Entre outros aspectos, é necessário avaliar 
os níveis de eritroascorbato em levedura em diferentes fases do ciclo de vida desse microorganismo.

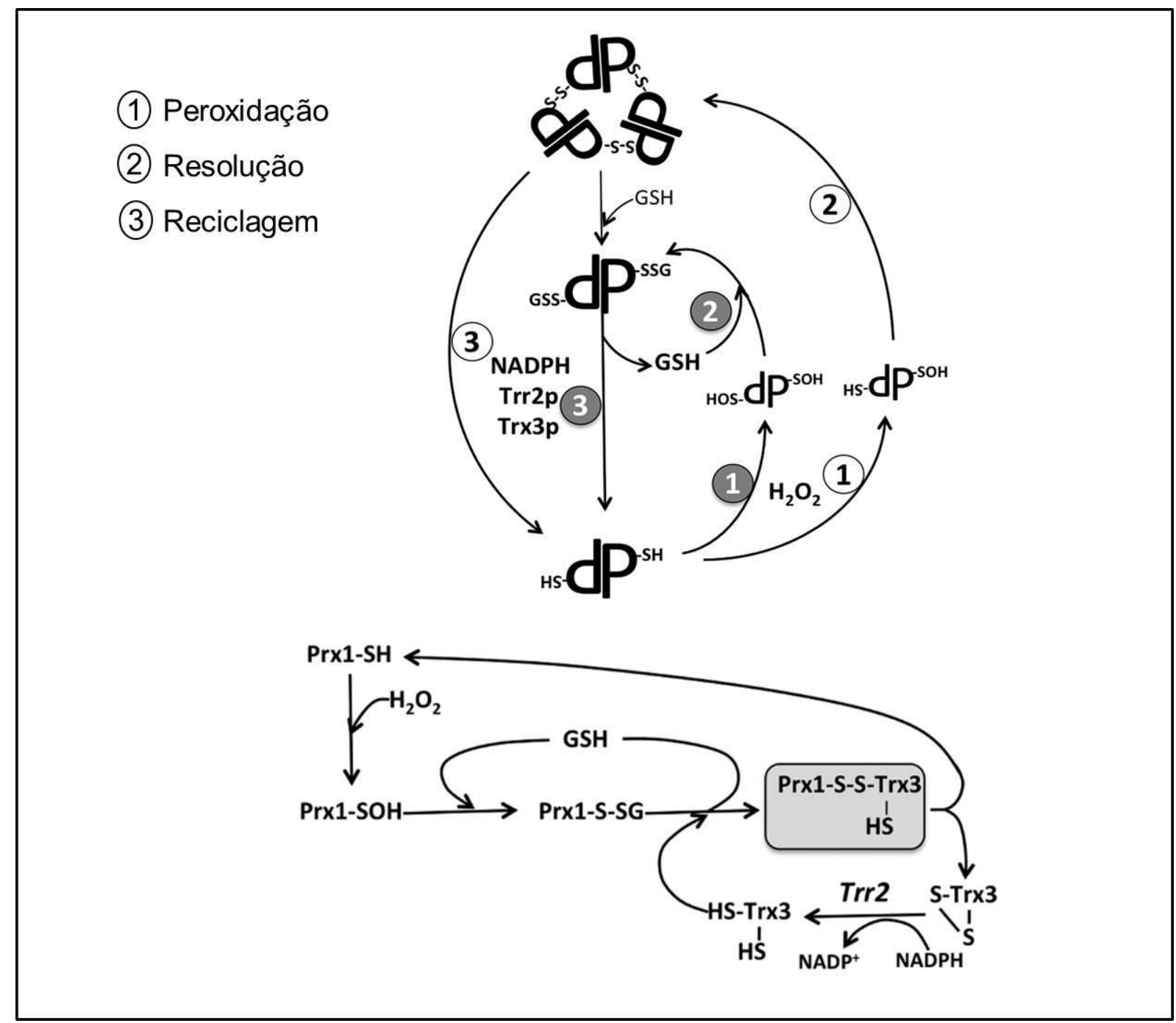

Figura 14. Ciclo catalítico de Prx1 deduzido a partir dos dados apresentados no trabalho de Pedrajas et al. (2016). Cada monômero de Prx1 é representado pela letra $\mathrm{P}$ grande com a cisteína catalítica destacada nos diferentes estados de oxidação: forma sulfidrila reduzida SH, ácido sulfênico - $\mathrm{SOH}$, ligação dissulfeto $\mathrm{S}-\mathrm{S}$ e glutationilada -SSG. Cada etapa do ciclo catalítico é indicada com um número envolto em um círculo. As etapas com círculos destacados em cinza representam reações mais favoráveis de acontecerem sob condições fisiológicas, com a glutationa desempenhando um papel catalítico ou protetor durante a etapa de resolução do ácido sulfênico. $\mathrm{O}$ sistema Trx desempenharia um papel proeminente na etapa de reciclagem da enzima para sua forma reduzida. A reciclagem de Prx1 glutationilada catalisada por Trx3 ocorre pelo mecanismo ditiólico. Nesse mecanismo, Trx3 reduzida forma um dissulfeto misto com Prx1 ao qual é posteriormente resolvido pelo segundo resíduo de cisteína de Trx3. Trx3 oxidada é então reduzida por Trr2 através de elétrons fornecidos pelo NADPH.

Dada à profusão de mecanismos catalíticos propostos, uma caracterização cinética rigorosa faz-se necessária, além das determinações das concentrações dos possíveis redutores para melhor compreender as relevâncias de cada um deles. 
Em relação ao padrão de expressão de Prx1, nosso grupo realizou uma caracterização detalhada sobre diferentes condições de crescimento (MONTEIRO et al., 2002, MONTEIRO et al., 2004). Na presença de uma fonte de carbono fermentável, tal como a glicose, a expressão de Prx1 é completamente inibida. O mecanismo pelo qual a glicose inibe a expressão de Prx1 é mediado pelos fatores de transcrição Msn2/Msn4, de uma maneira dependente das vias de sinalização compostas por RAS-cAMP-PKA e TOR quinase (MONTEIRO et al., 2002; MONTEIRO et al., 2004). Por outro lado, o crescimento sob uma fonte de carbono respiratória, como por exemplo, o etanol/glicerol, induz a expressão de Prx1. $\mathrm{O}$ mesmo ocorreu quando as células de levedura foram submetidas ao tratamento com $\mathrm{H}_{2} \mathrm{O}_{2}$, mesmo na presença de glicose como fonte de carbono (MONTEIRO et al., 2002; PEDRAJAS et al., 2000). Portanto, a indução por $\mathrm{H}_{2} \mathrm{O}_{2}$ sobrepõe-se a repressão por glicose. Estes resultados demonstram o envolvimento de Prx1 na proteção contra o estresse oxidativo, gerado através do metabolismo respiratório.

Conforme salientado acima, diversas proteínas envolvidas no metabolismo das EROs são direcionadas para os diferentes compartimentos da mitocôndria. No entanto, sabemos muito pouco sobre os mecanismos de importação dessas proteínas, bem como a regulação das suas atividades enzimáticas in vivo.

Especificamente, apesar dos estudos demonstrarem que Prx1, Trr2 e Trx3 são direcionadas para a mitocôndria (PEDRAJAS et al., 1999; PEDRAJAS et al., 2000), não existem informações sobre a localização dessas proteínas nos diferentes subcompartimentos mitocondriais. Para saber se, de fato, o sistema tiorredoxina mitocondrial está envolvido na redução de Prx1 in vivo é preciso determinar a localização e/ou o processamento dessas proteínas durante o processo de importação mitocondrial.

A localização celular de uma proteína fornece informações sobre o seu papel fisiológico in vivo. Há poucas informações sobre a função de Prx1 na manutenção da homeostase redox mitocondrial assim como na regulação de vias de sinalização redox. 


\section{CONCLUSÕES}

- A peroxirredoxina Prx1, assim como o sistema tiorredoxina mitocondrial composto pelas enzimas Trx3 e Trr2, se localizam no compartimento da matriz mitocondrial. Ambas as enzimas se associam fracamente com a membrana mitocondrial interna com face voltada para a matriz mitocondrial.

- Prx1 apresenta dupla localização estando presente também no espaço intermembrana mitocondrial possivelmente na forma solúvel.

- Durante a importação para a matriz mitocondrial, Prx1 é inicialmente clivada pela peptidase de processamento mitocondrial (MPP), ao qual remove a sequência de endereçamento mitocondrial ou pressequencia. Após este primeiro evento de clivagem, a protease octapeptidil aminopeptidase Oct1 remove oito aminoácidos adicionais (octapeptídeo) da região N-terminal de Prx1.

- A importação de Prx1 para o espaço intermembrana envolve a liberação da proteína precursora na bicamada lipídica da membrana interna devido à presença de uma região hidrofóbica localizada no interior do octapeptídeo clivado por Oct1. Em seguida, Prx1 é clivada pela subunidade Imp2 do complexo IMP liberando a proteína madura no espaço intermembrana mitocondrial.

- A clivagem de Prx1 por Oct1 não interfere na importação de Prx1 para o compartimento da matriz mitocondrial nem a atividade peroxidásica de Prx1 in vitro. Por outro lado, a clivagem aumenta a estabilidade de Prx1 no interior da mitocôndria.

- Apsear de Trr2 e Trx3 não serem clivadas por Oct1, houve uma diminuição significaiva na estabilidade dessas proteínas na ausência da protease. Os mecanismos envolvidos nessa instabilidade permanecem desconhecidos.

- A clivagem de peroxirredoxinas por Oct1 parece ser um mecanismo conservado, visto que Oct1 de S. cerevisiae é capaz de clivar a peroxirredoxina mitocondrial humana Prx3 in vivo. No entanto, a clivagem de Prx3 humana por Oct1 de levedura não interfere na estabilidade de Prx3. 
- As enzimas Prx1 e Trr2 desempenham um papel proeminente na proteção das células de $S$. cerevisiae contra o estresse oxidativo exógeno. A linhagem mutante $\triangle P R X 1$ libera quantidades significativamente maiores de $\mathrm{H}_{2} \mathrm{O}_{2}$ mitocondrial comparado à linhagem selvagem WT, indicando que Prx1 é responsável pela redução de quantidades significativas de $\mathrm{H}_{2} \mathrm{O}_{2}$ gerado no interior da mitocôndria. 


\section{REFERÊNCIAS BIBLIOGRÁFICAS}

ABE, Y.; SHODAI, T.; MUTO, T.; MIHARA, K.; TORII, H.; NISHIKAWA, S.; ENDO, T.; KOHDA, D. Structural basis of presequence recognition by the mitochondrial protein import receptor Tom20. Cell., v. 100, p. 551-560, 2000.

ADAM-VIZI, V.; CHINOPOULOS, C. Bioenergetics and the formation of mitochondrial reactive oxygen species. Trends Pharmacol Sci., v. 27, p. 639-645, 2006.

AGUIRRE, J.; LAMBETH, J. D. Nox enzymes from fungus to fly to fish and what they tell us about Nox function in mammals. Free Radic. Biol. Med., v. 49, p. 1342-1353, 2010.

ALIKHANI, N.; BERGLUND, A. K.; ENGMANN, T.; SPÅNNING, E.; VÖGTLE, F. N.; PAVLOV, P.; MEISINGER, C.; LANGER, T.; GLASER, E. Targeting capacity and conservation of PreP homologues localization in mitochondria of different species. J. Mol. Biol., v. 410, p. 400-410, 2011.

ANDERSSON, S.G.; KURLAND, C.G.; Reductive evolution of resident genomes. Trends Microbiol., v. 6, p. 263-268, 1998.

AVERY, A. M.; AVERY, S. V. Saccharomyces cerevisiae expresses three phospholipid hydroperoxide glutathione peroxidases. J. Biol Chem., v. 276, p. 33730-33735, 2001.

AVERY, A. M.; WILlETTS, S. A.; AVERY, S. V. Genetic dissection of the phospholipid hydroperoxidase activity of yeast gpx3 reveals its functional importance. J. Biol Chem., v. 279, p. 46652-46658, 2004.

BACHMAIR, A.; FINLEY, D.; VARSHAVSKY, A. In vivo half-life of a protein is a function of its amino-terminal residue. Science, v. 234, p. 179-186, 1986.

BACHMAIR, A.; VARSHAVSKY, A. The degradation signal in a short-lived protein. Cell., v. 56, p. 1019-1032, 1989.

BAE, Y. S.; KANG, S. W.; SEO, M. S.; BAINES, I. C.; TEKLE, E.; CHOCK, P. B.; RHEE, S. G. Epidermal growth factor (EGF)-induced generation of hydrogen peroxide. Role in EGF receptormediated tyrosine phosphorylation. J. Biol.Chem., v. 272, p. 217-221, 1997.

BAKER, R. T.; VARSHAVSKY, A. Yeast N-terminal amidase. A new enzyme and component of the N-end rule pathway. J. Biol. Chem., v. 270, p. 12065-12074, 1995.

BAKKER, B. M.; OVERKAMP, K. M.; VAN MARIS, A. J. A.; KÖTTER, P.; LUTTICK, M. A. H.; VAN DIJKEN, J. P.; PRONK, J. T. Stoichiometry and compartmentation of NADH metabolism in Saccharomyces cerevisiae. FEMS Microb. Rev., v. 25, p.15-37, 2001.

BALABAN, R. S.; NEMOTO, S.; FINKEL, T. Mitochondria, oxidants, and aging. Cell, v. 120, 483495, 2005.

BALZI, E.; CHODER, M.; CHEN, W. N.; VARSHAVSKY, A.; GOFFEAU, A. Cloning and functional analysis of the arginyl-tRNA-protein transferase gene ATE1 of Saccharomyces cerevisiae. J. Biol. Chem., v. 265, p. 7464-7471, 1990.

BANCI, L.; BERTINI, I.; CEFARO, C.; CENACCHI, L.; CIOFI-BAFFONI, S.; FELLI, I. C.; GALLO, A.; GONNELLI, L.; LUCHINAT, E.; SIDERIS, D.; TOKATLIDIS, K. Molecular chaperone function of Mia40 triggers consecutive induced folding steps of the substrate in mitochondrial protein import. Proc. Natl. Acad. Sci. U S A., v. 107, p. 20190-20195, 2010. 
BARTEL, B.; WUNNING, I.; VARSHAVSKY, A. The recognition component of the $\mathrm{N}$-end rule pathway. EMBO J., v. 9, p. 3179-3189, 1990.

BASU, U.; SOUTHRON, J. L.; STEPHENS, J. L.; TAYLOR, G. J. Reverse genetic analysis of the glutathione metabolic pathway suggests a novel role of PHGPX and URE2 genes in aluminum resistance in Saccharomyces cerevisiae. Mol. Genet. Genomics., v. 271, p. 627-637, 2004.

BAUER, M.; BEHRENS, M.; ESSER, K.; MICHAELIS, G.; PRATJE, E. PET1402, a nuclear gene required for proteolytic processing of cytochrome oxidase subunit 2 in yeast. Mol. Gen. Genet., v. 245, p. 272-278, 1994.

BECKER, T.; BÖTTINGER, L.; PFANNER, N. Mitochondrial protein import: from transport pathways to an integrated network. Trends Biochem. Sci., v. 37, p. 85-91. 2012.

BECKMANN, J. D.; LJUNGDAHL, P. O.; TRUMPOWER, B. L. Mutational analysis of the mitochondrial Rieske iron-sulfur protein of Saccharomyces cerevisiae. I. Construction of a RIP1 deletion strain and isolation of temperature-sensitive mutants. J. Biol. Chem., v. 264, p. 3713-3722, 1989.

BELL, E. L.; KLIMOVA, T. A.; EISENBART, J.; MORAES, C. T.; MURPHY, M. P.; BUDINGER, G. R. S.; CHANDEL, N. S. The $\mathrm{Q}_{0}$ site of the mitochondrial complex III is required for the transduction of hypoxic signal-ing via reactive oxygen species production. J. Cell Biol., v. 177, p. 1029-1036, 2007.

BIEN, M.; LONGEN, S.; WAGENER, N.; CHWALLA, I.; HERRMANN, J. M.; RIEMER, J. Mitochondrial Disulfide Bond Formation Is Driven by Intersubunit Electron Transfer in Erv1 and Proofread by Glutathione. Mol. Cell., v. 37, p. 516-528, 2010.

BIHLMAIER, K.; MESECKE, N.; TERZIYSKA, N.; BIEN, M.; HELL, K.; HERRMANN, J. M. The disulfide relay system of mitochondria is connected to the respiratory chain. J. Cell Biol., v. 179, p. 389-395, 2007.

BLEIER, L.; WITTIG, I.; HEIDE, H.; STEGER, M.; BRANDT, U.; DROSE, S. Generator-specific targets of mitochondrial reactive oxygen species. Free Radic. Biol. Med., v. 78, p. 1-10, 2015.

BOHNERT, M.; PFANNER, N.; van der LAAN M. Mitochondrial machineries for insertion of membrane proteins. Curr. Opin. Struct. Biol., v. 33, p. 92-102, 2015.

BOLDOGH, I. R.; PON, L. A. Purification and subfractionation of mitochondrial from yeast Saccharomyces cerevisiae. Methods in Cell Biol., v. 80, p. 45-64, 2007.

BOLENDER, N.; SICKMANN, A.; WAGNER, R.; MEISINGER, C.; PFANNER N. Multiple pathways for sorting mitochondrial precursor proteins. EMBO Rep., v. 9, p 42-49, 2008.

BRADFORD, M. M. A rapid and sensitive method for the quantitation of microgram quantities of protein utilizing the principle of protein-dye binding. Anal Biochem., v. 72, p. 248-254, 1976.

BRAGOSZEWSKI, P.; WASILEWSKI, M.; SAKOWSKA, P.; GORNICKA, A.; BÖTTINGER, L.; QIU, J.; WIEDEMANN, N.; CHACINSKA, A. Retro-translocation of mitochondrial intermembrane space proteins. Proc. Natl. Acad. Sci. U S A., v. 112, p. 7713-7718, 2015.

BRAND, M. D. The sites and topology of mitochondrial superoxide production. Exp. Gerontol., v. 45, p. 466-472, 2010. 
BRANDA, S. S.; ISAYA, G. Prediction and identification of new natural substrates of the yeast mitochondrial intermediate peptidase. J. Biol. Chem., v. 270, p. 27366-27373, 1995.

BRANDA, S. S.; YANG, Z. Y.; CHEW, A.; ISAYA, G. Mitochondrial intermediate peptidase and the yeast frataxin homolog together maintain mitochondrial iron homeostasis in Saccharomyces cerevisiae. Hum. Mol. Genetics., v. 8, p. 1099-1110, 1999.

BRAUN, N. A.; MORGAN, B.; DICK, T. P.; SCHWAPPACH, B. The yeast CLC protein counteracts vesicular acidification during iron starvation. J. Cell. Sci., v., 123, p. 2342-2350, 2010.

BYRD, C.; TURNER, G. C.; VARSHAVSKY, A. The N-end rule pathway controls the import of peptides through degradation of a transcriptional repressor. EMBO J., v. 17, p. 269-277, 1998.

CAMIER, S.; MA, E.; LEROY C.; PRUVOST, A.; TOLEDANO, M.; MARSOLIER-KERGOAT, M. C. Visualization of ribonucleotide reductase catalytic oxidation establishes thioredoxins as its major reductants in yeast. Free Radic. Biol. Med., v. 42, p. 1008-1016, 2007.

CAMPUZANO, V.; MONTERMINI, L.; MOLTÒ, M. D.; PIANESE, L.; COSSÈE, M.; CAVALCANTI, F.; MONROS, E.; RODIUS, F.; DUCLOS, F.; MONTICELLI, A.; ZARA, F.; CAÑIZARES, J.; KOUTNIKOVA, H.; BIDICHANDANI, S. I.; GELLERA, C.; BRICE, A.; TROUILlAS, P.; MICHELE, G. D.; FILlA, A.; FRUTOS, R. D.; PALAU, F.; PATEL, P. I.; DONATO, S. D.; MANDEL, J.-L.; COCOZZA, S.; KOENIG, M.; PANDOLFO. M. Friedreich's ataxia: autosomal recessive disease caused by an intronic GAA triplet repeat expansion. Science, v. 271, p.1423-1427, 1996.

CARMEL-HAREL, O.; STORZ, G. Roles of the glutathione- and thioredoxin-dependent reduction systems in the Escherichia coli and Saccharomyces cerevisiae responses to oxidative stress. Annu. Rev. Microbiol., v. 54, p. 439-461, 2000.

CHACINSKA, A.; PFANNSCHMIDT, S.; WIEDEMANN, N.; KOZJAK, V.; SANJUÁN SZKLARZ, L .K.; SCHULZE-SPECKING, A.; TRUSCOTT, K. N.; GUIARD, B.; MEISINGER, C.; PFANNER, N. Essential role of Mia40 in import and assembly of mitochondrial intermembrane space proteins. EMBO J., v. 23, p. 3735-46, 2004.

CHACINSKA, A.; LIND, M.; FRAZIER, A. E.; DUDEK, J.; MEISINGER, C.; GEISSLER, A.; SICK-MANN, A.; MEYER, H. E.; TRUSCOTT, K. N.; GUIARD, B.; PFANNER, N.; REHLING, P. Mitochondrial pre-sequence translocase: switching between TOM tethering and motor recruitment involves Tim21 and Tim17. Cell., v. 120, p. 817-829, 2005.

CHACINSKA, A.; KOEHLER, C. M.; MILENKOVIC, D.; LITHGOW, T.; PFANNER, N. Importing mitochondrial proteins: machineries and mechanisms. Cell., v. 138, p. 628-644, 2009.

CHAE, H. Z.; CHUNG, S. J.; RHEE, S. G. Thioredoxin-dependent peroxide reductase from yeast. J. Biol. Chem., v. 269, p. 27670-27678, 1994a.

CHAE, H. Z.; UHM. T. B.; RHEE, S. G. Dimerization of thiol-specific antioxidant and the essential role of cysteine 47. Proc. Natl. Acad. Sci. U. S. A., v. 91, p. 7022-7026, 1994 b.

CHANDEL, N. S.; MALTEPE, E.; GOLDWASSER, E.; MATHIEU, C. E.; SIMON, M. C.; SCHUMACKER, P. T. Mitochondrial reactive oxygen species trigger hypoxia-induced transcription. Proc. Natl Acad. Sci. USA., v. 95, p. 11715-11720, 1998.

CHANDEL, N. S.; McCLINTOCK, D. S.; FELICIANO, C. E.; WOOD, T. M.; MELENDEZ, J. A.; RODRIGUEZ, A. M.; SCHUMACKER, P. T. Reactive oxygen species generated at mitochondrial 
complex III stabilize hypoxia-inducible factor-1 $\alpha$ during hypoxia. A mechanism of $\mathrm{O}_{2}$ sensing. $\mathbf{J}$. Biol. Chem., v. 275, 25130-25138, 2000.

CHANDEL, N. S. Mitochondria as signaling organelles. BMC Biol., v. 12, p. 34-40, 2014.

CHANDEL, N. S. Evolution of mitochondria as signaling organelles. Cell Metab., v. 22, p. 204-206, 2015.

CHAUWIN, J. F.; OSTER, G.; GLICK, B. S. Strong precursor-pore interactions constrain models for mitochondrial protein import. Biophys J., v. 74, p. 1732-1743, 1998.

CHEW, A.; ROLLINS, R. A.; SAKATI, W. R.; ISAYA, G. Mutations in a putative zinc binding domain inactivate the mitochondrial intermediate peptidase. Biochem. Biophys. Res. Commun., v. 226, p. 822-829, 1996.

CHOI, H. J.; KANG, S. W.; YANG, C. H.; RHEE, S. G.; RYU, S. E. Crystal structure of a novel human peroxidase enzyme at 2.0 A resolution. Nat. Struct. Biol., v. 5, p. 400-406, 1998.

CLAROS, M. G.; VINCENS, P. Computational method to predict mitochondrially imported proteins and their targeting sequences. Eur. J. Biochem., v. 241, p. 779-786, 1996.

COPPOCK, D. L.; THORPE, C. Multidomain flavin-dependent sulfhydryl oxidases. Antiox. Redox Signal., v. 8, p. 300-311, 2005.

COX, A. G.; WINTERBOURN, C. C.; HAMPTON, M. B. Mitochondrial peroxiredoxin involvement in antioxidant defence and redox signalling. Biochem J. v. 425, p. 313-325, 2010.

CULOTTA, V. C.; YANG, M.; O'HALLORAN, T. V. Activation of superoxide dismutases: putting the metal to the pedal. Biochim. Biophys. Acta., v. 1763, p. 747-758, 2006.

D'AUTRÉAUX, B.; TOLEDANO, M. B. ROS as signalling molecules: mechanisms that generate specificity in ROS homeostasis. Nat. Rev. Mol. Cell. Biol., v. 8, p. 813-824, 2007.

DElAunAY, A.; PFLIEGER, D.; BARRAUlT, M. B.; VINH, J.; TOLEDANO, M. B. A thiol peroxidase is an $\mathrm{H} 2 \mathrm{O} 2$ receptor and redox-transducer in gene activation. Cell., v. 111, p. 471-481, 2002.

DEPONTE, M. Glutathione catalysis and the reaction mechanisms of glutathione-dependent enzymes. Biochim. Biophys. Acta., v. 1830, p. 3217-3266, 2013.

de WINDE, J. H.; GRIVELL, L. A. Global regulation of mitochondrial biogenesis in Saccharomyces cerevisiae. Progres. Nucleic Acid Res. Mol. Biol., v. 46, p. 51-9, 1993.

DIENHART, M. K.; STUART, R. A. The yeast Aac2 protein exists in physical association with the cytochrome $b c 1-$ COX supercomplex and the TIM23 machinery. Mol. Biol. Cell., v. 19, p. 39343943, 2008.

DISCOLA, K. F.; de OLIVEIRA, M. A.; ROSA, CUSSIOL, J. R.; MONTEIRO, G.; BÁRCENA, J. A.; PORRAS, P.; PADILLA, C. A.; GUIMARÃES, B. G; NETTO, L. E. Structural aspects of the distinct biochemical properties of glutaredoxin 1 and glutaredoxin 2 from Saccharomyces cerevisiae. J. Mol. Biol., v. 385, p. 889-901, 2009.

DOHMEN, R. J.; MADURA, K.; BARTEL, B.; VARSHAVSKY, A. The N-end rule is mediated by the UBC2 (RAD6) ubiquitin-conjugating enzyme. Proc. Natl. Acad. Sci. USA., v. 88, p. 7351-7355, 1991. 
DOLEZAL, P.; LIKIC, V.; TACHEZY, J.; LITHGOW, T. Evolution of the molecular machines for protein import into mitochondria. Science, v. 313, p. 314-318, 2006.

DOUGAN, D. A.; MICEVSKI, D.; TRUSCOTT, K. N. The N-end rule pathway: from recognition by N-recognins, to destruction by AAA+proteases. Biochim. Biophys. Acta., v. 1823, p. 83-91, 2012.

DOWHAN, W.; BIBUS, C. R.; SCHATZ, G. The cytoplasmically-made subunit IV is necessary for assembly of cytochrome c oxidase in yeast. EMBO J., v. 4, p. 179-184, 1985.

DRÖSE, S.; BRANDT, U.; WITTIG, I. Mitochondrial respiratory chain complexes as sources and targets of thiol-based redox-regulation. Biochim. Biophys. Acta., v. 1844, p. 1344-1354, 2014.

DU, F.; NAVARRO-GARCIA, F.; XIA, Z.; TASAKI, T.; VARSHAVSKY, A. Pairs of dipeptides synergistically activate the binding of substrate by ubiquitin ligase through dissociation of its autoinhibitory domain. Proc. Natl Acad. Sci. USA., v. 99, p. 14110-14115, 2002.

DUDEK, J.; REHLING, P.; van der LAAN, M. Mitochondrial protein import: common principles and physiological networks. Biochim. Biophys. Acta., v. 1833, p. 274-285, 2013.

EMANUELSSON, O.; BRUNAK, S.; VON HEIJNE, G.; NIELSEN, H. Locating proteins in the cell using TargetP, SignalP and related tools. Nat. Protocols., v. 2, p. 953-971, 2007.

EMERLING, B. M.; WEINBERG, F.; SNYDER, C.; BURGESS, Z.; MUTLU, G. M.; VIOLLET, B.; BUDINGER, G. R.; CHANDEL, N. S. Hypoxic activation of AMPK is dependent on mitochondrial ROS but independent of an increase in AMP/ATP ratio. Free Radic. Biol. Med, v. 46, p. 1386-1391, 2009.

ENDO, T.; YAMANO, K.; KAWANO, S. Structural insight into the mitochondrial protein import system. Biochim. Biophys. Acta., v. 1808, p. 955-970, 2011.

ESSER, K.; JAN, P. S.; PRATJE, E.; MICHAELIS, G. The mitochondrial IMP peptidase of yeast: functional analysis of domains and identification of Gut2 as a new natural substrate. Mol. Genet. Genomics., v. 271, p. 616-626, 2004.

FANG, J.; BEATTIE, D.S. External alternative NADH dehydrogenase of Saccharomyces cerevisiae: a potential source of superoxide. Free Radic. Biol. Med., v. 34, p. 478-488, 2003.

FASS, D. The Erv family of sulfhydryl oxidases. Biochim. Biophys. Acta., v. 1783, p. 557-566, 2008.

FERNANDES, A. P.; HOLMGREN, A. Glutaredoxins: glutathione-dependent redox enzymes with functions far beyond a simple thioredoxin backup system. Antioxid. Redox Signal., v. 6, p. 63-74, 2004.

FIGUEIRA, T. R.; BARROS, M. H.; CAMARGO, A. A.; CASTILHO, R. F.; FERREIRA, J. C.; KOWALTOWSKI, A. J.; SLUSE, F. E.; SOUZA-PINTO, N. C.; VERCESI, A. E. Mitochondria as a source of reactive oxygen and nitrogen species: from molecular mechanisms to human health. Antioxid. Redox Signal., v. 18, p. 2029-2074, 2013.

FISCHER, F.; HAMANN, A.; OSIEWACZ, H. D. Mitochondrial quality control: an integrated network of pathways. Trends Biochem Sci., v. 37, p. 284-292, 2012.

FISCHER, M.; RIEMER, J. The mitochondrial disulfide relay system: roles in oxidative protein folding and beyond. Int. J.Cell Biol., v. 2013, p. 742923, 2013. 
FLOHÉ, L.; GÜNZLER, W. A.; SCHOCK, H. H. Glutathione peroxidase: a selenoenzyme. FEBS Lett., v. 32, p. 132-134, 1973.

FLOHÉ, L.; TOPPO, S.; COZZA, G.; URSINI, F. A comparison of thiol peroxidase mechanisms. Antioxid. Redox Signal., v. 15, p. 763-780, 2011.

FORMAN, H. J.; AUGUSTO, O.; BRIGELIUS-FLOHE, R.; DENNERY, P. A.; KALYANARAMAN, B.; ISCHIROPOULOS, H.; MANN, G. E.; RADI, R.; ROBERTS, L. J 2nd, VINA, J.; DAVIES, K. J. Even free radicals should follow some rules: a guide to free radical research terminology and methodology. Free Radic. Biol. Med., v. 78, p. 233-235, 2015.

FOURY, F.; ROGANTI, T.; LECRENIER, N.; PURNELLE, B. The complete sequence of the mitochondrial genome of Saccharomyces cerevisiae. FEBS Lett., v. 440, p. 325-331, 1998.

FREY, T. G.; MANNELLA, C. A. The internal structure of mitochondria. Trends Biochem. Sci., v. 25, p. 319-324, 2000.

FRIDOVICH, I. Superoxide dismutases. An adaptation to a paramagnetic gas. J. Biol. Chem., v. 264, p. 7761-7764, 1989.

FRIDOVICH, I. Superoxide radical and superoxide dismutases. Annu. Rev. Biochem., v.64, p. 97$112,1995$.

GAKH, O.; CAVADINI, P.; ISAYA, G. Mitochondrial processing peptidases. Biochim. Biophys. Acta., v. 1592, p. 63-77, 2002.

GAN, Z. R. Yeast thioredoxin genes. J. Biol. Chem., v. 266, p. 1692-1696, 1991.

GASSER, S. M.; OHASHI, A.; DAUM, G.; BOHNI, P. C.; GIBSON, J.; REID, G. A.; YONETANI, T.; SCHATZ, G. Imported mitochondrial proteins cytochrome b2 and cytochrome c1 are processed in two steps. Proc. Natl. Acad. Sci. U.S.A., v. 79, p. 267-271, 1982.

GAVEL, Y.; von HEIJNE, G. Cleavage-site motifs in mitochondrial targeting peptides. Protein Eng., v. 4, p. 33-37, 1990.

GEISSLER, A.; CHACINSKA, A.; TRUSCOTT, K. N.; WIEDEMANN, N.; BRANDNER, K.; SICKMANN, A.; MEYER, H. E.; MEISINGER, C.; PFANNER, N.; REHLING, P. The mitochondrial presequence translocase: an essential role of Tim50 in directing preproteins to the import channel. Cell., v. 111, p. 507-518, 2002.

GEVAERT, K.; GOETHALS, M.; MARTENS, L.; VAN DAMME, J.; STAES, A.; THOMAS, G. R.; VANDEKERCKHOVE, J. Exploring proteomes and analyzing protein processing by mass spectrometric identification of sorted N-terminal peptides. Nat. Biotechnol., v. 21, p. 566-569, 2003.

GLICK, B. S.; BRANDT, A.; CUNNINGHAM, K.; MÜLLER, S.; HALLBERG, R. L.; SCHATZ, G. Cytochromes $c_{1}$ and $b_{2}$ are sorted to the intermembrane space of yeast mitochondria by a stop-transfer mechanism. Cell., v. 69, p. 809-822, 1992.

GLICK, B. S. Pathways and energetics of mitochondrial protein import in Saccharomyces cerevisiae. Methods Enzymol, v. 260, p. 224-31, 1995.

GOFFEAU, A.; BARRELL, B. G.; BUSSEY, H.; DAVIS, R. W.; DUJON, B.; FELDMANN, H.; GALIBERT, F.; HOHEISEL, J. D.; JACQ, C.; JOHNSTON, M.; LOUIS, E. J.; MEWES, H. W.; MURAKAMI, Y.; PHILIPPSEN, P.; TETTELIN, H.; OLIVER, S. G. Life with 6000 genes. Science, v. 274, p. 563-567, 1996. 
GOMES, F.; TAHARA, E. B.; BUSSO, C.; KOWALTOWSKI, A. J.; BARROS, M. H. nde1 deletion improves mitochondrial DNA maintenance in Saccharomyces cerevisiae coenzyme Q mutants. Biochem J., v. 449, p. 595-603, 2013.

GRAHAM, L. A.; BRANDT, U.; SARGENT, J. S.; TRUMPOWER, B. L.Mutational analysis of assembly and function of the iron-sulfur protein of the cytochrome bc1 complex in Saccharomyces cerevisiae. J. Bioenerg. Biomembr., v. 25, p. 245-257, 1993.

GRANT, C. M.; MACIVER, F. H.; DAWES, I. W. Glutathione is an essential metabolite required for resistance to oxidative stress in the yeast Saccharomyces cerevisiae. Curr. Genet., v. 29, p. 511-515, 1996.

GRANT, C.; MACIVER, F. H.; DAWES, I. W. Glutathione synthetase is dispensable for growth under both normal and oxidative stress conditions in the yeast Saccharomyces cerevisiae due to an accumulation of the dipeptide gamma-glutamylcysteine. Mol. Biol. Cell., v. 8, p. 1699-1707, 1997.

GRAY, M. W.; BURGER, G.; LANG, B. F. Mitochondrial evolution. Science, v. 283, p. 1476-1481, 1999.

GREETHAM, D.; GRANT, C. M. Antioxidant activity of the yeast mitochondrial one-Cys peroxiredoxin is dependent on thioredoxin reductase and glutathione in vivo. Moll. Cell. Biol., v. 29, p. 3229-3240, 2009.

GREETHAM, D.; KRITSILIGKOU, P.; WATKINS, R. H.; CARTER, X.; PARKIN, J.; GRANT, C. M. Oxidation of the yeast mitochondrial thioredoxin promotes cell death. Antioxid. Redox Signal., v. 18, p. 376-385, 2013.

GREGG, C.; KYRYAKOV, P.; TITORENKO, V. I. Purification of mitochondria from yeast cells. J. Vis. Exp., 2009.

GRIFFITH, O. W.; MEISTER, A. Origin and turnover of mitochondrial glutathione. Proc. Natl. Acad. Sci. USA., v. 82, p. 4668-4672, 1985.

GRUMBT, B.; STROOBANT, V.; TERZIYSKA, N.; ISRAEL, L.; HELL, K. Functional characterization of Mia40p, the central component of the disulfide relay system of the mitochondrial intermembrane space. J. Biol. Chem., v. 282, p. 37461-37470, 2007.

GUIDOT, D. M.; MCCORD, J. M.; WRIGHT, R. M.; REPINE, J. E. Absence of electron transport (Rho 0 state) restores growth of a manganese-superoxide dismutase-deficient Saccharomyces cerevisiae in hyperoxia. Evidence for electron transport as a major source of superoxide generation in vivo. J Biol Chem., v. 268, p. 26699-26703, 1993.

GUZY, R. D.; SCHUMACKER, P. T. Oxygen sensing by mitochondria at complex III: the paradox of increased reactive oxygen species during hypoxia. Exp. Physiol., v. 91, p. 807-819, 2006.

HABIB, S. J.; NEUPERT, W.; RAPAPORT, D. Analysis and prediction of mitochondrial targeting signals. Methods Cell Biol., v. 80, p. 761-781, 2007.

HALL, A.; NELSON, K.; POOLE, L. B.; KARPLUS, P. A. Structure-based insights into the catalytic power and conformational dexterity of peroxiredoxins. Antioxid. Redox Signal., v. 15, p.795-815, 2011.

HAMANAKA, R. B.; CHANDEL, N. S. Mitochondrial reactive oxygen species regulate cellular signaling and dictate biological outcomes. Trends Biochem Sci., v. 35, p. 505-513, 2010. 
HAMZA, I.; DAILEY, H. A. One ring to rule them all: trafficking of heme and heme synthesis intermediates in the metazoans. Biochim. Biophys. Acta, v. 1823, p. 1617-1632, 2012.

HARBAUER, A. B.; ZAHEDI, R. P.; SICKMANN, A; PFANNER, N.; MEISINGER, C. The protein import machinery of mitochondria-a regulatory hub in metabolism, stress, and disease. Cell Metab., v. 19, p. 357-372, 2014.

HARDING, A. E. Friedreich's ataxia: a clinical and genetic study of 90 families with an analysis of early diagnostic criteria and intrafamilial clustering of clinical features. Brain., v.104, 589-620, 1981.

HARTL, F. U.; OSTERMANN, J.; GUIARD, B.; NEUPERT, W. Successive translocation into and out of the mitochondrial matrix: targeting of proteins to the intermembrane space by a bipartite signal peptide. Cell., v. 51, p. 1027-1037, 1987.

HATEFI, H. The mitochondrial electron transport and oxidative phosphorylation system. Annu. Rev. Biochem., v. 54, p. 1015-1069, 1985.

HENDRICK, J. P.; HODGES, P. E.; ROSENBERG, L. E. Survey of amino-terminal proteolytic cleavage sites in mitochondrial precursor proteins: leader peptides cleaved by two matrix proteases share a three-amino acid motif. Proc. Natl. Acad. Sci. USA., v. 86, p. 4056-4060, 1989.

HERBETTE, S.; ROECKEL-DREVET, P.; DREVET, J. R. Seleno-independent glutathione peroxidases. More than simple antioxidant scavengers. FEBS J., v. 274, p. 2163-2180, 2007.

HERRERO, E.; ROS, J.; BELLÍ, G.; CABISCOL, E. Redox control and oxidative stress in yeast cells. Biochim. Biophys. Acta, v. 1780, p. 1217-1235, 2008.

HERRMANN, J. M.; RIEMER, J. Oxidation and reduction of cysteines in the intermembrane space of mitochondria: multiple facets of redox control. Antioxid. Redox Signal., v. 13, p. 1323-1326, 2010a.

HERRMANN, J. M.; RIEMER, J. The intermembrane space of mitochondria. Antioxid. Redox. Signal., v. 13, p. 1341-1358, 2010 b.

HERRMANN, J. M.; LONGEN, S.; WECKBECKER, D.; DEPUYDT, M. Biogenesis of Mitochondrial Proteins. In: KADENBACH, B. (Ed.). Mitochondrial oxidative phosphorylation: nuclear-encoded genes, enzyme regulation, and pathophysiology. New York: Springer, 2012. p. 41-64.

HERRMANN, J. M.; RIEMER, J. Mitochondrial disulfide relay: Redox-regulated protein import into the intermembrane space. J. Biol. Chem., v. 287, p. 4426-4433, 2012.

HERRMANN, J. M.; RIEMER, J. Three approaches to one problem: protein folding in the periplasm, the endoplasmic reticulum, and the intermembrane space. Antioxid. Redox Signal., v. 21, p. 438-56, 2014.

HOLMGREN, A. Thioredoxin and glutaredoxin systems. J. Biol. Chem., v. 264, p. 13963-13966, 1989.

HOLMSTRÖM, K. M.; FINKEL, T. Cellular mechanisms and physiological consequences of redoxdependent signalling. Nat. Rev. Mol. Cell. Biol., v. 15, p. 411-421, 2014.

HU, J.; DONG, L.; OUTTEN, C. E. The redox environment in the mitochondrial intermembrane space is maintained separately from the cytosol and matrix. J. Biol. Chem., v. 283, p. 29126-29134, 2008. 
HURT, E. C.; PESOLD-HURT, B.; SUDA, K.; OPPLIGER, W.; SCHATZ, G. The first twelve amino acids (less than half of the pre-sequence) of an imported mitochondrial protein can direct mouse cytosolic dihydrofolate reductase into the yeast mitochondrial matrix. EMBO J., v.4, p. 2061-2068, 1985.

INOUE, Y.; MATSUDA, T.; SUGIYAMA, K.; IZAWA, S.; KIMURA, A. Genetic analysis of glutathione peroxidase in oxidative stress response of Saccharomyces cerevisiae. J Biol Chem., v. 274, p. 27002-27009, 1999.

ISAYA, G.; MIKLOS, D.; ROLLINS, R. A. MIP1, a new yeast gene homologous to the rat mitochondrial intermediate peptidase gene, is required for oxidative metabolism in Saccharomyces cerevisiae. Mol Cell Biol., v. 14, p. 5603-5616, 1994.

ITOH, K.; NAKAMURA, K.; IIJIMA, M.; SESAKI, H. Mitochondrial dynamics in neurodegeneration. Trends Cell Biol., v. 23, p. 64-71, 2013.

JAMIESON, D J. Oxidative stress responses of the yeast Saccharomyces cerevisiae. Yeast., v. 14, p. 1511-1527, 1998.

JAN, P. S.; ESSER, K.; PRATJE, E.; MICHAELIS, G. Som1, a third component of the yeast mitochondrial inner membrane peptidase complex that contains Imp1 and Imp2. Mol Gen Genet., v. 263, p. 483-491, 2000.

JOHnStON, M.; RILES, L.; HEGEMANN, J. H. Gene disruption. Methods Enzymol., v. 350, p. 290-315, 2002.

KALOUSEK, F.; ISAYA, G.; ROSENBERG, L. E. Rat liver mitochondrial intermediate peptidase (MIP): purification and initial characterization. EMBO J., v. 11, p. 2803-2809, 1992.

KALOUSEK, F.; NEUPERT, W.; OMURA, T.; SCHATZ, G.; SCHMITZ, U. K. Uniform nomenclature for the mitochondrial peptidases cleaving precursors of mitochondrial proteins. Trends Biochem Sci., v. 18, p. 249, 1993.

KARNKOWSKA, A.; VACEK, V.; ZUBÁČOVÁ, Z.; TREITLI, S. C.; PETRŽELKOVÁ, R.; EME, L.; NOVÁK, L.; ŽÁRSKÝ, V.; BARLOW, L. D.; HERMAN, E. K.; SOUKAL, P.; HROUDOVÁ, M.; DOLEŽAL, P.; STAIRS, C. W.; ROGER, A. J.; ELIÁS̆, M.; DACKS, J. B.; VLČEK, Č.; HAMPL, V. A Eukaryote without a Mitochondrial Organelle. Curr Biol., v. 26, p. 1274-1284, 2016.

KAYA, A.; GERASHCHENKO, M. V.; SEIM, I.; LABARRE, J.; TOLEDANO, M. B; GLADYSHEV, V. N. Adaptive aneuploidy protects against thiol peroxidase deficiency by increasing respiration via key mitochondrial proteins. Proc. Natl. Acad. Sci. USA., v. 112, p. 10685-10690, 2015.

LARKIN, M. A.; BLACKSHIELDS, G.; BROWN, N. P.; CHENNA, R.; MCGETTIGAN, P. A.; MCWILLIAM, H.; VALENTIN, F.; WALLACE, I. M.; WILM, A.; LOPEZ, R.; THOMPSON, J. D.; GIBSON, T. J.; HIGGINS, D. G. Clustal W and Clustal X version 2.0. Bioinformatics., v.23, p.29472948, 2007.

KIM, K.; KIM, I. H.; LEE, KI-Y.; RHEE, S. G. STADTMAN, E. R. The isolation and purification of a specific "protector" protein which inhibits enzyme inactivation by a thiol/Fe(III)/O2 mixed-function oxidation system. J. Biol. Chem., v. 263, p. 4704-4711, 1988.

KOC, A.; MATHEWS, C. K.; WHEELER, L. J.; GROSS, M. K.; MERRILL, G. F. Thioredoxin is required for deoxyribonucleotide pool maintenance during S phase. J. Biol Chem., v. 281, p. 1505815063, 2006. 
KOEHLER, C. M.; TIENSON, H. L. Redox regulation of protein folding in the mitochondrial intermembrane space. Biochim. Biophys. Acta., v. 1793, p. 139-145, 2009.

KOJER, K.; BIEN, M.; GANGEL, H.; MORGAN, B.; DICK, T. P.; RIEMER, J. Glutathione redox potential in the mitochondrial intermembrane space is linked to the cytosol and impacts the Mia40 redox state. EMBO J., v. 31, p. 3169-3182, 2012.

KOJER, K.; RIEMER, J. Balancing oxidative protein folding: the influences of reducing pathways on disulfide bond formation. Biochim. Biophys. Acta., v. 1844, p. 1383-1390, 2014.

KOJER, K.; PELEH, V.; CALABRESE, G.; HERRMANN, J. M.; RIEMER, J. Kinetic control by limiting glutaredoxin amounts enables thiol oxidation in the reducing mitochondrial intermembrane space. Mol Biol Cell., v. 26, p. 195-204, 2015.

KOOPMAN, W. J.; NIJTMANS, L. G.; DIETEREN, C. E.; ROESTENBERG, P.; VALSECCHI, F.; SMEITINK J. A.;WILLEMS, P. H. Mammalian mitochondrial complex I: biogenesis, regulation and reactive oxygen species generation. Antiox. Redox Signal., v. 12, p. 1431-1470, 2010.

KOPPEN, M.; LANGER, T. Protein degradation within mitochondria: versatile activities of AAA proteases and other peptidases. Crit. Rev. Biochem. Mol. Biol., v. 42, p. 221-242, 2007.

KOWALTOWSKI, A. J.; SOUZA-PINTO, N. C.; CASTILHO, R. F.; VERCESI, A. E. Mitochondria and reactive oxygen species. Free Radic. Biol. Med., v. 47, p. 333-343, 2009.

KRAYL, M.; LIM, J. H.; MARTIN, F.; GUIARD, B.; VOOS, W. A cooperative action of the ATPdependent import motor complex and the inner membrane potential drives mitochondrial preprotein import. Mol. Cell. Biol., v. 27, p. 411-425, 2007.

KUMAR, C. IGBARIA, A.; D’AUTREAUX, B.; PLANSON, A. G.; JUNOT, C.; GODAT, E.; BACHHAWAT, A. K.; DELAUNAY-MOISAN, A.; TOLEDANO, M. B. Glutathione revisited: a vital function in iron metabolism and ancillary role in thiol-redox control. EMBO J., v. 30, p. 20442056, 2011.

LAEMMLI, D. K. Cleavage of structural proteins during in assembly of the head of bacteriophage T4. Nature, v. 227, p. 680-683, 1970.

LARSSON, N. G. Somatic mitochondrial DNA mutations in mammalian aging. Annu. Rev. Biochem., v. 79, p. 683-706, 2010.

LENAZ, G.; GENOVA, M. L. Structure and organization of mitochondrial respiratory complexes: a new understanding of an old subject. Antioxid. Redox Signal., v. 12, p. 961-1008, 2010.

LILL, R.; HOFFMANN, B.; MOLIK, S.; PIERIK, A. J.; RIETZSCHEL, N.; STEHLING, O.; UZARSKA, M. A.; WEBERT, H.; WILBRECHT, C.; MÜHLENHOFF, U. The role of mitochondria in cellular iron-sulfur protein biogenesis and iron metabolism. Biochim. Biophys. Acta., v. 1823, p. 1491-1508, 2012.

LIU, Q.; D'SILVA, P.; WALTER, W.; MARSZALEK, J.; CRAIG, E. A. Regulated cycling of mitochondrial Hsp70 at the protein import channel. Science, v. 300, p. 139-141, 2003.

LUO, W.; FANG, H.; GREEN, N. Substrate specificity of inner membrane peptidase in yeast mitochondria. Mol Genet Genomics., v. 275, p. 431-436, 2006. 
LUTTIK, M. A. H.; OVERKAMP, K. M.; KÖTTER, P.; DE VRIES, S.; VAN DIJKEN, J. P.; PRONK, J. T. The Saccharomyces cerevisiae NDE1 and NDE2 genes encode separate mitochondrial NADH dehydrogenases catalyzing the oxidation of cytosolic NADH. J. Biol.Chem., v. 273, p. 24529-24534, 1998.

MANNELLA, C. A.; MARKO, M.; PENCZEK, P.; BARNARD, D.; FRANK, J. The internal compartmentation of rat-liver mitochondria: tomographic study using the high-voltage transmission electron microscope. Microsc. Res. Tech., v. 27, p. 278-283,1994.

MANNELLA, C. A.; MARKO, M.; BUTTLE, K. Reconsidering mitochondrial structure: new views of an old organelle. Trends Biochem. Sci., v. 22, p. 37-38, 1997.

MARCONDES, M. F.; TORQUATO, J. S. R.; ASSIS, D. M.; JULIANO, M. A.; HAYASHI, M. A. F.; OLIVEIRA, V. Mitochondrial intermediate peptidase: Expression in Escherichia coli and improvement of its enzymatic activity detection with FRET substrates. Biochem. Biophys. Res. Commun., v. 391, p. 123-128, 2010.

MARGIS, R.; DUNAND, C.; TEIXEIRA, F. K.; MARGIS-PINHEIRO, M. Glutathione peroxidase family - an evolutionary overview. FEBS J., v. 275, p. 3959-3970, 2008.

MARÍ, M.; MORALES, A.; COLELL, A.; GARCÍA-RUIZ, C.; KAPLOWITZ, N.; FERNÁNDEZCHECA, J. C. Mitochondrial glutathione: features, regulation and role in disease. Biochim. Biophys. Acta., v. 1830, p. 3317-3328, 2013.

MARRES, C. A. M.; DE VRIES, S.; GRIVEL, L. A. Isolation and inactivation of the nuclear gene encoding the rotenone-insensitive internal NADH: ubiquinone oxidoreductase of mitochondria from Saccharomyces cerevisiae. Eur. J. Biochem., v. 195, p. 857-862, 1991.

MARTIN, L. J. Mitochondrial and cell death mechanisms in neurodegenerative diseases. Pharmaceuticals (Basel)., v. 3, p. 839-915, 2010.

MARTINEZ-CABALLERO, S.; GRIGORIEV, S. M.; HERRMANN, J. M.; CAMPO, M. L.; KINNALLY, K. W. Tim17p regulates the twin pore structure and voltage gating of the mitochondrial protein import com-plex TIM23. J. Biol. Chem., v. 282, p. 3584-3593, 2007.

MEIER, S.; NEUPERT, W.; HERRMANN, J. M. Conserved N-terminal negative charges in the Tim17 subunit of the TIM23 translocase play a critical role in the import of preproteins into mitochondria. J. Biol. Chem., v. 280, p. 7777-7785, 2005.

MEINECKE, M.; WAGNER, R.; KOVERMANN, P.; GUIARD, B.; MICK, D. U.; HUTU, D. P.; VOOS, W.; TRUSCOTT, K. N.; CHACINSKA, A.; PFANNER, N.; REHLING, P. Tim50 maintains the permeability barrier of the mitochondrial inner membrane. Science, v. 312, p. 1523-1526, 2006.

MEISINGER, C.; SOMMER, T.; PFANNER, N. Purification of Saccharomcyes cerevisiae mitochondria devoid of microsomal and cytosolic contaminations. Anal. Biochem., v. 287, p. 339$342,2000$.

MEISINGER, C.; PFANNER, N.; TRUSCOTT, K. N. Isolation of yeast mitochondria. Methods Mol Biol., v. 13, p. 33-39, 2006.

MEISINGER, C.; SICKMANN, A.; PFANNER, N. The mitochondrial proteome: from inventory to function. Cell., v. 134, p. 22-24, 2009.

MEISTER, A.; ANDERSON, M. E. Glutathione. Annu. Rev. Biochem., v. 52, p. 711-760, 1983. 
MENG, T. C.; FUKADA, T.; TONKS, N. K. Reversible oxidation and inactivation of protein tyrosine phosphatases in vivo. Mol. Cell., v. 9, p. 387-399, 2002.

MESECKE, N.; TERZIYSKA, N.; KOZANY, C.; BAUMANN, F.; NEUPERT, W.; HELL, K.; HERRMANN, J. M. A disulfide relay system in the intermembrane space of mitochondria that mediates protein import. Cell, v. 121, p. 1059-1069, 2005.

MESECKE, N.; BIHLMAIER, K; GRUMBT, B.; LONGEN, S.; TERZIYSKA, N.; HELL, K.; HERRMANN, J. M. The zinc-binding protein Hot13 promotes oxidation of the mitochondrial import receptor Mia40. EMBO REP., v. 9, p. 1107-13, 2008.

MILENKOVIC, D.; GABRIEL, K.; GUIARD, B.; SCHULZE-SPECKING, A.; PFANNER, N.; CHACINSKA, A.. Biogenesis of the essential Tim9-Tim10 chaperone complex of mitochondria: Sitespecific recognition of cysteine residues by the intermembrane space receptor Mia40. J. Biol. Chem., v. 282, p. 22472-22480, 2007.

MISHRA, P; CHAN, D. C. Mitochondrial dynamics and inheritance during cell division, development and disease. Nat. Rev. Mol. Cell Biol., v. 15, p. 634-646, 2014.

MOKRANJAC, D.; SICHTING, M.; POPOV-CELEKETIC, D.; MAPA, K.; GEVORKYANAIRAPE-TOV, L.; ZOHARY, K.; HELL, K.; AZEM, A.; NEUPERT, W. Role of Tim50 in the transfer of precursor proteins from the outer to inner membrane of mitochondria. Mol. Biol. Cell., v. 20, p. 1400-1407, 2009.

MOLINA, M. M.; BELLÍ, G.; de la TORRE, M. A.; RODRÍGUEZ-MANZANEQUE MT, HERRERO, E. Nuclear monothiol glutaredoxins of Saccharomyces cerevisiae can function as mitochondrial glutaredoxins. J. Biol. Chem., 279, p. 51923-51930, 2004.

MONTEIRO, G.; PEREIRA, G. A. G.; NETTO, L. E. S. Regulation of mitochondrial thioredoxin peroxidase I expression by two different pathways: one dependent on cAMP and the other on heme. Free Radic. Biol. Med., v. 32, p. 278-88, 2002.

MONTEIRO, G,; NETTO, L. E. S. Glucose repression of PRX1 expression is mediated by Tor1p and Ras2p through inhibition of Msn2/4p in Saccharomyces cerevisiae. FEMS Microbiol. Lett., v. 241, p. 221-8, 2004.

MONTEIRO, G.; HORTA, B. B.; PIMENTA, D. C.; AUGUSTO, O. NETTO, L E. Reduction of 1 Cys peroxiredoxins by ascorbate changes the thiol-specific antioxidant paradigm, revealing another function of vitamin C. Proc. Natl. Acad. Sci. USA., v. 104, p. 4886-4891, 2007.

MORANO, K. A.; GRANT, C. M.; MOYE-ROWLEY, W. S. The response to heat shock and oxidative stress in Saccharomyces cerevisiae. Genetics., v. 190, p. 1157-1195, 2012.

MORGAN, B.; SOBOTTA, M. C.; DICK, T. P. Measuring E(GSH) and H(2)O(2) with roGFP2-based redox probes. Free Radic. Biol. Med., v. 51, 1943-1951, 2011.

MOSSMANN, D.; MEISINGER, C.; NORA VÖGTLE, N. Processing of mitochondrial presequences. Biochim. Biophys. Acta., v. 1819, p. 1098-1106, 2012.

MÜHLENHOFF, U.; GERBER, J.; RICHHARDT, N.; LILL, R. Components involved in assembly and dislocation of iron-sulfur clusters on the scaffold protein Isu1p. EMBO J. v. 22, p. 4815-4825, 2003.

MULLER, E. G. Thioredoxin deficiency in yeast prolongs $S$ phase and shortens the G1 interval of the cell cycle. J Biol Chem., v. 266, p. 9194-9202, 1991. 
MURPHY, M. P. How mitochondria produce reactive oxygen species. Biochem. J., v. 417, p. 1-13, 2009.

MURPHY, M. P.; HOLMGREN, A.; LARSSON, N. G.; HALlIWELL, B.; CHANG, C. J.; KALYANARAMAN, B.; RHEE, S. G.; THORNALLEY, P. J.; PARTRIDGE, L.; GEMS, D.; NYSTROM, T.; BELOUSOV, V.; SCHUMACKER, P. T.; WINTERBOURN, C. C. Unraveling the biological roles of reactive oxygen species. Cell Metab., v. 13, p. 361-366, 2011.

MURPHY, M. P. Mitochondrial thiols in antioxidant protection and redox signaling: distinct roles for glutathionylation and other thiol modifications. Antioxid. Redox Signal., v. 16, p. 476-495, 2012.

NAAMATI, A.; REGEV-RUDZKI, N.; GALPERIN, S.; LILL, R.; PINES, O. Dual targeting of Nfs1 and discovery of its novel processing enzyme, Icp55, J. Biol. Chem., v. 284, p. 30200-30208, 2009.

NELSON, K. J.; KNUTSON, S. T.; SOITO, L.; KLOMSIRI, C.; POOLE, L. B.; FETROW, J. S. Analysis of the peroxiredoxin family: using active site structure and sequence information for global classification and residue analysis. Proteins., v. 79, p. 947-964, 2011.

NETT, J. H.; DENKE, E.; TRUMPOWER, B. L. Two-step processing is not essential for the import and assembly of functionally active iron-sulfur protein into the cytochrome bc1 complex in Saccharomyces cerevisiae. J. Biol. Chem., v. 272, p. 2212-2217, 1997.

NETT, J. H.; TRUMPOWER, B. L. Intermediate length Rieske iron-sulfur protein is present and functionally active in the cytochrome bc1 complex of Saccharomyces cerevisiae. J. Biol Chem., v. 274, p. 9253-9257, 1999.

NETTO, L. E.; DE OLIVEIRA, M. A.; MONTEIRO, G.; DEMASI, A. P.; CUSSIOL, J. R.; DISCOLA, K. F.; DEMASI, M.; SILVA, G. M.; ALVES, S. V.; FARIA, V. G.; HORTA, B. B. Reactive cysteine in proteins: protein folding, antioxidant defense, redox signaling and more. Comp. Biochem. Physiol. C. Toxicol. Pharmacol., v. 146, p. 180-193, 2007.

NETTO, L. E.; ANTUNES, F. The roles of peroxiredoxin and thioredoxin in hydrogen peroxide sensing and in signal transduction. Mol Cells., v.1, p. 65-71, 2016.

NETTO, L. E.; de OLIVEIRA, M. A.; TAIRUM, C. A.; da SILVA NETO, J. F. Conferring specificity in redox pathways by enzymatic thiol/disulfide exchange reactions. Free Radic.

Res., v. 50, 206-245, 2016.

NEUPERT, W.; HERRMANN, J. M. Translocation of proteins into mitochondria. Annu. Rev. Biochem., v. 76, p. 723-749, 2007.

NUNNARI, J.; FOX, T. D.; WALTER, P. A mitochondrial protease with two catalytic subunits of nonoverlapping specificities. Science, v. 262, p. 1997-2004, 1993.

NUNNARI, J.; SUOMALAINEN, A. Mitochondria: in sickness and in health. Cell. v. 148, p. 11451159, 2012.

OGUSUCU, R.; RETTORI, D.; MUNHOZ, D. C.; NETTO, L. E. S.; AUGUSTO, O. Reactions of yeast thioredoxin peroxidases I and II with hydrogen peroxide and peroxynitrite: rate constants by competitive kinetics. Free Radic. Biol. Med., v. 42, 326-334, 2007.

OHDATE, T.; KITA, K.; INOUE, Y. Kinetics and redox regulation of Gpx1, an atypical 2-Cys peroxiredoxin, in Saccharomyces cerevisiae. FEMS Yeast Res., v. 10, p. 787-790, 2010. 
OHLMEIER, S.; KASTANIOTIS, A. J.; HILTUNEN, J. K.; BERGMANN, U. The yeast mitochondrial proteome, a study of fermentative and res piratory growth. J. Biol. Chem., v. 279, p. 3956-3979, 2004.

OHTAKE, Y.; YABUCHI, S. Molecular cloning of the gamma-glutamylcysteine synthetase gene of Saccharomyces cerevisiae. Yeast., v. 7, p. 953-961, 1991.

OJEDA, L.; KELLER, G.; MUHLENHOFF, U.; RUTHERFORD, J. C.; LILL, R.; WINGE, D. R. Role of glutaredoxin-3 and glutaredoxin-4 in the iron regulation of the Aft1 transcriptional activator in Saccharomyces cerevisiae. J. Biol. Chem., v. 281, p. 17661-17669, 2006.

OKAMOTO, K.; BRINKER, A.; PASCHEN, S. A.; MOAREFI, I.; HAYER-HARTL, M.; NEUPERT, W.; BRUNNER, M. The protein import motor of mitochondria: a targeted molecular ratchet driving unfolding and translocation. EMBO J., v. 21, p. 3659-3671, 2002.

OLAFSDOTTIR, K.; REED, D. J. Retention of oxidized glutathione by isolated rat liver mitochondria during hydroperoxide treatment. Biochim. Biophys. Acta., v. 964, p. 377-382, 1988.

OLIVEIRA, M. A.; DISCOLA, K. F.; ALVES, S. V.; MEDRANO, F. J.; GUIMARÃES, B. G.; NETTO, L. E. Insights into the specificity of thioredoxin reductase-thioredoxin interactions. A structural and functional investigation of the yeast thioredoxin system. Biochemistry., v. 49, p 33173326, 2010.

OSTERGAARD, H.; TACHIBANA, C.; WINTHER, J. R Monitoring disulfide bond formation in the eukaryotic cytosol. J. Cell Biol., v. 166, p. 337-345, 2004.

OUTTEN, C. E.; CULOTTA, V. C. Alternative start sites in the Saccharomyces cerevisiae GLR1 gene are responsible for mitochondrial and cytosolic isoforms of glutathione reductase. J. Biol. Chem., v. 279, p. 7785-7791, 2004.

PALADE, G. E. The fine structure of mitochondria. Anat. Rec. v. 114, p. 427-451, 1952.

PARK, S.; G.; CHA, M.; K.; JEONG, W.; KIM, I.; H.; Distinct physiological functions of thiol peroxidase isoenzimas in Saccharomyces cerevisiae. J. Biol. Chem., v. 275, p. 5723-5732, 2000.

PARSONAGE, D.; YOUNGBLOOD, D. S.; SARMA, G. N.; WOOD, Z. A.; KARPLUS, P. A.; POOLE, L. B. Analysis of the link between enzymatic activity and oligomeric state in AhpC, a bacterial peroxiredoxin. Biochemistry, v. 44, p. 10583-10592, 2005.

PEDRAJAS, J. R.; KOSMIDOU, E.; MIRANDA-VIZUETE, A.; GUSTAFFSON, J. A.; WRIGHT, A. P. H.; SPYROU, G. Identification and functional characterization of a novel mitochondrial thioredoxin system in Saccharomyces cerevisiae. J. Biol. Chem., v. 274, p. 6566-6573, 1999.

PEDRAJAS, J. R.; MIRANDA-VIZUETE, A.; JAVANMARDY, N.; GUSTAFS-SON, J. A.; SPYROU, G. Mitochondria of Saccharomyces cerevisiae contain one-conserved cysteine type peroxiredoxin with thiore-doxin peroxidase activity. J. Biol. Chem., v. 26, p.16296-6301, 2000.

PEDRAJAS, J. R.; PADILLA, C. A.; MCDONAGH, B.; BARCENA, J. A. Glutaredoxin participates in the reduction of peroxides by the mitochondrial 1-CYS peroxiredoxin in Saccharomyces cerevisiae. Antioxid. Redox Signal., v. 13, p. 249-258, 2010.

PEDRAJAS, J. R.; McDONAGH, B.; HERNÁNDEZ-TORRES, F.; MIRANDA-VIZUETE, A.; GONZÁLEZ-OJEDA, R.; MARTÍNEZ-GALISTEO, E.; PADILLA, C. A.; BÁRCENA, J. A. 
Glutathione is the resolving thiol for thioredoxin peroxidase activity of 1-Cys peroxiredoxin without being consumed during the catalytic cycle. Antioxid. Redox Signal., v. 24, p. 115-128, 2016.

PENNINCKX, M. J.; ELSKENS, M. T. Metabolism and functions of glutathione in micro-organisms. Adv. Microb. Physiol., v. 34, p. 239-301, 1993.

PERKINS, G.; RENKEN, C.; MARTONE, M. E.; YOUNG, S. J.; ELLISMAN, M.; FREY, T. Electron tomography of neuronal mitochondria: three-dimensional structure and organization of cristae and membrane contacts. J. Struct. Biol., v. 119, p. 260-272, 1997.

PESKIN, A. V.; LOW, F. M.; PATON, L. N.; MAGHZAL, G. J.; HAMPTON, M. B.; WINTERBOURN, C.C. The high reactivity of peroxiredoxin 2 with $\mathrm{H}_{2} \mathrm{O}_{2}$ is not reflected in its reaction with other oxidants and thiol reagents. J. Biol. Chem., v. 282, p. 11885-11892, 2007.

PORRAS, P.; PADILLA, C. A.; KRAYL, M.; VOOS, W.; BÁRCENA, J. A. One single in-frame AUG codon is responsible for a diversity of subcellular localizations of glutaredoxin 2 in Saccharomyces cerevisiae. J. Biol. Chem., v. 281, p. 16551-16562, 2006.

PORRAS, P.; MCDONAGH, B.; PEDRAJAS, J. R.; BARCENA, J. A.; PADILLA, C. A. Structure and function of yeast glutaredoxin 2 depend on postranslational processing and are related to subcellular distribution. Biochim. Biophys. Acta., v. 1804, p. 839-845, 2010.

POVEDA-HUERTES, D.; MULICA, P.; VÖGTLE F. N. The versatility of the mitochondrial presequence processing machinery: cleavage, quality control and turnover. Cell Tissue Res., v. p. 2016

PRAKASH, S.; TIAN, L.; RATLIFF, K. S.; LEHOTZKY, R. E.; MATOUSCHEK, A. An unstructured initiation site is required for efficient proteasome-mediated degradation. Nat. Struct. Mol. Biol., v. 11, p. 830-837, 2004.

PUJOL-CARRION, N.; BELLI, G.; HERRERO, E.; NOGUES, A.; de la TORRE-RUIZ, M. A. Glutaredoxins Grx3 and Grx4 regulate nuclear localisation of Aft1 and the oxidative stress response in Saccharomyces cerevisiae. J. Cell Sci., v. 119, p. 4554-4564, 2006.

QIN, J.; ClORE, G. M.; KENNEDY, W. M.; HUTH, J. R.; GRONENBORN, A. M. Solution structure of human thioredoxin in a mixed disulfide intermediate complex with its target peptide from the transcription factor NF kappa B. Structure, v. 15, p. 289-297, 1995.

REINDERS, J.; ZAHEDI, R. P.; PFANNER, N.; MEISINGER, C.; SICKMANN, A. Toward the complete yeast mitochondrial proteome: multidimensional separation techniques for mitochondrial proteomics. J. Proteome Res. v. 5, p. 1543-1554, 2006.

RHEE, S. G.; KANG, S. W.; JEONG, W.; CHANG, T. S.; YANG, K. S.; WOO, H. A. Intracellular messenger function of hydrogen peroxide and its regulation by peroxiredoxins. Curr. Opin. Cell Biol., v. 17, p. 183-189, 2005.

RHEE, S. G.; WOO, H. E. Multiple functions of peroxiredoxins: peroxidases, sensors and regulators of the intracellular messenger $\mathrm{H}_{2} \mathrm{O}_{2}$, and protein chaperones. Antioxid. Redox Signal., v. 15, p. 781794, 2011.

RHEE, S. G.; WOO, H. A.; KIL, I. S.; BAE, S. H. Peroxiredoxin functions as a peroxidase and a regulator and sensor of local peroxides J. Biol. Chem., v. 287, p. 4403-4410, 2012.

RIEMER, J.; BULLEID, N.; HERRMANN, J. M. Disulfide formation in the ER and mitochondria: two solutions to a common process. Science, v. 324, p. 1284-1287, 2009. 
RIEMER, J.; FISCHER, M.; HERRMANN, J. M. Oxidation-driven protein import into mitochondria: Insights and blind spots. Biochim. Biophys. Acta Biomem., v. 1808, p. 981-989, 2011.

RIEMER, J.; SCHWARZLÄNDER, M.; CONRAD, M.; HERRMANN. J. M. Thiol switches in mitochondria: operation and physiological relevance. Biol. Chem., v. 396, p. 465-482, 2015.

RIETSCH, A.; BECKWITH, J. The genetics of disulfide bond metabolism. Annu. Rev. Genet., v. 32, p. $163-184,1998$.

RODRÍGUEZ-MANZANEQUE, M. T.; TAMARIT, J.; BELLÍ, G.; ROS, J.; HERRERO, E. Grx5 is a mitochondrial glutaredoxin required for the activity of iron/sulfur enzymes. Mol. Biol. Cell., v. 13, p. 1109-1121, 2002.

ROVERI, A.; MAIORINO, M.; URSINI, F. Enzymatic and immunological measurements of soluble and membrane-bound phospholipid-hydroperoxide glutathione peroxidase. Methods Enzymol., v. 233, p. 202-212, 1994.

SAITOH, T.; IGURA, M.; NOBITA, T.; OSE, T.; KOJIMA, R.; MAENAKA, K.; ENDO, T.;

Kohda, D. Tom 20 recognizes mitochondrial presequences through dynamic equilibrium among multiple bound states. EMBO J., v. 26, p. 4777-4787, 2007.

SARASTE, M. Oxidative phosphorylation at the fin de siècle. Science, v. 283, p. 1488-1493, 1999.

SCHAFFER, S. W.; SULEIMAN, M. S. Mitochondria: The dynamic organelle. New York: Springer, 2007. 359 p.

SCHIESTL, R. H.; GIETZ, R. D. High efficiency transformation of intact cells using single stranded nucleic acids as a carrier. Curr. Genet., v. 16, p. 339-346, 1989.

SCHMIDT, O.; PFANNER, N.; MEISINGER, C. Mitochondrial protein import: from proteomics to functional mechanisms. Nat. Rev. Mol. Cell Biol., v. 11, p. 655-667, 2010.

SCHNEIDER, A.; OPPLIGER, W.; JENÖ, P. Purified inner membrane protease I of yeast mitochondria is a heterodimer. J. Biol. Chem., v. 269, p. 8635-8638, 1994.

SCHULTZ, B. E.; CHAN, S. I. Structures and proton-pumping strategies of mitochondrial respiratory enzymes. Annu. Rev. Biophys. Biomol. Struct., v. 30, p. 23-65, 2001.

SCHULZ, C.; LYTOVCHENKO, O.; MELIN, J.; CHACINSKA, A.; GUIARD, B.; NEUMANN, P.; FICNER, R.; JAHN, O.; SCHMIDT, B.; REHLING, P. Tim50's presequence receptor domain is essential for signal driven trans-port across the TIM23 complex. J. Cell Biol., v. 195, p. 643-656, 2011.

SENA, L. A.; CHANDEL, N. S. Physiological roles of mitochondrial reactive oxygen species. Mol. Cell., v. 48, 158-167, 2012.

SHELTON, M. D.; CHOCK, P. B.; MIEYAL, J. J. Glutaredoxin: role in reversible protein sglutathionylation and regulation of redox signal transduction and protein translocation. Antioxid. Redox Signal., v. 7, p. 348-366, 2005.

SHIOTA, T.; MABUCHI, H.; TANAKA-YAMANO, S.; YAMANO, K.; ENDO, T. In vivo proteininteraction mapping of a mitochondrial translocator protein Tom22 at work. Proc Natl Acad Sci., v. 108, p. 15179-15183, 2011. 
SIDERIS, D. P.; TOKATLIDIS, K. Oxidative folding of small Tims is mediated by site-specific docking onto Mia40 in the mitochondrial intermembrane space. Mol. Microbiol., v. 65, p. 1360-1373, 2007.

SIPOS, K.; LANGE, H.; FEKETE, Z.; ULLMANN, P.; LILL, R.; KISPAL, G. Maturation of cytosolic iron-sulfur proteins requires glutathione. J. Biol. Chem., v. 277, p. 26944-26949, 2002.

SJOSTRAND, F.S. Electron microscopy of mitochondria and cytoplasmic double membranes. Nature, v. 171, p. 30-32, 1953.

SRIRAM, S. M.; KWON, Y. T. The molecular principles of N-end rule recognition. Nat. Struct. Mol. Biol., v. 17, p. 1164-1165, 2010.

SRIRAM, S. M.; KIM, B. Y.; KWON, Y. T. The N-end rule pathway: emerging functions and molecular principles of substrate recognition. Nat. Rev. Mol. Cell Biol. v. 12, p. 735-747, 2011.

STEPHEN, D. W.; JAMIESON, D. J. Glutathione is an important antioxidant molecule in the yeast Saccharomyces cerevisiae. FEMS Microbiol Lett., v. 141, p. 207-212, 1996.

STOJANOVSKI, D.; BOHNERT, M; PFANNER, N.; van der LAAN, M. Mechanisms of protein sorting in mitochondria. Cold Spring Harb. Perspect. Biol., v. 4, p. 1-40, 2012.

STOLDT, S.; WENZEL, D.; HILDENBEUTEL, M.; WURM, C. A.; HERRMANN, J. M.; JAKOBS, S. The inner-mitochondrial distribution of Oxa1 depends on the growth conditions and on the availability of substrates. Mol. Biol. Cell., v.23, p. 2292-2301, 2012.

STURTZ, L. A.; DIEKERT, K.; JENSEN, L. T.; LILL, R.; CULOTTA, V. C. A fraction of yeast $\mathrm{Cu}, \mathrm{Zn}$-superoxide dismutase and its metallochaperone, CCS, localize to the intermembrane space of mitochondria. A physiological role for SOD1 in guarding against mitochondrial oxidative damage. J. Biol. Chem., v. 276, p. 38084-38089, 2001.

SUN, J.; TRUMPOWER, B. L. Superoxide anion generation by the cytochrome bc1 complex. Arch. Biochem. Biophys., v. 419, p. 198-206, 2003.

SUNDARESAN, M.; YU, Z. X.; FERRANS, V. J.; IRANI, K.; FINKEL, T. Requirement for generation of $\mathrm{H}_{2} \mathrm{O}_{2}$ for platelet-derived growth factor signal transduction. Science., v. 270, p. 296-299, 1995.

SUZUKI, T.; VARSHAVSKY, A. Degradation signals in the lysine-asparagine sequence space. EMBO J., v. 18, p. 6017-6026, 1999.

SZTUL, E. S.; HENDRICK, J. P.; KRAUS, J. P.; WALL, D.; KALOUSEK, F.; ROSENBERG, L. E. Import of rat ornithine transcarbamylase precursor into mitochondria: two-step processing of the leader peptide. J. Cell Biol., v. 105, p. 2631-2639, 1987.

TAHARA, E. B.; BARROS, M. H.; OLIVEIRA, G. A.; NETTO, L. E.; KOWALTOWSKI, A. J. Dihydrolipoyl dehydrogenase as a source of reactive oxygen species inhibited by caloric restriction and involved in Saccharomyces cerevisiae aging. FASEB J., v. 21, p. 274-83, 2007.

TAIT, S. W.; GREEN, D. R. Mitochondria and cell death: outer membrane permeabilization and beyond. Nat. Rev. Mol. Cell. Biol., v. 11, p. 621-632, 2010.

TAMURA, Y.; HARADA, Y.; SHIOTA, T.; YAMANO, K.; WATANABE, K.; YOKOTA, M.; YAMAMOTO, H.; SESAKI, H.; ENDO, T. Tim23-Tim50 pair coordinates func-tions of translocators and motor proteins in mitochondrial protein import. J. Cell Biol., v. 184, p. 129-141, 2009. 
TANAKA, T.; IZAWA, S.; INOUE, Y. GPX2, encoding a phospholipid hydroperoxide glutathione peroxidase homologue, codes for an atypical 2-Cys peroxiredoxin in Saccharomyces cerevisiae. $\mathbf{J}$. Biol. Chem., v. 280, p. 42078-42087, 2005.

TASAKI, T.; SRIRAM, S. M.; PARK, K. S.; KWON, Y. T. The N-end rule pathway. Annu. Rev. Biochem., v. 81, p. 261-289, 2012.

TAYLOR, A. B.; SMITH, B. S.; KITADA, S.; KOJIMA, K.; MIYAURA, H.; OTWINOWSKI, Z.; ITO, A.; DEISENHOFER, J. Crystal structures of mitochondrial processing peptidase reveal the mode for specific cleavage of import signal sequences. Structure., v. 9, p. 615-625, 2001.

TEIXEIRA, P. F.; GLASER, E. Processing peptidases in mitochondria and chloroplasts. Biochim. Biophys. Acta., v. 1833, p. 360-370, 2013.

TERZIYSKA, N.; GRUMBT, B.; KOZANY, C.; HELL, K. Structural and functional roles of the conserved cysteine residues of the redox-regulated import receptor Mia40 in the intermembrane space of mitochondria. J. Biol. Chem., v. 284, p. 1353-1363, 2009.

TOLEDANO, M. B.; KUMAR, C.; Le MOAN, N.; SPECTOR, D.; TACNET, F. The system biology of thiol redox system in Escherichia coli and yeast: differential functions in oxidative stress, iron metabolism and DNA synthesis. FEBS Lett., v. 581, p. 3598-3607, 2007.

TOLEDANO, M. B.; DELAUNAY-MOISAN, A.; OUTTEN, C. E.; IGBARIA, A. Functions and cellular compartmentation of the thioredoxin and glutathione pathways in yeast. Antioxid. Redox Signal., v. 18, p.1699-1711, 2013.

TOleDO, J. C.; AUDI, R.; OGUSUCU, R.; MONTEIRO, G.; NETTO, L. E. S.; AUGUSTO, O. Horseradish peroxidase compound I as a tool to investigate reactive protein-cysteine residues: from quantification to kinetics. Free Radic. Biol. Med., v. 50, p. 1032-1038, 2011.

TROTTER, E W.; GRANT, C. M. Overlapping roles of the cytoplasmic and mitochondrial redox regulatory systems in the yeast Saccharomyces cerevisiae. Eukaryot Cell. v. 4, p. 392-400, 2005.

TRUJILLO, M.; CLIPPE, A.; MANTA, B.; FERRER-SUETA, G.; SMEETS, A.; DECLERCQ, J. P.; KNOOPS, B.; RADI, R. Pre-steady state kinetic characterization of human peroxiredoxin 5: taking advantage of Trp84 fluorescence increase upon oxidation. Arch. Biochem. Biophys., v. 467, p. 95106, 2007.

TRUSCOTT, K. N.; KOVERMANN, P.; GEISSLER, A.; MERLIN, A.; MEIJER, M.; DRIESSEN, A. J.; RASSOW, J.; PFANNER, N.; WAGNER, R. A presequence- and voltage-sensitive channel of the mitochondrial preprotein translocase formed by Tim23. Nature Struct. Biol., v. 8, p. 1074-1082, 2001.

TURRENS, J. F. Mitochondrial formation of reactive oxygen species. J. Physiol., v. 552, p. 335-344, 2003.

TZAGOLOFF, A. Mitochondria. New York: Plenum Press, 1982. 342 p.

UKAI, Y.; KISHIMOTO, T.; OHDATE, T.; IZAWA, S.; INOUE, Y. Glutathione peroxidase 2 in Saccharomyces cerevisiae is distributed in mitochondria and involved in sporulation. Biochem. Biophys. Res. Commun., v. 411, p. 580-585, 2011. 
VACA JACOME, A. S.; RABILLOUD, T.; SCHAEFFER-REISS, C.; ROMPAIS, M. AYOUB, D.; LANE, L. BAIROCH, A.; VAN DORSSELAER, A.; CARAPITO, C. N-terminome analysis of the human mitochondrial proteome. Proteomics., v. 15, p. 2519-2524, 2015.

van DAMME, P.; MARTENS, L.; VAN DAMME, J.; HUGELIER, K.; STAES, A.; VANDEKERCKHOVE, J.; GEVAERT, K. Caspase-specific and nonspecific in vivo protein processing during Fas-induced apoptosis. Nat. Methods, v. 2, p. 771-777, 2005.

van der LAAN, M.; BOHNERT, M.; WIEDEMANN, N.; PFANNER. N. Role of MINOS in mitochondrial membrane architecture and biogenesis. Trends Cell Biol., v. 22, p. 185-192, 2012.

van der LAAN, M.; HORVATH, S. E.; PFANNER, N. Mitochondrial contact site and cristae organizing system. Curr. Opin. Cell Biol., v. 41, p. 33-42, 2016.

van der LAAN, M.; WIEDEMANN, N.; MICK, D. U.; GUIARD, B.; REHLING, P.; PFANNER, N. A role for Tim 21 in membrane-potential-dependent preprotein sorting in mitochondria. Curr. Biol., v. 16, p. 2271-2276, 2006.

van LOON, A. P.; PESOLD-HURT, B.; SCHATZ, G. A yeast mutant lacking mitochondrial manganese-superoxide dismutase is hypersensitive to oxygen. Proc. Natl. Acad. Sci. USA., v. 83, p. 3820-3824, 1986.

VARSHAVSKY, A. The N-end rule: functions, mysteries, uses. Proc. Natl. Acad. Sci. USA., v. 93, p. 12142-12149, 1996.

VARSHAVSKY A. The N-end rule at atomic resolution. Nat. Struct. Mol. Biol., v.15, p. 1238-1240, 2008.

VEAL, E. A.; DAY, A. M.; MORGAN, B. A. Hydrogen peroxide sensing and signaling. Mol. Cell., v. 26, p. 1-14, 2007.

VÖGTLE, F. N.; WORTELKAMP, S.; ZAHEDI, R. P.; BECKER, D.; LEIDHOLD, C.; GEVAERT, K.; KELLERMANN, J.; VOOS, W.; SICKMANN, A.; PFANNER, N.; MEISINGER, C. Global analysis of the mitochondrial $\mathrm{N}$-proteome identifies a processing peptidase critical for protein stability. Cell., v.139, p. 428-439, 2009.

VÖGTLE, F.N.; PRINZ, C.; KELLERMANN, J.; LOTTSPEICH, F.; PFANNER, N.; MEISINGER, C. Mitochondrial protein turnover: role of the precursor intermediate peptidase Oct1 in protein stabilization. Mol. Biol. Cell., v. 22 p. 2135-2143, 2011.

VÖGTLE, F. N.; BURKHART, J. M.; RAO, S.; GERBETH, C.; HINRICHS, J.; MARTINOU, J. C.; CHACINSKA A.; SICKMANN, A.; ZAHEDI, R. P.; MEISINGER, C. Intermembrane space proteome of yeast mitochondria. Mol. Cell. Proteomics., v. 12, p. 1840-1852, 2012.

WAYPA, G. B.; GUZY, R.; MUNGAI, P. T.; MACK, M. M.; MARKS, J. D.; ROE, M. W.; SCHUMACKER, P. T. Increases in mitochondrial reactive oxygen species trigger hypoxia-induced calcium responses in pulmonary artery smooth muscle cells. Cir. Res., v. 99, p. 970-978, 2006.

WIEDEMANN, N.; VAN DER LAAN, M.; HUTU, D. P.; REHLING, P.; PFANNER, N. Sorting switch of mitochondrial presequence translocase involves coupling of motor module to respiratory chain. J. Cell Biol., v. 179, p. 1115-1122, 2007.

WINTERBOURN, C. C. Reconciling the chemistry and biology of reactive oxygen species. Nat Chem Biol., v. 4, p. 278-286, 2008. 
WITTIG, I; BRAUN, H. P.; SCHÄGGER, H. Blue native PAGE. Nat. Protoc., v. 1, p. 418 - 428, 2006.

WOOD, Z. A.; POOLE, L. B.; KARPLUS, P. A. Peroxiredoxin evolution and the regulation of hydrogen peroxide signaling. Science, v. 300, p. 650-653, $2003 \mathrm{a}$.

WOOD, Z. A.; SCHRODER, E.; HARRIS, J. R.; POOLE, L. B. Structure, mechanism and regulation of peroxirredoxins. Trends Biochem. Sci., v. 28, p. 32-40, $2003 \mathrm{~b}$.

YAMAMOTO, H.; ESAKI, M.; KANAMORI, T.; TAMURA, Y.; NISHIKAWA, SI.; ENDO, T. Tim50 is a subunit of the TIM23 complex that links protein translocation across the outer and inner mitochondrial membranes. Cell., v. 111, p. 519-528, 2002.

YAMANO, K.; KUROYANAGI-HASEGAWA, M.; ESAKI, M.; YOKOTA, M.; ENDO, T. Step-size analyses of the mitochondrial Hsp70 import motor reveal the Brownian ratchet in operation. J. Biol. Chem., v. 283, p. 27325-27332, 2008a.

YAMANO, K.; YATSUKAWA, Y.; ESAKI, M.; HOBBS, A. E.; JENSEN, R. E.; ENDO, T. Tom20 and Tom 22 share the common signal recognition pathway in mitochondrial protein import. J. Biol. Chem., v. 283, p. 3799-3807, 2008b.

ZAMAN, S.; LIPPMAN, S. I.; ZHAO, X.; BROACH, J. R. How Saccharomyces cerevisiae responds to nutrients. Annu. Rev. Genet., v. 42, p. 27-81, 2008.

ZHANG, L., HACH, A. Molecular mechanism of heme signaling in yeast: the transcriptional activator Hap1 serves as the key mediator. Cell Mol. Life Sci., v. 56, p. 415-426, 1999. 